Portland State University

PDXScholar

7-15-2021

\title{
Anti-Muslim Bias: Investigating Individual \\ Differences, Threat Perceptions, and Emotions in Islamophobic Policy Support
}

Aeleah M. Granger

Portland State University

Follow this and additional works at: https://pdxscholar.library.pdx.edu/open_access_etds

Part of the Social Psychology and Interaction Commons, and the Sociology of Culture Commons Let us know how access to this document benefits you.

\section{Recommended Citation}

Granger, Aeleah M., "Anti-Muslim Bias: Investigating Individual Differences, Threat Perceptions, and Emotions in Islamophobic Policy Support" (2021). Dissertations and Theses. Paper 5769.

https://doi.org/10.15760/etd.7640

This Thesis is brought to you for free and open access. It has been accepted for inclusion in Dissertations and Theses by an authorized administrator of PDXScholar. Please contact us if we can make this document more accessible: pdxscholar@pdx.edu. 
Anti-Muslim Bias:

Investigating Individual Differences, Threat Perceptions, and Emotions in Islamophobic Policy Support

by

Aeleah M. Granger

A thesis submitted in partial fulfillment of the requirements for the degree of

\author{
Master of Science \\ in \\ Psychology
}

Thesis Committee:

Kimberly Barsamian Kahn, Chair

Tessa Dover

Joel Steele

Portland State University

2021 


\begin{abstract}
Following the terrorist attacks of 9/11, Muslims in the United States were victims of increased surveillance by law enforcement on the basis of their religious identity, often resulting in mistreatment and unjustified imprisonment. These biases against Muslims and subsequent policy shifts have been pervasive and have had negative impacts on the growing number of Muslims in the United States. The current study focuses on individual differences that predict Islamophobia, including Social Dominance Orientation (SDO), Right-wing Authoritarianism (RWA), and Nationalism, as well as the specific types of intergroup threat perceptions (i.e., realistic, symbolic, terroristic) and subsequent emotional reactions (e.g., anger, fear) that may drive these relationships. Participants $(N=$ 603) completed a survey measuring SDO, RWA, Nationalism, threat perceptions, Islamophobia, emotional reactions toward Muslims, and support for anti-Muslim policies. Results demonstrated that higher levels of SDO, RWA, and Nationalism each independently predicted more Islamophobia through increased realistic, symbolic, and terroristic threat perceptions, respectively. Further, Islamophobia independently mediated the relationships between each type of perceived threat and anti-Muslim policy support (e.g., Muslim ban), such that those with higher levels of each type of perceived threat were more likely to hold Islamophobic attitudes which predicted more support for antiMuslim policies. Together, these findings suggest that the susceptibility of individuals high in SDO, RWA, and Nationalism to perceive Muslims as threatening influences their support for policies related to those ideologies through the activation of perceived threats. The emotional components of each type of threat perception and their relation to anti-
\end{abstract}


Muslim policy support, however, remain unclear. Potential avenues for improving our understanding of the role of emotions in threat-based attitudes and behaviors are discussed. 
Table of Contents

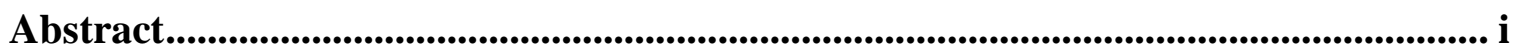

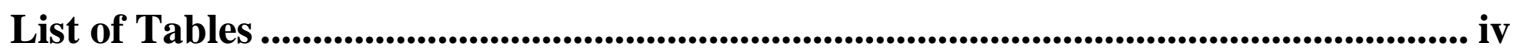

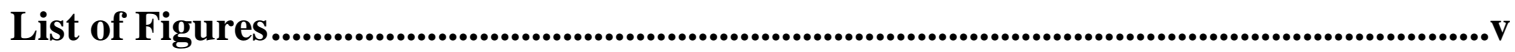

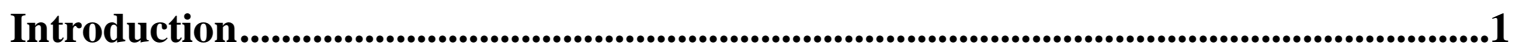

Islamophobia in the United States: Definition, targets, and sources ........................

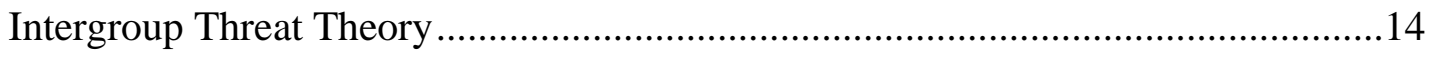

The Role of Emotion in Intergroup Bias.............................................................21

Individual Differences in Ideology as Predictors of Prejudice ..............................25

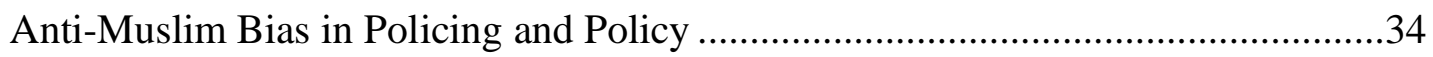

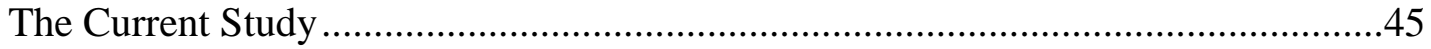

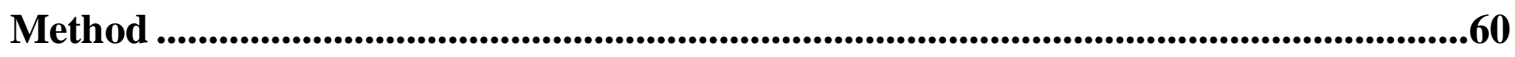

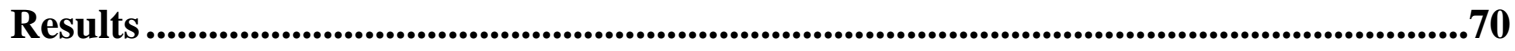

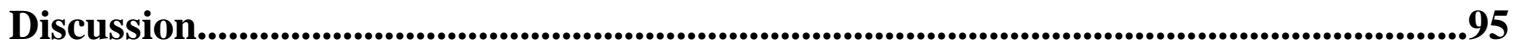

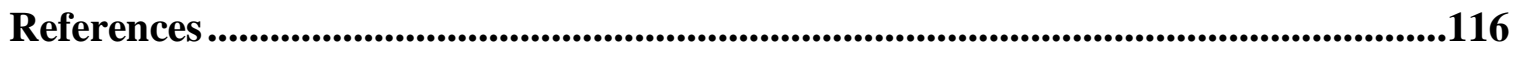

Appendix: Survey Materials ........................................................................................................133 


\section{List of Tables}

Table 1: Means, Standard Deviations, and Correlations for Aim 1 Structural Equation Model .72

Table 2: Means, Standard Deviations, and Correlations for Aim 2 Cluster Analyses 72

Table 3: Means, Standard Deviations, and Correlations for Aim 3 Structural Equation Model .73

Table 4: Direct and Indirect Effects for Aim 1 Structural Equation Model .80

Table 5: Regression Analyses for Hypothesis 2a: Threat Perceptions Predicting Anger

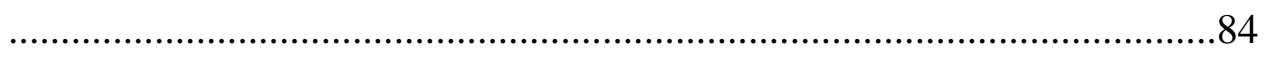

Table 6: Regression Analyses for Hypothesis 2b: Threat Perceptions Predicting Distrust .85

Table 7: Regression Analyses for Hypothesis 2c: Threat Perceptions Predicting Fear .87

Table 8: Direct and Indirect Effects for Aim 3 Structural Equation Model 92

Table 9: Summary of Hypothesis Support ............................................94 


\section{List of Figures}

Figure 1: Intergroup Threat Theory ……………………………….......16

Figure 2: Aim 1 Full Model ...................................................................48

Figure 3: Theoretical Model for Hypothesis 1 a ........................................49

Figure 4: Theoretical Model for Hypothesis $1 b$.......................................50

Figure 5: Theoretical Model for Hypothesis $1 c$.......................................50

Figure 6: Theoretical Model for Hypothesis 1d .......................................52

Figure 7: Aim 3 Full Model ...................................................................57

Figure 8: Theoretical Model for Hypothesis $3 a$......................................58

Figure 9: Theoretical Model for Hypothesis $3 b$......................................58

Figure 10: Theoretical Model for Hypothesis 3c ....................................59

Figure 11: Structural Equation Model 1: Hypotheses 1a-1d .....................76

Figure 12: Structural Equation Model 1: Full Direct Significant Paths ...81

Figure 13: Structural Equation Model 1: Hypotheses 3a-3c .....................89

Figure 14: Structural Equation Model 2: Full Direct Significant Paths ....93 


\section{Introduction}

In 2015, Islam was identified as one of the world's fastest growing religions, with a global population that is expected to more than double by the year 2060 (Lipka \& Hackett, 2017). In the United States alone, the Muslim population will increase from 3.45 million in 2017 to about 8.1 million in 2050 and is expected to exceed the Jewish population as the country's second largest religious group by the year 2040 (Mohamed, 2018). Increases in the United States Muslim population are largely due to immigration, with about $58 \%$ of Muslim adults having been born in another country and $18 \%$ having at least one parent who immigrated to the United States (Pew Research Center, 2017). Muslims who immigrate to the United States come from at least 77 different countries (Pew Research Center, 2011) within several regions including 35\% from South Asia, $25 \%$ from the Middle East, and 23\% from other parts of Asia (Pew Research Center, 2017). No individual country accounts for more than $15 \%$ of the United States Muslim immigrant population, however, indicating that American Muslims are a racially and ethnically diverse group (Pew Research Center, 2017). Despite the growing prevalence of Muslims in the United States, $43 \%$ of Americans reported feeling prejudiced attitudes toward Muslims in 2010, a rate more than double that of any other major religious group including Christians, Jews, and Buddhists (Morales, 2010). As recent developments in globalization have resulted in religiously motivated conflicts, it is becoming increasingly important to understand how intergroup bias impacts the daily lives of members of this religious minority group in the United States. 
Anti-Muslim sentiment and discrimination are not restricted to the general public. For example, $28 \%$ of Muslims in the United States report being looked at with suspicion, and $34 \%$ report being singled out by airport security or other law enforcement (Pew Research Center, 2011). Overall, 52\% of Muslims in the United States feel that antiterrorism policies have led to Muslim profiling and increased surveillance. Moreover, $25 \%$ of Muslims in the United States indicate that mosques or Islamic centers in their communities have been controversial and another $14 \%$ report local opposition to the building of mosques and Islamic centers in their communities (Pew Research Center, 2011). Muslims in the United States have also become the victims of increased surveillance by law enforcement following the terrorist attacks on 9/11 (e.g., Blackwood et al., 2016; Henderson et al., 2006; Keeling \& Hughes, 2011; Meeropol, 2015). The surveillance of Muslims and their communities includes increased questioning by police, more arrests, and the insertion of undercover police officers into Muslim-American communities and mosques (Ali, 2016; Henderson et al., 2006; Meeropol, 2015). Coinciding with increases in scrutiny by law enforcement, a surge in hate crimes toward Muslim Americans also occurred in the months following the 9/11 attacks (North et al., 2014). This trend has continued to climb, such that in 2016, the number of assaults against Muslims in the United States surpassed that of 2001 (Kishi, 2017), suggesting that there is more to the story than a single event. Increases in anti-Muslim bias and Islamophobia have negative consequences for Muslim communities in the United States, including feeling less safe in public and reporting lower quality of life as a result of perceived religious discrimination (Abu-Ras et al., 2018). 
In the years immediately following 9/11, the Federal Bureau of Investigation (FBI), the U.S. Immigration and Naturalization Services (INS), and 18,000 state and local police departments across the United States worked in conjunction to arrest individuals who fit the profile of the attackers (Henderson et al., 2006; Meeropol, 2015). Specifically, Muslims, Arabs, and those from Middle Eastern countries were routinely surveilled, questioned, and detained by law enforcement, even in the absence of evidence of terrorist activities. Law enforcement agencies were told to treat those arrested as if they were terrorists or people who might know terrorists [Office of the Inspector General (OIG), 2003] even though this widespread abuse of Muslim and Arab communities resulted in few terrorism-related prosecutions (Meeropol, 2015). For many, including 762 individuals detained in New York and New Jersey between the years 2001 and 2002, immigration status alone was used as a justification for detainment until proven innocent (OIG, 2003). Subsequently, many of these individuals were deported following detainment, despite being cleared of all terrorism charges (Henderson et al., 2006; Meeropol, 2015). In a speech given at the U.S. Conference of Mayors in October of 2001, Attorney General Ashcroft outlined the department's new focus on intercepting terrorism through any possible legal means:

Let the terrorists among us be warned: If you overstay your visa - even by one day - we will arrest you. If you violate a local law, you will be put in jail and kept in custody as long as possible. We will use every available statute. We will seek every prosecutorial advantage. We will use all our weapons within the law and 
under the Constitution to protect life and enhance security for America (OIG, 2003, p. 12).

Under the guidelines laid out by the FBI and the Attorney General, the role of state and local police officers was largely to use their street-level positions to surveil Muslim and Arab communities and collect intelligence (Henderson et al., 2006; Wasserman, 2015). For example, the New York Police Department (NYPD) created a "Demographics Unit" which attempted to implant an informative in every mosque within a 250-mile radius of New York City (Apuzzo \& Goldman, 2011; Wasserman, 2015). Such informants, often referred to as "mosque crawlers," would monitor the activities of Muslims and mosque services, regardless of any evidence of criminal or terrorist activity. In addition to these activities, police officers reportedly monitored which businesses sold halal products, which businesses closed their doors for daily prayer, and how often Muslim students at universities prayed (Wasserman, 2015). Police officers also tracked the racial and ethnic makeup of many of these communities. For example, one Muslim client who sued the City of New York for the religious profiling and surveillance of Muslims [Center for Constitutional Rights (CRC), 2018] was surveilled for operating a grade school for Muslim girls. Police took note of details such that most of the girls attending were African American, suggesting that officers were not only monitoring Muslim communities but that they believed that their racial and ethnic identities were relevant to terrorism-related investigations. Although the main goal of this police surveillance was to detect any terrorism-related plans or activity, few terrorism-related investigations or charges resulted from the widespread monitoring of Muslims and their 
communities (Blackwood et al., 2016; Ramirez, 2012). Further, Muslims who were eventually cleared of all charges and released from custody often experienced continued surveillance by law enforcement in their communities (Ali, 2016; Keeling \& Hughes, 2011).

In addition to continued surveillance by law enforcement, anti-Muslim bias has persisted through the promotion of policies that restrict religious freedom and Muslim immigration to the United States. For example, shortly after his election in 2016, thenPresident Trump signed an Executive Order that restricted immigration and travel from seven Muslim-majority countries including Iraq, Syria, Sudan, Iran, Somalia, Libya, and Yemen (Trump, 2017a). This Executive Order purported to reduce terrorism through restrictions on immigration and travel from majority Muslim nations to the United States. Although this policy initially received support from up to $48 \%$ of United States respondents (Collingwood et al., 2018), the policy quickly became controversial and was ultimately revoked as a result of its implementation having violated existing court orders (OIG, 2018). The Trump administration persisted by adding other countries to the Executive Order that they considered a potential threat to the United States. Still, eight out of the eleven countries included in the most recent version of the Executive Order were Muslim-majority countries, bringing into question the role of perceived threat in this immigration policy decision.

Biases against Muslims and subsequent policy shifts, such as state-sanctioned surveillance, have been pervasive and have greatly harmed the growing number of Muslims in the United States (Elsheikh et al., 2017; Meeropol, 2015). Existing social 
psychological research presents an incomplete understanding of the relationship between individual differences in ideology, threat perceptions, and subsequent emotional reactions in the context of prejudice toward Muslims by only investigating one or a few of these factors in isolation. Although informative, this research lacks a comprehensive understanding of how these factors interact and is unable to assess the relative contributions of different ideologies in bias against Muslims. The current study aimed to address these gaps by 1) evaluating the roles of individual differences in ideology and threat perceptions on prejudice and anti-Muslim policy support, 2) exploring the emotional components of different types of threat perceptions regarding Muslims, and 3) investigating emotional reactions as mediators in the relationship between threat perceptions and support for anti-Muslim policies, focusing on police surveillance of Muslims and Muslim communities.

The current study aimed to understand factors that predict and perpetuate prejudice toward Muslims, as well as the implications of such bias for discriminatory policies that result in increased surveillance and policing of Muslim and Middle Eastern communities in the United States. After discussing the social context and experiences of Muslims with Islamophobia in the United States, this paper will discuss several theories relevant to understanding bias against Muslims and discriminatory policy support. First, given commonly held stereotypes of Muslims as radical and dangerous, social psychological theories of intergroup threat (Stephan et al., 2015) and the sociofunctional approach to prejudice (Cottrell \& Neuberg, 2005) can aid in understanding prejudice toward Muslims. These theories suggest that perceptions of threat (i.e., symbolic threat, 
or threats to one's values; realistic threat, or threats to one's resources and power; terroristic threat, or threats to one's physical safety) underlie prejudice toward different groups (e.g., religious, racial/ethnic; Stephan et al., 2015). Each specific threat then leads to different emotional reactions, such as anger for realistic threats and distrust for symbolic threats (Cottrell \& Neuberg, 2005). These different emotional responses have implications for behavioral reactions (e.g., Cottrell \& Neuberg, 2005; Lerner \& Keltner, 2000; Lerner \& Keltner, 2001; Schwarz, 2012; Stephan et al., 2015).

After laying the foundation for the influence of threat and emotion in anti-Muslim bias, the role of several individual differences in ideology will be explored, including Social Dominance Orientation (i.e., endorsement of existing social hierarchies; SDO; Pratto et al., 1994), Right-wing Authoritarianism (i.e., a belief that the norms and rules of a society should be followed and enforced; RWA; Altemeyer, 1981), and Nationalism (Kosterman \& Feshbach, 1989). Although SDO plays an explanatory role in threat perceptions associated with bias against Muslims (Uenal, 2016), incorporating RWA and Nationalism may better illuminate the driving forces behind different types of threat perceptions given their associations and conceptual overlap with symbolic and terroristic threats, respectively (e.g., Craig \& Richeson, 2014b; Kyriakides et al., 2009). Thus, understanding the roles of these factors is important for elucidating which mechanisms best predict biases and discriminatory behaviors toward Muslims.

Finally, a deeper review of discriminatory policy support is provided with an emphasis on policing policies that rely on religious and ethnic profiling. This discussion provides more context to the issues facing Muslims in the United States, such as 
surveillance of mosques and Muslim communities by local law enforcement. Although many have criticized the treatment of Muslim and Middle Eastern communities by law enforcement following 9/11 (e.g., Henderson et al., 2006; Wasserman, 2015), discriminatory policies against Muslims have received relatively high levels of support from the public (Andersen et al., 2012; Collingwood et al., 2018; Saleem, et al., 2017). These policies range from those that restrict the civil liberties of Muslims, such as voting rights or increased surveillance by law enforcement (Andersen et al., 2012; Saleem et al., 2017), to those that reduce immigration and increase military action in Muslim-majority countries and regions (Collingwood et al., 2018; Saleem et al., 2017). Many of the policies regarding increased surveillance and civil liberty restrictions operate on a national level which can have broad implications for Muslims' experiences as members of American society. The current study aims to understand several factors which may predict support for anti-Muslim policies in the United States.

\section{Islamophobia in the United States: Definition, targets, and sources}

Some of the earliest uses of the term "Islamophobia" have been traced to the late 1980s and early 1990s when the term was used to represent discrimination toward Muslims (Allen, 2006, as cited in Bravo López, 2011). In 1997, the Runnymede Trust developed and popularized the concept of Islamophobia as baseless hostility toward Islam and subsequent fear and prejudice toward Muslims (Runnymede Trust, 1997, as cited in Lee et al., 2009). Though Islamophobia has broadly been used to indicate prejudice and discrimination toward Muslims and the religion of Islam, the specific definition of this word has varied in its meaning and scope across time and disciplines 
(for a review, see Bleich, 2011). For example, while some researchers identify

Islamophobia as a form of xenophobia (e.g., Sheridan, 2006) or religious intolerance (e.g., Geisser, 2003, as cited in Bravo López, 2011), others argue that Islamophobia is driven by cultural and religious differences as well as racial identity (e.g., Bravo López, 2011; Garner \& Selod, 2015; Schiffer \& Wagner, 2011). Regardless of the specific definition used, there is significant evidence suggesting that stereotypes of Muslims and Middle Easterners as terrorists fuel anti-Muslim sentiment and Islamophobia (e.g., Andersen et al., 2012; Dubosh et al., 2015; Keeling \& Hughes, 2011; Lee et al., 2009; Lee et al., 2013; Saleem et al., 2017).

Islamophobia stems from bias against Muslims and the religion of Islam, with Muslims frequently being perceived as inferior and threatening to Christian and western values (Bravo López, 2011; Schiffer \& Wagner, 2011; Sheridan, 2006). Islamophobia is characterized by a belief that Muslims' religious beliefs underlie their behaviors and that the behaviors and attitudes of a few represent those of all Muslims (Schiffer \& Wagner, 2011). One of the main issues with defining Islamophobia is that it is often unclear whether this prejudice stems from one's religious identity, skin color, or ethnic origin (Bravo López, 2011). For example, Islamophobia shares many similarities and differences with both racism and anti-Semitism. Schiffer and Wagner (2011) argue that Islamophobia may be considered a form of "cultural racism," in which the religious and cultural identity, "Muslim," is used as a grouping mechanism in place of a racial identity. Specifically, the Muslim identity has been racialized such that perceptions of one belonging to the group "Muslim" can stem from both physical and cultural characteristics 
(e.g., skin color, language, clothing; Garner \& Selod, 2015). This broader definition of race means that even when markers of Islam are not present, Muslim identity may be presumed on the basis of other physical markers, such as skin tone. The resulting conflation of multiple identities under the umbrella of one group as "Muslims" has led to a homogenization of diverse groups of individuals, which has implications for individuals that identify as Muslim as well as those erroneously perceived to be Muslim (Wang et al., 2019). This homogenization is not only present in public discourse, but also in research that uses terms like "Muslim" and "Arab" interchangeably (e.g., Echebarria-Echabe \& Guede, 2007) or uses ethnic identity as a proxy for religious identity (e.g., Adelman \& Verkuyten, 2019).

Islamophobia appears to be on the rise in the United States and other parts of the Westernized world in recent decades. For example, British Muslims reported experiencing more implicit (e.g., microaggressions) and explicit (e.g., exclusory policies) discrimination following the 9/11 attacks compared to before (Sheridan, 2006). Implicit and explicit attitudes are part of a dual-processing model which consists of both unconscious (i.e., without awareness) and conscious (i.e., with awareness) processing (Devine, 1989; Smith \& DeCoster, 2000). Implicit attitudes refer to those that occur outside of conscious awareness or control (Fazio \& Olson, 2003; Greenwald \& Banaji, 1995) and are formed over time through repeated exposure to stimuli and associated concepts (Smith \& DeCoster, 2000). Explicit attitudes refer to conscious attitudes that involve controlled, conscious processing (Greenwald \& Banaji, 1995). These attitudes are readily available and can be explicitly called to mind and expressed when asked about 
them. In the United States, people tend to hold more negative implicit attitudes toward Muslims relative to Christians, White people, Black people, and people with non-Middle Eastern or Islamic sounding foreign names (Gonsalkorale et al., 2009; Nosek et al., 2007; Park et al., 2007; Rowatt et al., 2005). Although explicit attitudes are not always aligned with implicit attitudes, particularly for intergroup attitudes (Devine, 1989; Nosek et al., 2007), Muslims represent a group for which implicit and explicit attitudes are often partially aligned (Park et al., 2007; Rowatt et al., 2005), with explicit negative attitudes sometimes being more negative than implicit negative attitudes (Nosek et al., 2007). For example, not only is negative affect highest against Muslims compared to several other religious groups (i.e., Jews, Catholics, Protestants, Evangelical Christians, Buddhists, Hindus, Mormons, and Atheists; Pew, 2017), but research suggests that people are more willing to openly express bias against Muslims accused of religiously motivated crimes compared to Christians (Miller et al., 2020). Together, these findings suggest people feel more comfortable openly expressing negative attitudes toward Muslims, which is consistent with the overall support for government-condoned monitoring and surveillance of this group. Research suggests that implicit attitudes may exert more influence on spontaneous and less controllable behaviors (e.g., body language, fast-paced decision making), whereas explicit attitudes may exert more influence on deliberative and controllable behaviors (e.g., verbal communication, slow-paced decision making; Dovidio et al., 2002). Thus, while implicit attitudes toward Muslims may be more predictive of performance on fast-paced decisions, such as shooting decisions (Essien et 
al., 2017; Unkelbach et al., 2008), explicit attitudes may be more important in predicting support for long-term policy implementation (Andersen et al., 2012).

Perceptions and stereotypes of Muslims are influenced by media portrayals (e.g., Kearns et al., 2019a; Kearns et al., 2019b; Shen et al., 2018), which may be many people's only exposure to Muslims or Islam (Pratt, 2011). Terrorism is overrepresented in the media compared to the number of deaths it is responsible for, with terrorism receiving between $33.3 \%$ and $35.6 \%$ of media coverage despite terrorism making up less than $0.01 \%$ of deaths in the United States (Shen et al., 2018). Moreover, across all media outlets investigated, terrorist attacks receive as much as $357 \%$ more coverage if the attacker was Muslim compared to other perpetrators of terrorism (Kearns et al., 2019b). For major news sources such as $\mathrm{CNN}$ and the New York Times, this bias increased to $758 \%$ more coverage. The disparity between the proportion of attacks perpetrated by Muslims and the subsequent news coverage is further highlighted by the fact that even though only $12.5 \%$ of terrorist attacks in the United States were perpetrated by Muslims over the last decade, these attacks made up 50\% of media coverage of terrorist attacks (Kearns et al., 2019b). This overemphasis of Muslim-terrorist stereotypes is particularly problematic in light of research suggesting that people are more willing to express bias against Muslims who are accused of religiously motivated crimes (Miller et al., 2020).

Despite contention over the specific definition of Islamophobia and whom it applies to, most empirical research has focused on the threat and fear of Muslims and Islam (e.g., Bravo López, 2011; Lee et al., 2009; Lee et al., 2013; Obaidi et al., 2018; Schiffer \& Wagner, 2011; Uenal, 2016). Based on previous work establishing the 
psychometric properties of Islamophobia, the current study defines Islamophobia as a fear of Muslims and the Islamic faith (Lee et al., 2009; Lee et al., 2013), while also acknowledging that implications of this work may extend to those perceived to be Muslims. This conceptualization of Islamophobia is comprised of two subcomponents, including anti-Muslim attitudes and anti-Islam attitudes, to allow for a distinction between negative attitudes and fear felt toward a group (i.e., Muslims) and a religious doctrine (i.e., Islam). Although these are two distinct features of Islamophobia that can be investigated separately (Uenal, 2016), their strong relation also allows for a global measure of Islamophobia (Lee et al., 2009; Lee et al., 2013).

To date, research has implicated a number of factors that influence levels of Islamophobia and related anti-Muslim attitudes including threat perceptions (e.g., Dunwoody \& McFarland, 2018; Velasco Gonzàlez et al., 2008; Uenal, 2016). The specific type of threat perception influences affective experiences, which then predict behavioral reactions, including whether to approach or avoid a potential threat (Cottrell \& Neuberg, 2005; Lerner \& Keltner, 2000; Lerner \& Keltner, 2001; Schwarz, 2012; Stephan et al., 2015). Several individual differences in ideology are also commonly associated with intergroup bias (e.g., Social Dominance Orientation, Right-wing authoritarianism, Nationalism; Altemeyer, 1981; Kosterman \& Feshbach, 1989; Pratto et al., 1994) and different types of threat perceptions (e.g., realistic, symbolic; Crowson, 2009; Golec de Zavala et al., 2017), which may be useful in predicting which kinds of people are most susceptible to perceiving Muslims as threatening in different ways and how these perceptions may influence subsequent behavioral responses. 


\section{Intergroup Threat Theory}

Although group living has evolutionarily promoted survival and success for humans, it also comes with associated costs and risks, as living within and among groups of people inherently means surrounding oneself with others who could potentially cause harm to oneself or the group (Cottrell \& Neuberg, 2005; Stephan et al., 2015). Thus, to minimize this risk, humans are attuned to the various threats that others could potentially pose. Awareness of potential threats in our environment is thought to serve an evolutionary function, as those who are more sensitive to perceived threats in the environments would be able to decide on an appropriate course of action to either overcome or avoid the threat (Cottrell \& Neuberg, 2005; Stephan et al., 2015). Notably, threats need only be perceived in order to influence intergroup relations, regardless of whether the group in question is actually attempting to shift the status quo in some way or enact harm (Stephan et al., 2002; Stephan et al., 2009; Stephan \& Stephan, 2000; Stephan et al., 2015). Accordingly, while from an evolutionary perspective, greater attention to threats is adaptive for survival, in terms of intergroup relations, the human predisposition to perceive threats may underlie prejudice toward many groups (Stephan et al., 2002; Stephan et al., 2009; Stephan \& Stephan, 2000; Stephan et al., 2015). Based on research emphasizing the role of threat in attitudes toward Muslims (e.g., Uenal, 2016; Wirtz et al., 2015), the current study utilized an intergroup threat theory framework in understanding what predicts and mediates levels of Islamophobia.

Conceptualizations of intergroup threat theory (e.g., Stephan et al., 2015) focus on three different types of threat perceptions: realistic, symbolic, and more recently, 
terroristic (Uenal, 2016). Realistic threat perceptions refer to threats to the political or economic power of one or one's group (Rios et al., 2018; Stephan \& Stephan, 2000; Stephan et al., 2015; Uenal, 2016). Symbolic threat perceptions encompass threats to the cultural values or beliefs that a group or individual holds (Rios et al., 2018; Stephan \& Stephan, 2000; Stephan et al., 2015; Uenal, 2016). Terroristic threat perceptions refer to threats to the physical safety and well-being of an individual or their group (Doosje et al., 2009; Uenal, 2016). In early conceptualizations of intergroup threat theory, realistic threat perceptions encompassed political, economic, and safety threats (e.g., Stephan et al., 2002; Stephan et al., 2009; Stephan \& Stephan, 2000). Realistic threat perceptions, however, may be experienced and expressed in different ways based on context and activated stereotypes about a group, which may lead to different affective and behavioral outcomes (Stephan et al., 2015). Consequently, realistic and terroristic threat perceptions have been delineated from one another to allow for a more comprehensive understanding of the contributing factors of threat perceptions and subsequent outcomes (Uenal, 2016).

Similar to how stereotypes and evaluations of different groups differ in content, the nature of perceived threats can vary depending on who is posing the threat and what is being threatened in a specific context (Rios et al., 2018; Stephan et al., 2015). For example, White people tend to perceive Black people as realistic threats to their political power and social standing, whereas Christians tend to perceive Atheists as symbolic threats to their values and worldview (Rios et al., 2018). Threat perceptions tend to be positively correlated, however, suggesting that group-based differences in threat perceptions may be explained by the context in which one is evaluating threat (Rios et al., 
2018; Stephan et al., 2015). Specifically, stereotypes are thought to be a primary source of threat perceptions, suggesting that an interaction between one's identity and different contexts may activate different stereotypes about that group, which may lead to different types of threat perceptions depending on the nature of the activated stereotype (Rios et al., 2018). The nature of these threat perceptions may, in turn, predict different attitudes and behavioral outcomes (see Figure 1 for theoretical model).

\section{Figure 1}

Intergroup Threat Theory

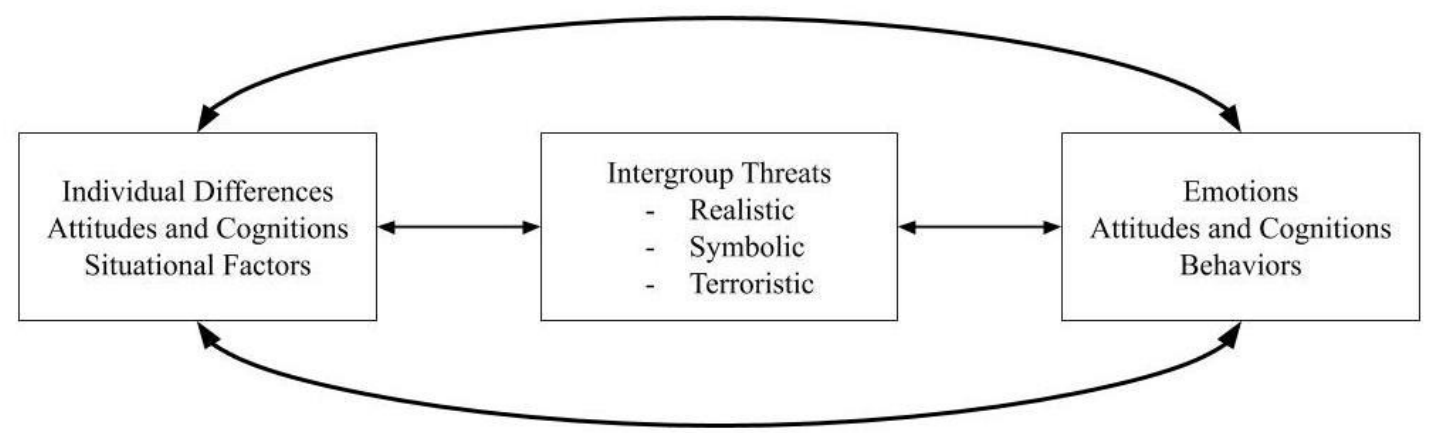

Note. Diagram based on Intergroup Threat Theoretical Model proposed by Stephan et al. (2015).

Just as the content of activated stereotypes may influence the type of threat perceived, individual differences in ideology tend to be associated with threat perceptions related to the content of those ideologies (Rios et al., 2018; Stephan et al., 2015). For example, individuals who prefer societies that are hierarchically organized and who desire to maintain the current social order may be more attuned to perceive threats by certain groups, especially those perceived to pose realistic threats (Stephan et al., 2015). 
Additionally, those high in beliefs that a society's way of being should be maintained tend to be more susceptible to perceptions of symbolic threats, which challenge a given worldview or certain values (Rios et al., 2018). For example, SDO better predicted prejudice toward a fictitious immigrant group when described as threatening economic resources, whereas RWA better predicted prejudice when this immigrant group was described as threatening cultural values (Duckitt \& Sibley, 2010). Further, for those high in RWA, perceived intergroup threat mediated the relationship between a multiculturalism prime, which threatened national cultural values, and prejudice toward immigrants (Kauff et al., 2017). The social context in which one is evaluating threat can also influence levels of each type of threat perception. For example, both immediately following the attack of 9/11 and a year later, symbolic threat perceptions of Arab immigrants were higher than symbolic threat perceptions of Mexican immigrants, likely due to the attacks targeting national monuments (Hitlan et al., 2007). In contrast, perceptions of Mexican immigrants as realistic threats increased following $9 / 11$ due to the negative impacts of the attacks on the existing economic recession. Similarly, following the July 2005 Islamic terrorist attacks on London, terroristic and symbolic threat perceptions of Muslims increased, whereas economic realistic threat perceptions did not (Abrams et al., 2017).

Once activated, threat perceptions exert influence on intergroup attitudes and outcomes either independently (e.g., realistic threat perceptions only) or in combination with one another (e.g., realistic and symbolic threat perceptions; Stephan et al., 2015). For example, although both realistic and symbolic threat perceptions contributed to 
negative attitudes toward Black people, perceived threats to power and resources were a stronger predictor of anti-Black attitudes (Stephan et al., 2002). Further, threat perceptions influenced levels of support for policies that would impact relevant groups, such as immigration, affirmative action, and surveillance to expose terrorist plots (Stephan et al., 2015). For instance, people in the United States were more likely to support tougher punishment for immigration violations for immigrants who were perceived as symbolic threats to American identity (i.e., Mexicans) compared to immigrants who were perceived as less symbolically threatening (i.e., Canadians; Mukherjee et al., 2013). Threat perceptions are important for understanding and predicting behavioral outcomes, as well. Specifically, behavioral responses to intergroup threat (e.g., attack, flight, negotiation) are impacted by affective and physiological responses to the type of perceived threat, which has implications for many real-world outcomes including policy initiatives and individual-level harassment and discrimination (Cottrell \& Neuberg, 2005; Stephan et al., 2015). Affective and physiological responses will be further discussed in the next section on intergroup emotions.

Several studies have investigated the role of threat perceptions of Muslims in antiMuslim attitudes. In line with intergroup threat theory, which suggests that threat perceptions are often correlated and shift in saliency depending on the context, Muslims tend to be perceived by non-Muslims as symbolic, realistic, and terroristic threats (e.g., Dunwoody \& McFarland, 2018; Obaidi et al., 2018; Raiya et al., 2008; Rios et al., 2018; Uenal, 2016). Specifically, Muslims have been perceived as symbolic threats due to stereotypes of Muslims as inherently sexist (Moss et al., 2019) and culturally 
incompatible with the Westernized world (Velasco Gonzàlez et al., 2008) and Christian values (Raiya et al., 2008). Although Muslims were perceived as threatening to Christian values based on ideological differences between each religion (Raiya et al., 2008), Muslims can be perceived as symbolic threats by the general public, as well. For example, in the context of the Netherlands, stereotypes about Muslims as threats to national values and culture were often emphasized over stereotypes of Muslims as threatening resources and power (Velasco González et al., 2008). Accordingly, Muslims were perceived by participants as more symbolic threats than realistic threats in this national context.

Muslims are also perceived as terroristic threats in accordance with stereotypes of Muslims as extremists or terrorists (e.g., Ekman, 2015; Fischer et al., 2007; Uenal, 2016). Support for this stems from investigations of the role of realistic threats in anti-Muslim attitudes which focused on perceived safety, rather than power or economic threats (e.g., Ciftci, 2012; Velasco Gonzalez et al., 2008). For example, although Ciftci (2012) found that stereotypes and attitudes toward Muslims were driven by perceptions of Muslims as symbolic and realistic threats, their operationalization of realistic threats focused on safety threats related to terrorism, which parallels current conceptualizations of terroristic threat perceptions. In some contexts, however, Muslims also elicit perceptions of political and economic realistic threat perceptions. For instance, voting intentions for the United Kingdom (UK) to leave the European Union (EU) were predicted by perceptions that Muslims threaten cultural values (i.e., symbolic threats) as well as economic well-being and political power (i.e., realistic threats; Swami et al., 2018). 
Although past research illuminates the complexity of threat perceptions and attitudes toward Muslims, few studies have investigated each of these threat perceptions simultaneously, often focusing on one or two threats in isolation instead. Of the studies investigating all three threat perceptions concurrently (i.e., symbolic, realistic, terroristic), levels of each threat perception toward Muslims exist but are influenced by several factors (Obaidi et al., 2018; Uenal, 2016). For example, one study found that realistic, symbolic, and terroristic threat perceptions each mediated the relationship between SDO and Islamophobia (Uenal, 2016). Specific to policy support, Norwegians' intentions to support anti-Islamic movements were best predicted by symbolic threat perceptions (Obaidi et al., 2018). These effects were also driven in part by realistic threat perceptions but not terroristic threat perceptions, likely a result of the cultural context in which there was no recent or imminent threat of Islamic extremist terrorism at the time of the survey and emphasis on cultural incompatibility in Norway's social discourse (Obaidi et al., 2018). Still, more work is needed to better understand the complexities of perceptions of Muslim threat and subsequent anti-Muslim attitudes and policy support, which the current study aimed to address.

Overall, these findings indicate the existence of a complex relationship between the socio-political context and threat perceptions toward Muslims, who may be perceived as threatening in different ways depending on the nature of salient stereotypes. Different types of threats may further have implications for policy support, as research suggests that changes in support for discriminatory policies are influenced by the nature of perceived threats (Rios et al., 2018). For example, while priming symbolic threat 
perceptions influenced support for policies that would impact homosexuals, a group perceived as threatening traditional family values, it did not influence support for policies regarding welfare recipients, a group perceived as threatening economic resources (Brambilla \& Butz, 2013). The differential impact of threat perceptions on policy support may be driven by more than just content compatibility, however, as research suggests that threat perceptions beget different emotional reactions that impact attitudes and behavior in various ways (e.g., Wirtz et al., 2015).

\section{The Role of Emotion in Intergroup Bias}

Emotions refer to relatively short-lived affective responses and feelings that are typically evoked by a known cause (Schwarz, 2012), such as perceived threats (Brown \& Hewstone, 2005; Stephan et al., 2015), and have the power to influence information processing, judgment, and decision making (Clore et al., 2000). Affective responses are considered a source of information about the environment that indicate the appraisal of a target stimulus and impact subsequent evaluations and behaviors (Brown \& Hewstone, 2005; Clore et al., 2000; Schwarz, 2012). Specifically, emotions can act as indicators of whether to engage in certain behaviors with the goal of maintaining, decreasing, or increasing the current emotional response or a desired emotional response (Barrett et al., 2007). Affective appraisals are ongoing as individuals are nearly always receiving affective cues from their social surroundings at both conscious (e.g., cognitive) and unconscious (e.g., perceptual) levels of awareness (Clore et al., 2000). Importantly, the affective responses that guide behaviors are part of an individual's subjective construal of situations, suggesting that the influence of intergroup emotions on behavioral outcomes 
may be driven by stereotypes and perceptions of a group rather than objective information in a given environment (Tapias et al., 2007).

Emotional responses to a member of a particular group can occur at two different levels. Specifically, emotions can be situationally constrained in which an episodic instance or interaction elicits an emotion, or more chronically felt in which the salience of the group category elicits an emotion (Kauff et al., 2017). Although both types of intergroup emotional responses are important for understanding intergroup relations, more chronically felt intergroup emotions better predict behavioral tendencies toward different groups both directly and as a mediator between episodic intergroup emotions and behavioral tendencies (Kauff et al., 2017). Therefore, chronic emotional responses to different groups may be particularly relevant for global outcomes of threat appraisals, such as discriminatory policy support, due to their broad, sweeping nature and their impact on behaviors toward the entire group.

Emotions are thought to have evolved in order to alert individuals to potential threats that require attention which suggests that threat perceptions and emotions are two components of a single detection system (Clore et al., 2000; Cottrell \& Neuberg, 2005; Schwarz, 2012). The sociofunctional approach to prejudice posits that different emotional responses arise systematically from distinct threat perceptions (e.g., realistic, symbolic, terroristic; Cottrell \& Neuberg, 2005; Schwarz, 2012; Stephan et al., 2015). For example, higher perceptions of realistic threats predicted feelings of anger whereas higher perceptions of safety threats predicted feelings of fear (Cottrell \& Neuberg, 2005). Further, Atheists, a group perceived as a symbolic threat by Christians, elicit feelings of 
moral disgust and distrust which are driven by stereotypes of Atheists as immoral (Cook et al., 2015; Gervais et al., 2011; Gervais, 2014). Together, these findings suggest that different types of threat perceptions, such as threats to one's resources or threats to one's values, elicit different emotional responses that vary according to the content of the threat at hand.

The nature of emotional reactions has important implications for behavioral outcomes in response to specific threat perceptions (e.g., Lerner \& Keltner, 2000; Lerner $\&$ Keltner, 2001; Schwarz, 2012; Stephan et al., 2015). For instance, anger is associated with riskier approach tendencies in response to threat (e.g., aggressive confrontation), whereas fear is associated with less risky avoidance tendencies in response to threat (e.g., withdrawal from a situation; Cook et al., 2018; Kauff et al., 2017; Lerner \& Keltner, 2000; Lerner \& Keltner, 2001; Mackie et al., 2000; Schwarz, 2012). These differences in behavioral responses are likely driven by differences in one's appraisal of their level of control and certainty regarding the threat at hand. Specifically, anger indicates more certainty and control whereas fear indicates less certainty and control (Lerner \& Keltner, 2001). Thus, despite both emotional responses being high in negative valence and arousal (Lerner \& Keltner, 2000; Lerner \& Keltner, 2001), the nature of the underlying threat and subsequent emotion can result in different behavioral responses that can have important implications for Muslims' intergroup experiences in the United States. To illustrate, individuals who perceive Muslims as terroristic threats may take extra precautions to avoid Muslims or vote to enact policies that would restrict immigration from Muslimmajority countries. 
Investigations of the roles of emotions in attitudes toward Muslims also suggest that emotions mediate the relationships between perceived threats and behavioral outcomes. For example, perceptions of Muslims as symbolic threats predicted both social distancing intentions as well as political intolerance (i.e., support for anti-Muslim policies), but these effects were mediated by different emotions (Wirtz et al., 2015). Specifically, the relationship between perceived symbolic threat and social distancing intentions was mediated by disgust and pity, whereas anger mediated the relationship between perceived symbolic threats and political intolerance toward Muslims. This is consistent with the idea that disgust is associated with avoidance behaviors, while anger is associated with behaviors aimed at correcting a perceived injustice or removing a source of frustration (Mackie et al., 2000; Nabi, 2002; Wirtz et al., 2015). Intergroup disgust sensitivity, or the tendency to respond to minority groups with disgust (Choma et al., 2012; Hodson \& Costello, 2007; Hodson et al., 2013), also differentially predicted levels of Islamophobia (Choma et al., 2012). This effect was strengthened by dispositional or chronic fear toward Muslims, suggesting that various threat perceptions and emotions can interact, potentially compounding the impact of emotions on behavioral responses. For example, as both fear and disgust predict avoidant behaviors, it is possible that the combination of these two emotions would exacerbate the tendency to avoid certain groups of people, such as Muslims. These findings also suggest that individual differences in the tendency to perceive certain groups of people as threatening in specific ways are important in understanding attitudes and behavioral reactions toward those groups. 


\section{Individual Differences in Ideology as Predictors of Prejudice}

Social psychology has identified many individual differences in personality and ideology that can predict intergroup attitudes, including Social Dominance Orientation (SDO; Pratto, et al., 1994), Right-wing Authoritarianism (RWA; Altemeyer, 1981), and Nationalism (Kosterman \& Feshbach, 1989). In addition to the predictive validity of each of these constructs for intergroup outcomes and support for policies that impact intergroup relations, the relevance of these specific individual differences in ideology for the current study lie in their associations with different types of threat perceptions. Thus, the roles of individual differences in SDO, RWA, and Nationalism in intergroup relations and threat perceptions were delineated both separately and in combination with one another.

\section{Social Dominance Orientation}

Social dominance theory posits that social systems are inherently organized into group-based hierarchies with at least one dominant social group, often a racial, religious, or national group (Sidanius et al., 1994). Dominance within social systems is maintained through both individual and structural factors which perpetuate a caste-like system in which the dominant group holds a disproportionate amount of social power and value (Pratto et al., 2006; Sidanius et al., 1994; Sidanius et al., 2004). SDO represents an individualized preference for hierarchically arranged social structures in which some groups are dominant while others are subordinate (Pratto et al., 1994; Sidanius et al., 1994). SDO may be further broken down into two subcomponents, one which indicates a preference for forcefully oppressing lower status groups (i.e., Dominance; SDO-D) and 
the second involving the utilization of subtler hierarchy-enhancing policies (i.e., Egalitarianism; SDO-E) in order to maintain group-based dominance (Ho et al., 2015). In some contexts, each component of SDO may predict different attitudes. For example, SDO-D better predicted support for Trump in the 2016 presidential election than SDO-E (Womick et al., 2018). Although the subcomponents of SDO are sometimes examined separately in this way, most work investigates these components together in a single composite scale (e.g., Golec de Zavala et al., 2017; Pratto et al., 1998).

In general, White individuals and men both tend to be higher in SDO (Pratto et al., 1994; Pratto et al., 1998; Sidanius et al., 1994). Those who are higher in SDO tend to support hierarchy-enhancing policies and take hierarchy-enhancing roles, which contribute to maintaining hierarchical social structures (Pratto et al., 2006; Sidanius et al., 1994). Conversely, individuals lower in SDO tend to lean toward hierarchy-attenuating policies and roles, which contribute to creating equality in the social structure. For example, police officers (a hierarchy-enhancing role) tended to be higher in SDO than public defenders (a hierarchy-attenuating role), even when controlling for differences in demographics such as gender, education, and social class (Sidanius et al., 1994). Socially dominant attitudes and support for hierarchy-enhancing policies largely stem from legitimizing myths, which justify the need for policies that reinforce existing social structures (Pratto et al., 2006). For example, SDO predicted support for increased military spending, support for war, and opposition for increased funding for social welfare (Pratto et al., 1998). Further, each of these relationships was mediated by several legitimizing 
myths such as conservatism, which legitimizes wealth inequality through the promotion of capitalism.

SDO may indicate behavioral predispositions, as it is a relatively stable predictor of intergroup attitudes and support for policies that directly impact subordinate groups (e.g., Pratto et al., 2006; Pratto et al., 1994; Sidanius et al., 1994; Sidanius et al., 2004). For example, it could be that perceptions of Muslims as immigrants who threaten the jobs and economic prosperity of Americans serve to legitimize the perceived need for policies that reduce immigration from Muslim-majority countries. Accordingly, higher levels of SDO were related to perceived threats of Muslims by non-Muslims (Dunwoody \& McFarland, 2018). Relationships between SDO and intergroup attitudes were driven in part by perceived competition with other groups, which may be conceptually related to realistic threat perceptions (Craig \& Richeson, 2014b; Perry et al., 2013). Consequently, the current study aimed to examine the predictive validity of SDO in realistic threat perceptions, as well as subsequent anti-Muslim attitudes and support for anti-Muslim policies.

\section{Right-wing Authoritarianism}

Right-wing authoritarianism (RWA) is a multidimensional individual difference construct that refers to one's preference for social order and obedience to authorities (Altemeyer, 1981; Mallinas et al., 2019; Manganelli Rattazzi et al., 2007; Smith \& Winter, 2002). RWA consists of several components including RWA submission, RWA aggression, and RWA conservatism (Altemeyer, 1981; Johnson et al., 2012; Manganelli Rattazzi et al., 2007). RWA submission encompasses the belief that authority figures in 
society should be obeyed. RWA aggression refers to beliefs that those who violate rules imposed by society's authority figures should be punished. RWA conservatism includes beliefs that a society's traditional values should be upheld. RWA is often considered as a moralization of a given society, meaning that cultural norms and values are seen as correct and true, and at times, requiring reinforcement. In particular, the conservatism component of RWA has been shown to align with other constructs relating to violations of one's fundamental beliefs about the world (e.g., morality, religious fundamentalism; Johnson et al., 2012; Mallinas et al., 2019), suggesting that this construct may be useful in predicting attitudes toward groups perceived as violating cultural and societal norms and values. Accordingly, research suggests that RWA is associated with implicit and explicit prejudice toward a number of groups including Muslims and Arabs (Johnson et al., 2012; Rowatt et al., 2005), as well as attitudes surrounding social policies (Wilson \& Sibley, 2013) and police use of force (Gerber \& Jackson, 2017). Specifically, research suggests that those high in RWA tend to be more supportive of conservative policies (e.g., restricting abortion, disenfranchising labor unions) and more supportive of war (Wilson \& Sibley, 2013).

Although conceptually related in many ways, SDO and RWA are distinct constructs that can predict different outcomes (e.g., Gerber \& Jackson, 2017; Golec de Zavala et al., 2017; Pettigrew, 2017). For example, SDO and RWA accounted for a substantial amount of the variance in prejudice toward Black people, women, and homosexuals, despite moderate correlations between the constructs (Altemeyer, 1998 as cited in Reynolds et al., 2001). Additionally, SDO and RWA may differentially predict 
support for police use of force based on the level of force used. Specifically, while SDO predicted support for reasonable use of force by police, RWA predicted support for excessive use of force by police, presumably due to increased levels of trust in the ingroup's authority figures (Gerber \& Jackson, 2017). In certain contexts, however, SDO and RWA appear to have both interactive and additive effects on one another (e.g., Lehmiller \& Schmitt, 2006; Osborne et al., 2017; Wilson \& Sibley, 2013). For example, very low levels of SDO and RWA predicted liberalism, reflecting their interactive effects on one another (Wilson \& Sibley, 2013). Very high levels of SDO and RWA, however, predicted conservatism, reflecting the additive effects of each individual difference (Wilson \& Sibley, 2013). The nature of the effects of these constructs on one another may be in part due to identity salience and relevance in a specific context.

In terms of threat perceptions, complementary patterns to the relation between SDO and realistic threat perceptions emerge between RWA and symbolic threat perceptions. For example, the relationship between RWA and support for stricter immigration laws was mediated by perceptions of cultural threat, whereas the relationship between SDO and support for stricter immigration laws was mediated by perceived competition (Craig \& Richeson, 2014b). Consistent with this pattern, RWA also predicted support for ethnic persecution when participants were primed with immigrant targets who failed to assimilate to national ingroup norms, presumably representing threats to social values (Thomsen et al., 2008). Conversely, SDO predicted support for ethnic persecution when participants were primed with immigrant targets who successfully assimilated to national ingroup norms, presumably representing a threat to 
one's standing in the social hierarchy as more people successfully enter a given society. Together, these findings suggest that different individual differences in ideology may be more or less relevant in perceiving different types of threats. RWA may be particularly important for understanding support for discriminatory policing policies regarding Muslim surveillance. For instance, those who are high in RWA may be more likely to perceive certain groups as threatening their cultural values and social order, as well as being more willing to allocate resources to enforcing societal norms through policing practices such as surveillance. Thus, the current study also aimed to elucidate the role of RWA in symbolic threat perceptions as well as subsequent anti-Muslim attitudes and policy support.

\section{Nationalism}

Nationalism is a feeling of belonging to a particular nation accompanied by beliefs that one's nation is superior to others and a desire to maintain national purity (Dekker et al., 2003; Kosterman \& Feshbach, 1989; Zmigrod et al., 2018). This specific national attitude differs from related constructs such as patriotism, which represents feelings of attachment to one's nation, or national identity, which represents identification as a member of one's nation (Kosterman \& Feshbach, 1989). Unlike patriotism and national identification, Nationalism is characterized by the promotion of rigid national exclusionism to the detriment of other nations or those perceived to belong to other nations (Dekker et al., 2003; Huddy \& Khatib, 2007; Kosterman \& Feshbach, 1989; Osborne et al., 2019; Zmigrod et al., 2018). This type of nationalistic exclusionism tends to lead to negative intergroup attitudes and interactions which differ from the 
effects of patriotism (Ayub \& Jehn, 2010). For example, Nationalism, but not patriotism, predicted support for military nuclear armament (Kosterman \& Feshbach, 1989), as well as a preference for national cultural goods over international goods (Meuleman et al., 2013). Nationalism may be particularly relevant in understanding attitudes toward Muslims in the United States, as those who are Muslim tend to be perceived as "insider enemies" who must prove their loyalty to their western identity above and beyond that of their religious or ethnic identities (Poynting \& Mason, 2007). Those high in Nationalism may be more susceptible to perceiving threats to their national identity, and thus, more supportive of xenophobic and anti-Muslim political platforms (Kende \& Krekó, 2020). In line with these findings, flag-display behaviors, which are typically thought to represent patriotic attitudes and often occur following major national events such as the 9/11 terrorist attacks (Skitka, 2005), actually led to increased Nationalistic rather than patriotic attitudes (Kemmelmeier \& Winter, 2008). Together, these findings suggest that Nationalism may play a role in negative attitudes toward Muslims who are often perceived as not belonging to western national groups (e.g., Bravo López, 2011; Dubosh et al., 2015).

Nationalism is also conceptually related to RWA and SDO. Not only has RWA aggression positively related with Nationalism (Todosijevic, 1998), but SDO and RWA each moderately predicted Nationalism and support for military aggression (Crowson, 2009). Additionally, a longitudinal study in New Zealand found that SDO and RWA predicted Nationalism over time, with no longitudinal effect of Nationalism on SDO and RWA (Osborne et al., 2017). Still, the independent role of Nationalism as a distinct 
predictor of intergroup attitudes is evident. Specifically, SDO, RWA, and Nationalism each independently predicted support in the decision for the UK to leave the EU, and these relationships were mediated by the perceived threats of immigrants in the UK (Golec de Zavala et al., 2017). Despite items measuring each type of threat perception (i.e., realistic, symbolic, and terroristic), these studies aggregated their threat perception items into a single scale, potentially obscuring the nuances in the relationships between individual differences and discrete threat perceptions. Further, much of the current work on the consequences of Nationalistic attitudes for Muslims exists in contexts outside of the United States, leaving the question open of how these attitudes impact outcomes for Muslims in the specific political context of the United States.

Although each of these individual differences in ideology (i.e., SDO, RWA, Nationalism) and threat perceptions (i.e., realistic, symbolic, terroristic) have not previously been investigated concurrently (as is the goal of the current study), there is robust evidence that SDO, RWA, and Nationalism are related to threat perceptions in fundamentally different ways. Specifically, the effect of several of these constructs on intergroup attitudes and outcomes is mediated through perceptions of threat by relevant groups (e.g., Craig \& Richeson, 2014b; Crowson, 2009; Perry et al., 2013). For example, not only was RWA more strongly associated with perceptions of terrorists as symbolic threats than realistic threats, but RWA was also a better predictor of symbolic threat perceptions than SDO (Crowson, 2009). This is unsurprising considering that the nature of symbolic threats (i.e., threats to one's values or worldview) are highly relevant for individuals high in RWA who wish to maintain the traditional norms and values of their 
society and culture. Further, although less empirical evidence currently exists

investigating the relationship between Nationalism and SDO with perceived threats, these individual difference constructs map onto terroristic and realistic threat perceptions, respectively. For example, research suggests that Nationalism is strongly associated with perceptions of the national ingroup as ethnically and culturally homogenous (e.g., Kyriakides et al., 2009; Molina et al., 2014; Yogeeswaran et al., 2019) and that Muslims are often perceived as immigrants and terrorists (e.g., Andersen et al., 2012; Dubosh et al., 2015; Keeling \& Hughes, 2011; Noor et al., 2019). Together, this may hold implications for the role of Nationalism in predicting threat perceptions toward Muslims who may be perceived as a greater threat to public safety by someone who is predisposed to be concerned with national superiority and purity (i.e., someone high in Nationalism). Additionally, consistent with research that suggests that those high in SDO may be particularly sensitive to perceived competition with other groups (Craig \& Richeson, 2014b; Thomsen et al., 2008), it is likely that these individuals are also more susceptible to other forms of perceived threats to the social hierarchy, such as their ingroup's social standing and power within that hierarchy. Such concerns are often associated with issues of power and status in society which are conceptually related to realistic threat perceptions that center around economic well-being and political power (a form of social power; Uenal, 2016). These findings suggest that different individual differences in ideology may increase susceptibility to ideological-specific threats. For example, those who are high in SDO, and thus value the existing social power structure in society, may be particularly attuned to threat to that power structure (i.e., realistic threat). Taken 
together, the current study aimed to understand how individual differences in ideology may differentially predict attitudes toward Muslims and subsequent policy support through specific types of threat perceptions.

\section{Anti-Muslim Bias in Policing and Policy}

As mentioned previously, several anti-Muslim policies have been proposed and implemented in the years since 9/11, including increased surveillance (Apuzzo \& Goldman, 2011a; 2011b; Apuzzo et al., 2011), decreased immigration from Muslimmajority countries (Collingwood et al., 2018; Elsheikh et al., 2017), and the prohibition of Sharia law in the United States (Elsheikh et al., 2017). Many of these policies are rooted in stereotypes of Muslims as terrorists and a rising tide of Islamophobia (e.g., Lee et al., 2009; Lee, et al., 2013), which has resulted in non-empirically supported policing practices that characterize Muslims and their communities as a suspect class of citizens that necessitate extra inspection (Ali, 2016; Elsheikh et al., 2017). As each previous section has described, threat perceptions, emotions, and individual differences influence intergroup attitudes and related policies. The goal of the current section is to outline previous research implicating each of these factors in support for policies that disproportionately impact minority groups. After laying this foundation, research on support for anti-Muslim policies will be delineated in order to provide context and direction for the specific policy items considered in the current study.

Threat perceptions can influence policy support in different ways depending on the type of threat perceived and social context. For example, exposure to multiculturalism (Morrison et al., 2010) and increasing national diversity (Craig \& Richeson, 2014a) can 
increase both realistic and symbolic threat perceptions, which subsequently predict support for more conservative foreign, economic, and social policies that would reduce the perceived threat of increasing diversity and multiculturalism (Osborn et al., 2019). Moreover, exposure to increasing diversity in the United States predicted support for Trump in the 2016 presidential election through increased realistic threat perceptions (Osborn et al., 2019). These findings suggest that threat perceptions may influence individuals' support for policies and politicians whose goals align with reducing the perceived threat. Accordingly, participants who were presented with a news release indicating that the Hispanic population in the United States will outnumber the White population by the year 2042 showed increased support for Trump in the 2016 presidential election and anti-immigrant policies as well as more opposition to political correctness norms, all of which were mediated by perceived realistic threats to their group status (Major et al., 2018).

Emotions are relevant in understanding reactions to threat perceptions and subsequent policy support. Recall that, according to the sociofunctional approach, emotions can be a result of perceived threats (Cottrell \& Neuberg, 2005), which can predict different types of evaluations and behaviors (Lerner \& Keltner, 2000; Lerner \& Keltner, 2001). For instance, while fear is associated with avoidance tendencies, anger is associated with approach tendencies. These evaluations and behaviors can extend to outcomes such as policy support and voting intentions, as well. For example, in a sample of Americans, inducing fear about future threats by those responsible for the attacks of 9/11 led to increased support for policies aimed at preventing terrorism (Lerner et al., 
2003). Conversely, inducing anger by presenting participants with images of celebrations of the 9/11 attacks by people in Arab countries led to increased support for more punitive policies such as deportation. Further, in support of the sociofunctional approach, emotions appear to mediate the relationship between perceived threat and policy support. For example, in the Netherlands, those who reported higher levels of perceived symbolic threat by Muslims also reported higher feelings of anger and disgust when thinking about Muslims (Wirtz et al., 2015). Only anger, however, predicted support for the restriction of Muslim immigration and religious rights, such as wearing religious clothing in public and building local mosques. Disgust, on the other hand, predicted preferences for maintaining social distance from Muslims. These findings support the importance of understanding the role of both perceived threats and emotional evaluations in predicting attitudes toward Muslims and subsequent anti-Muslim policy support.

Individual differences in ideology also play a role in support for different policy measures both in isolation and in combination with threat perceptions and emotions. For instance, while SDO and RWA both predict similar outcomes, such as support for increased military spending and military action against terrorists (Crowson, 2009; Pratto et al., 1998), they may operate through different perceived threats. Consistent with intergroup threat theory, the relationships between SDO and RWA with support for stricter immigration laws were mediated by perceived realistic and symbolic threats, respectively (Craig \& Richeson, 2014b). Further, SDO predicted support for stricter immigration through perceived realistic threat regardless of whether the national context was in their home country (i.e., United States) or some other country (i.e., Singapore). 
RWA, however, only predicted support for stricter immigration through perceived realistic threat in the context of their home country, presumably because it was difficult for participants to empathize perceived symbolic threat with an outside nation that could itself present a symbolic threat to their ingroup (Craig \& Richeson, 2014b). Nationalism is also positively related to support for policies in important ways. Higher levels of Nationalism, for instance, predicted increased support for policies to punish undocumented immigrants, but not to punish the citizens who illegally hire them (Mukherjee et al., 2012). Further, this effect was strongest for those who held a cultural construction of American identity characterized by citizenship and the ability to speak English, suggesting that support for this policy may have been driven by perceived threats by immigrants. Thus, for those high in Nationalism, support for some policies may be based more on ethnocentrism and perceived threat by immigrants than their purported concern for law and order. Together, this research suggests the importance of considering multiple factors in understanding what predicts prejudice toward Muslims and subsequent policy support that can have very real impacts on the lives of Muslims residing in the United States.

As previously described, Muslims in the United States have been subject to increased surveillance and investigation since the attacks of $9 / 11$ by both federal and local law enforcement (e.g., Henderson et al., 2006; Meeropol, 2015; OIG, 2003; Wasserman, 2015). Several cases have been brought against the City of New York, the FBI, the Department of Justice (DOJ), and the Department of Homeland Security (DHS; e.g., CRC, 2018; 2020). Most relevant to the current study are Hassan v. City of New 
York (CRC, 2018) and Tanvir v. Tanzin (CRC, 2020). Hassan v. City of New York is a lawsuit against the City of New York for their surveillance of Muslim Americans, especially in New York and New Jersey. The NYPD's program for Muslim surveillance was brought to light in 2011 by a series of reports by the Associated Press, which highlighted the strategies used by police officers, their record keeping, and the largely unsuccessful outcomes of the program in detecting terrorism (Apuzzo \& Goldman, 2011a; 2011b; Apuzzo et al., 2011). Police officers worked from a list of "ancestries of interest," most of which were descendent from Muslim countries (e.g., Pakistani, Somali, Middle Eastern). Although the NYPD, and then-Mayor Bloomberg, refuted that they relied on religious profiling in this program, this claim is brought into doubt by the fact that "American Black Muslim" was also included as an ancestry of interest (Apuzzo \& Goldman, 2011b).

Police officers and other law enforcement agencies did not infiltrate Muslim communities alone, as they often worked to identify potential informants who could spy on their own communities and report back to law enforcement (Apuzzo \& Goldman, 2011b). As part of a "debriefing program," whenever a person was arrested who might be useful for collecting intelligence, police officers were instructed to subject them to extra questioning in an attempt to know more about their communities and hopefully, to put them to work as informants. Those who refused to comply with instructions to spy on their communities were often retaliated against. For example, Tanvir v. Tanzin is a lawsuit against the FBI, the DOJ, and the DHS for the placement of several American Muslim men with no criminal records on the No-Fly List, a subset of a larger U.S. 
government terrorist screening database. In this case, the four plaintiffs were reportedly approached by the FBI who sought to recruit them as informants within their Muslim communities. Following their denial, the men were placed on the No-Fly List which resulted in most not being able to see their families overseas for several years (CRC, 2020). One man was not able to visit his 93-year-old grandmother despite her severe illness and another was not able to see his wife and young children for nearly five years. The FBI disputes that the men were placed on the No-Fly list as an act of retaliation. The fact that each man was reportedly told by the FBI that they could fly again if they agreed to work as informants, however, suggests that the men were not truly considered to be dangerous, further bringing into question the FBI's reason for placing them on the No-Fly list.

Government sanctioned discrimination against Muslims in the United States has continued in other ways as well in the years since $9 / 11$. On January $27^{\text {th }}, 2017$, thenPresident Trump signed Executive Order 13769, more commonly known as the Muslim Ban (Trump, 2017a). The original Muslim Ban restricted travel from seven predominantly Muslim countries to the United States for 90 days, including Iran, Iraq, Libya, Somalia, Sudan, Syria, and Yemen, and suspended the entry of Syrian refugees to the United States indefinitely (Trump, 2017a). The Muslim Ban received much criticism from the public and the Office of the Inspector General and was determined to violate multiple existing court orders by preventing affected travelers from boarding airplanes bound for the United States (OIG, 2018). Some evidence also exists that the implementation of the Muslim Ban may have violated the Due Process and Equal 
Protection Clauses of the Constitution which, respectively, protect citizens from prosecution without due process of law, and set forth that the law will be applied equally to all individuals [Legal Information Institute (LII), n.d.a; n.d.b; OIG, 2018]. In the face of these challenges, however, the Trump administration continued to adapt the Muslim Ban in minor ways in order to successfully implement restrictions on travel from several Muslim-majority countries (ACLU, 2020). The final version of the Muslim Ban, Executive Order 13780, was implemented in October of 2017 and placed restrictions on travel from eleven countries, eight of which were Muslim-majority countries (i.e., Egypt, Iran, Libya, Mali, Somalia, Sudan, Syria, and Yemen; Trump, 2017b). Although this ban has since been revoked by President Biden (2021), the effects of the ban are expected to be enduring as the already slow process for vetting and approving immigration from these countries have become increasingly backlogged during the time the ban was in effect (Stone, 2021). Further, an ABC News/Ipsos poll showed that only a slight majority of American respondents (55\%) supported President Biden's revocation of the Muslim ban ("American Public Supports", 2021). Thus, not only have those wishing to enter the United States have been increasingly denied, but Muslim communities within the United States face increased bias and scrutiny by law enforcement.

Similar to findings regarding the low success rates of other racial profiling programs such as stop and frisk (e.g., Gelman et al., 2007), there is a growing body of research suggesting that increased policing of Muslims may be ineffective, resulting in few terrorism-related charges (Blackwood et al., 2016; Ramirez, 2012). Further, some argue that attempting to intercept terrorism through immigration policy is likely to be 
fruitless given that many of those who commit terrorist attacks are often in the country legally. For example, both the 9/11 hijackers and the Boston Marathon bombers were in the United States legally at the time of their attacks (Ramirez, 2012). Although terrorist attacks are undoubtedly memorable and horrific, there is little evidence that pre-9/11 methods of deterring terrorism were unsuccessful, considering that less than $0.01 \%$ of all deaths in the United States were the result of terrorism in the years preceding 2001 (Ritchie et al., 2019). Further, counterterrorism efforts have even backfired in some cases and led Muslims to identify less with their American identity (Blackwood et al., 2016). This could allow for the increased radicalization of those who feel they have lost their national identity, indicating a need for more empirically formed and less identity-based counterterrorism efforts. More specific to the surveillance programs outlined above, AP reporting reveals that the surveillance of Muslims and their communities in New York City and surrounding areas did not result in a single terrorism-related charge (Apuzzo et al., 2011).

At this point, it is clear that Muslims and Middle Easterners in the United States have been under excessive scrutiny for terrorism-related investigations on the basis of their perceived or actual racial and religious identities (CRC, 2018; 2020; Blackwood et al., 2016; Henderson et al., 2006). Empirical work demonstrating the prevalence and impact of Muslim surveillance by law enforcement, however, is limited, as evidenced by the media sources responsible for most of the coverage surrounding these issues and limited police reporting. Given that many Americans' only exposure to Muslims is through the media they consume (Pratt, 2011), much of the existing empirical research on 
support for anti-Muslim policies focuses on the role of media portrayals of Muslims, often with an emphasis on military actions and immigration. Mainstream media often perpetuates stereotypes of Muslims as outsider terrorists (Kearns et al., 2019b; Shen et al., 2018) which can influence attitudes and support for anti-Muslim policy (Andersen et al., 2012; Saleem et al., 2017). Specifically, portraying Muslims as terrorists in news broadcasts predicted increased support for a number of policies aimed at increasing surveillance of Muslims in the United States, as well as increasing military action in Muslim-majority countries (Saleem et al., 2017). Similarly, the source and manner in which news is communicated can also influence support for discriminatory policies against Muslims (Andersen et al., 2012). In particular, news broadcasting showed a stronger effect in subsequent policy support than entertainment media (e.g., clips from a movie about a Muslim terrorist group). Further, negative, stereotypical coverage led to increased support for anti-Muslim policies, while positive, counter-stereotypical coverage trended toward decreased support for these policies (Andersen et al., 2012). Recall, however, that terrorist attacks received $357 \%$ more coverage when perpetrated by a Muslim compared to other groups. Thus, not only does the overrepresentation of Islamic terrorist attacks in mainstream media perpetuate and reinforce stereotypes about Muslims, but it may also influence support for discriminatory policies against Muslims (Andersen et al., 2012; Saleem et al., 2017).

Less research exists on the specific roles of threat perceptions, emotions, and individual differences in anti-Muslim policy support. Still, related research provides some insights on how these factors influence support for anti-Muslim policies. For example, 
beliefs that being a "true" New Zealander encompasses specific ancestral heritage and cultural characteristics such as speaking English predicted more negative attitudes toward Muslims and opposition toward increasing diversity through immigration (Yogeeswaran et al., 2019). Although threat perceptions were not directly measured in this study, the pattern of findings is consistent with research suggesting that symbolic threat perceptions may emerge particularly for those who hold largely ethnic and cultural conceptions of their national identity (e.g., Morrison et al., 2010). Additionally, intentions to vote for the UK to leave the EU were influenced directly by realistic threat perceptions related to Muslim immigrants, as well as indirectly via symbolic threat perceptions (Swami et al., 2018). This suggests that both concerns about the availability of resources and concerns about the national purity of the UK with Islamic influence were able to impact participants' decisions regarding large-scale, national policy change.

Consistent with research suggesting that individual differences in ideology predict threat perceptions in general (e.g., Craig \& Richeson, 2014b), the same appears to be true for perceived threat by Muslims. Both SDO and RWA predicted threat perceptions of Muslims and subsequent support for anti-Muslim policies, specifically (Dunwoody \& McFarland, 2018). To expand, those with higher levels of SDO and RWA supported a law requiring Muslims to register with government organizations, as well as support for the use of physical force in order to make Muslims reveal the identity of unregistered Muslims. Moreover, each of these relationships was partially mediated by perceived threats. Although this study measured perceptions of threat related to realistic, symbolic, and terroristic threats, there were no apparent effects of threat type on policy support, and 
thus, threat perceptions were collapsed into a single score in analyses. One possible reason for the lack of effect by threat type, however, may have been a lack of consideration of the emotional components of threat perceptions. For example, as outlined earlier in this section, emotions appear to play a mediating role in the relationship between threat perceptions and anti-Muslim policy support, with anger predicting more political intolerance of Muslims, such as not allowing the building of mosques, and disgust predicting preference for increased social distance from Muslims, such as not wanting Muslims living in one's neighborhood (Wirtz et al., 2015). Together, these findings suggest that many factors may work together to influence attitudes toward Muslims, which holds implications for their treatment by both the public and by law enforcement in the United States.

The existing body of research investigating support for anti-Muslim policies leaves room for a deeper understanding of the underlying mechanisms that may be most pertinent for reducing stereotypes about Muslims and related fears. One of the challenges of creating positive change in policy and policing practices lies in the popularity of current policies which are often discriminatory (Andersen et al., 2012; Collingwood et al., 2018; Saleem et al., 2017; Swami et al., 2018). Specifically, the fact that much of this surveillance is publicly sponsored by state and federal law enforcement agencies (Henderson et al., 2006; Keeling \& Hughes, 2011; Meeropol, 2015) makes enacting change in Muslim policing practices more difficult. Therefore, it is important to understand what factors may influence support for discriminatory policies that directly impact Muslims and those perceived to be Muslim in the United States. Perceptions of 
Muslims appear to largely be a result of cultural ignorance and misrepresentation, characterized by threat and fear (Pratt, 2011) and several contributing factors of antiMuslim policy support have emerged from the existing body of research, including threat perceptions (Swami et al., 2018), emotional reactions (Wirtz et al., 2015), and individual differences in ideology (Dunwoody \& McFarland, 2018). Thus, the current study aimed to assess the process through which individual differences, threat perceptions, and emotions influence anti-Muslim attitudes and subsequent anti-Muslim policy support.

\section{The Current Study}

The goals of the current study were threefold. First, consistent with research which suggests that threat perceptions underlie prejudice toward Muslims (e.g., Dunwoody \& McFarland, 2018; Uenal, 2016) and that certain individual differences in ideology may influence perceptions of threat and intergroup bias (Altemeyer, 1981; Kosterman \& Feshbach, 1989; Pratto et al., 1994), this study focused on the roles of several individual differences in ideology and threat perceptions in levels of Islamophobia and subsequent support for anti-Muslim policies. Specifically, this research investigated the roles of SDO, RWA, and Nationalism in predicting Islamophobia, as well as the mediating roles of realistic, symbolic, and terroristic threat perceptions in these relationships. This aim was also based on my own pilot research that examined the relationships between SDO, RWA, and Nationalism on Islamophobia through realistic, symbolic, and terroristic threat perceptions. This preliminary study $(N=191)$ employed structural equation modeling (SEM) and showed that SDO, RWA, and Nationalism positively predicted realistic, symbolic, and terroristic threat perceptions, respectively, 
and that each type of threat positively predicted Islamophobia. Moreover, the indirect effects of SDO and RWA on Islamophobia through realistic and symbolic threat perceptions were significant and in the expected directions. The indirect effect of Nationalism on Islamophobia through terroristic threat perceptions, however, was nonsignificant in this sample. This study was underpowered due to the small sample size acquired and the large sample sizes needed to obtain adequate power in SEM. Thus, the current study builds on this work by recruiting a larger sample to reach a minimum power level of .80, accounting for the interrelations that likely exist between each individual difference in ideology (i.e., SDO, RWA, Nationalism) and each type of threat perception (i.e., realistic, symbolic, terroristic), and by expanding the model to include the impacts of these factors (i.e., individual differences, threat perceptions, Islamophobia) on antiMuslim policy support.

Similar to previous research (e.g., Cottrell \& Neuberg, 2005), the second aim of this study was to determine the emotional components predicted by each specific threat perception. Previous work suggests that several emotions are associated with distinct types of threat perceptions (e.g., anger with realistic threats, distrust with symbolic threats; Cottrell \& Neuberg, 2005). To date and to my knowledge, no empirical research has assessed the emotional components of each type of threat since the addition of terroristic threat perceptions into the intergroup threat framework. Thus, this study aimed to assess which emotions are associated with and predicted by different types of threat perceptions. 
The third and final aim of the current study was to examine the mediational effect of emotional reactions in the relationships between different types of threat perceptions and support for discriminatory policies toward Muslims. This aim was based on work suggesting that emotional reactions may be useful for predicting different types of behaviors (e.g., anger predicting aggression and fear predicting social distancing; Lerner \& Keltner, 2000; Lerner \& Keltner, 2001). Extant research has not fully investigated the roles of individual differences in ideology, threat perceptions, and emotional reactions in support for anti-Muslim policies, especially those regarding surveillance by law enforcement. Altogether, this study aimed to substantially contribute to our understanding of individual differences in perceptions of Muslims as threats and their subsequent emotional reactions as they relate to Muslim metering and surveillance policy support.

\section{Hypotheses}

The current study consists of three main aims which include two main hypotheses as well as one data-driven exploratory hypothesis with a theoretically based contingency hypothesis. Each of these aims and hypotheses focuses on the roles of individual differences in ideology, threat perceptions, and emotional reactions in bias toward and discrimination against Muslims.

\section{$\operatorname{Aim} 1$}

Aim 1 consists of 4 sub-hypotheses (1a-1d). Overall, it was expected that individual differences in ideology would predict threat perceptions which would predict Islamophobia and subsequent support for anti-Muslim policies, representing an ideologythreat-attitude-behavior model of anti-Muslim bias (see Figure 2). SEM was used to 
simultaneously test hypotheses $1 \mathrm{a}-\mathrm{d}$ in a single model. SEM refers to a broad family of theory-driven, causal inference techniques based on a given theoretical model and parameter specifications (Kline, 2015). Since SEM can take the covariances between variables into account when testing the fit of the model and hypotheses (Kline, 2015), these techniques can be particularly useful in cases where independent variables are expected to correlate, as is the case in the current analysis (e.g., SDO and RWA are expected to be related). This model was tested to establish the role of each individual difference in threat perceptions, anti-Muslim attitudes (i.e., Islamophobia), and subsequent anti-Muslim policy support by comparing the strengths of each mediational path.

Figure 2

Aim 1 Full Model

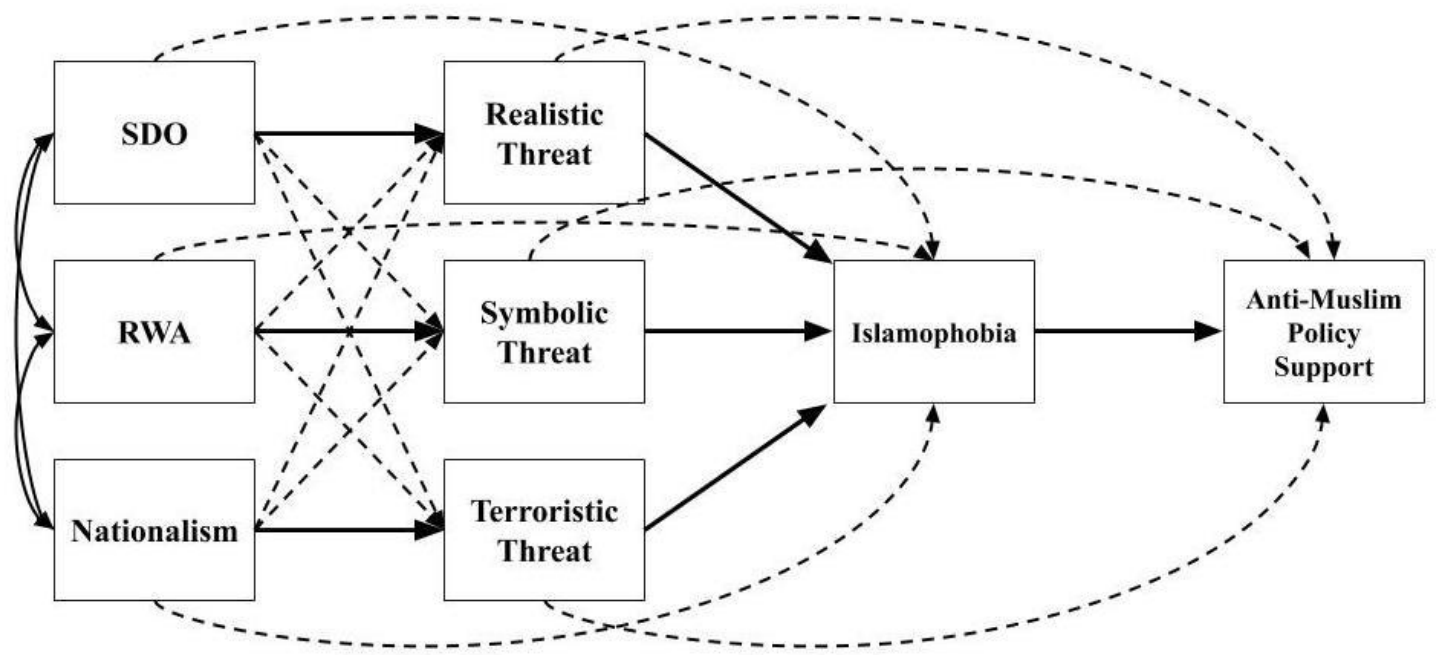

Note. Full hypothesized structural equation model for aim 1 with all paths included. 
Hypothesis 1a. Based on previous research suggesting that SDO predicts intergroup bias (e.g., Pratto et al., 2006; Pratto et al., 1994; Sidanius et al., 1994; Sidanius et al., 2004) and that SDO may be particularly relevant for realistic threat perceptions (e.g., Craig \& Richeson, 2014b; Thomsen et al., 2008), it was hypothesized that higher levels of SDO would predict Islamophobia, with realistic threat perceptions partially mediating this relationship. Specifically, it was expected that those with higher levels of SDO would be more likely to report perceptions of Muslims as a realistic threat, which would increase levels of Islamophobia (see Figure 3).

\section{Figure 3}

Theoretical Model for Hypothesis 1 a

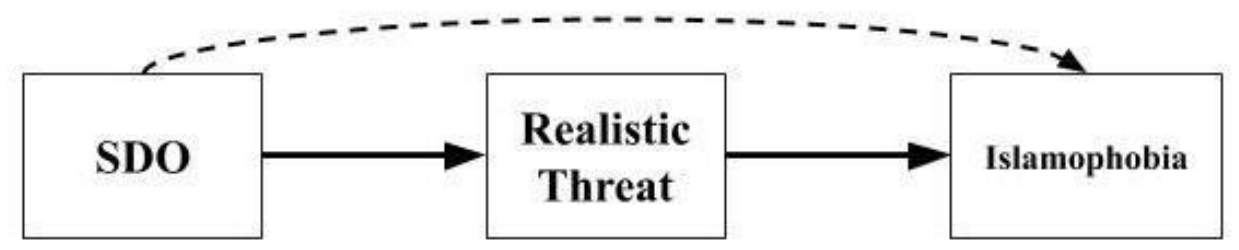

Note. See figure 2 for full hypothesized model.

Hypothesis 1b. Since research suggests that RWA also predicts intergroup bias (e.g., Johnson et al., 2012; Rowatt et al., 2005) and that it may be particularly relevant for symbolic threat perceptions (e.g., Crowson, 2009), it was hypothesized that RWA would predict Islamophobia with symbolic threat perceptions partially mediating this relationship. Specifically, it was expected that those with higher levels of RWA would be more likely to report perceptions of Muslims as a symbolic threat, which would increase levels of Islamophobia (see Figure 4). 


\section{Figure 4}

Theoretical Model for Hypothesis $1 b$

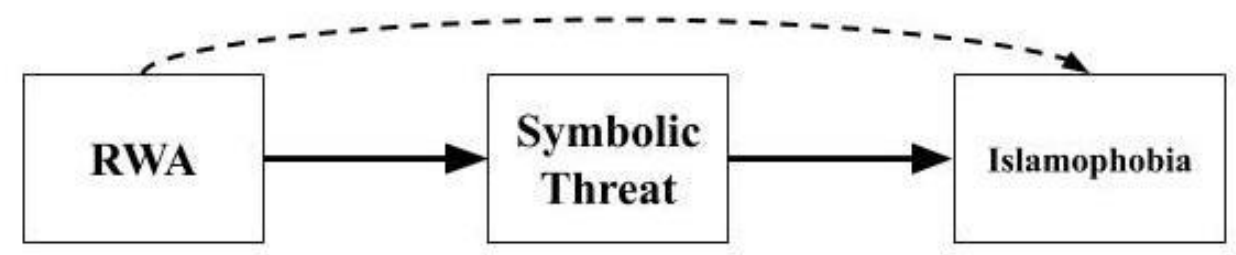

Note. See figure 2 for full hypothesized model.

Hypothesis 1c. Given research suggesting that Nationalism predicts intergroup bias (Ayub \& Jehn, 2010) and the theoretical correspondence between Nationalism and terroristic threat perceptions (e.g., Andersen et al., 2012; Yogeeswaran et al., 2019), it was hypothesized that Nationalism would predict Islamophobia with terroristic threat perceptions partially mediating this relationship. Specifically, it was expected that those with higher levels of Nationalism would be more likely to report perceptions of Muslims as a terroristic threat which would increase levels of Islamophobia (see Figure 5).

\section{Figure 5}

Theoretical Model for Hypothesis $1 c$

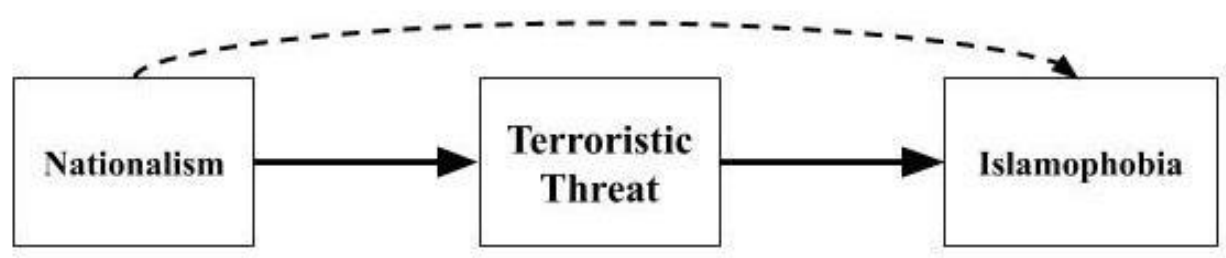

Note. See figure 2 for full hypothesized model.

Hypothesis 1d. Based on research suggesting that individual differences in ideology, threat perceptions, and Islamophobia may all impact levels of support for 
discriminatory policies (e.g., Elsheikh et al., 2017; Golec de Zavala et al., 2017; Swami et al., 2018), it was expected that Islamophobia would mediate the relationships between individual differences, threat perceptions, and support for anti-Muslim policies (e.g., increasing surveillance of Muslim communities in the United States). Specifically, it was expected that Islamophobia would act as a mediator between threat perceptions and policy support, such that those with higher levels of perceived threats would be more likely to hold higher levels of Islamophobia, and subsequently, be more likely to support anti-Muslim policies (see Figure 6). This is consistent with previous work suggesting that threat perceptions predict bias toward other groups and behavioral outcomes such as support for policies that would impact relevant groups (Rios et al., 2018; Stephan et al., 2015). Thus, in total, it was expected that higher levels of each individual difference in ideology (i.e., SDO, RWA, Nationalism) would differentially predict higher levels of each threat perception (i.e., realistic, symbolic, terroristic), which would predict higher levels of Islamophobia and subsequently, increased support for anti-Muslim policies. The ideology-threat-attitude-behavior order of predictions in the model is consistent with research implicating threat perceptions as mediators between individual differences and attitudes and behaviors (e.g., Golec de Zavala et al., 2017, Stephen et al., 2015; Uenal, 2016). 


\section{Figure 6}

Theoretical Model for Hypothesis 1d

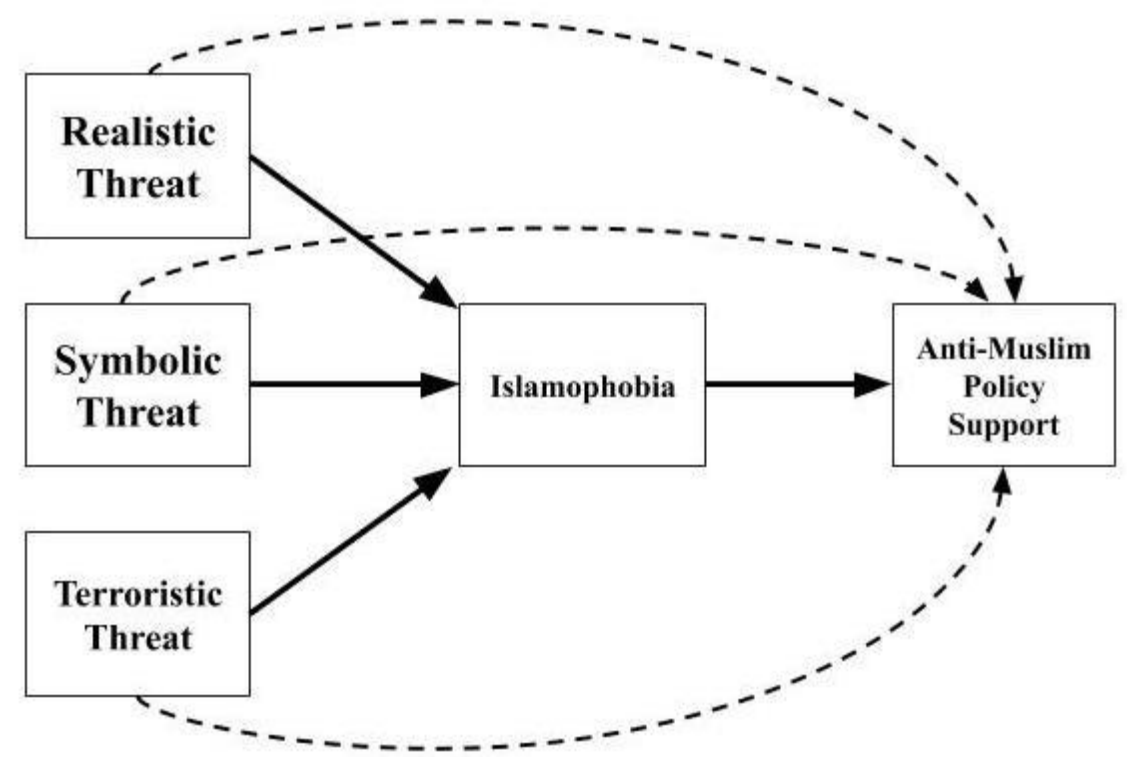

Note. See figure 2 for full hypothesized model.

$\operatorname{Aim} 2$

Similar to previous research investigating the role of threat perceptions in emotional reactions (Cottrell \& Neuberg, 2005), cluster analysis techniques were used to explore the emotional components of threat perceptions of Muslims. This type of analysis is an example of unsupervised learning in which the goal is not prediction, but rather to discover interesting patterns in a given dataset (James et al., 2013). Cluster analysis refers to a wide range of techniques that detect clusters by partitioning them into discrete groups in which components within a cluster are similar to one another but dissimilar to components within other clusters (James et al., 2013). Aim 2 also consisted of 3 subhypotheses $(2 a-2 c)$ that were planned to be tested in the event that the cluster analyses from the exploratory hypothesis resulted in unclear or theoretically inconsistent clusters 
of emotions (e.g., fear and distrust clustering together, all emotions cluster into a single cluster, results of each cluster analysis vary substantially) and prevented the testing of threat perceptions as predictors of emotion clusters. In this case, regression analyses would be completed with single-item measures of theoretically relevant emotional reactions (i.e., anger, distrust, fear) and compared for fit.

Exploratory Hypothesis. Although exploratory in nature, previous work investigating the emotional components of several types of threat perceptions allowed for a general hypothesis for my exploratory analyses. Specifically, based on the work of Cottrell and Neuberg (2005) and Gervais and colleagues (2011), it was expected that symbolic threat perceptions would be characterized by and predict emotions such as distrust and disgust. Given that previous work (e.g., Cottrell \& Neuberg, 2005) combined realistic and terroristic threats in their investigations, less clear hypotheses could be made. Still, considering research which suggests that perceptions of challenge and competition, which are conceptually similar to power, or realistic threat perceptions, may lead to anger, whereas threats to physical safety which are conceptually similar to terroristic threat perceptions, may lead to fear (e.g., Cottrell \& Neuberg, 2005; Lerner et al., 2003), it was expected that realistic threats would predict feelings of anger and that terroristic threats would predict feelings of fear.

To determine which emotions cluster with which threat perceptions, several clustering approaches were used. First, $k$-means cluster analysis was used to determine how emotions cluster with $k$ (i.e., the number of clusters) set to 3 in order to map onto the three threat perception measures being used. This iterative approach is useful for 
theoretically based questions in which the expected number of non-overlapping clusters can be determined (James et al., 2013). Following this approach, hierarchical cluster analysis was used to get a more robust picture of the emotion clusters. This approach differs from $k$-means clustering in that $k$ is not set a priori, but rather determined through the visualization of a dendrogram that presents all of the possible clusters for any number of total clusters from 1- $n$ (James et al., 2013). The solutions in which the within-cluster variation was minimized would then be selected from each technique (i.e., $k$-means and hierarchical cluster analysis) and compared to determine the best fit for the emotion cluster structure, overall.

Although one approach could have been to include threat perceptions in the cluster analyses to determine where the threat perceptions cluster with each emotion, the fact that these threat perceptions are often correlated (i.e., people who perceive one type of threat are likely to perceive the other types of threats) means that including threat perceptions in the data-driven clustering approach would likely have convoluted the results of the cluster analyses. To avoid this complication, the resulting emotion clusters were planned to be used as outcome variables in a series of regression analyses in order to determine which threat perceptions (i.e., symbolic, realistic, terroristic) best predict each emotion cluster.

Hypothesis 2a. Based on previous work looking at the emotional components of resource-based threat perceptions, it was expected that realistic threat perceptions would predict feelings of anger (Cottrell \& Neuberg, 2005). 
Hypothesis 2b. Although disgust has been shown to impact attitudes toward Muslims (Wirtz et al., 2015), other research suggests that distrust may be a more relevant emotional reaction when groups are perceived as violating religious values such as morality (Gervais et al., 2011). Based on these findings and the emphasis of perceived threats to western values of the symbolic threat measure used, it was expected that symbolic threat perceptions would predict feelings of distrust (Cottrell \& Neuberg, 2005; Gervais et al., 2011).

Hypothesis 2c. Based on previous work looking at the emotional components of safety-based threat perceptions, it was expected that terroristic threat perceptions would predict feelings of fear (Lerner et al., 2003).

Depending on the conclusions of the exploratory hypothesis, regression analyses using either the emotion cluster or the theoretically based discrete emotion predictions (hypotheses 2a-2c) were to be compared for fit using $R^{2}$ and Bayesian Information Criterion (BIC) estimates, where $Y=$ each emotion cluster or outcome (i.e., realistic cluster or anger, symbolic cluster or distrust, and terroristic cluster or fear), $r=$ realistic threat perceptions, $s=$ symbolic threat perceptions, and $t=$ terroristic threat perceptions:

$$
\begin{aligned}
& Y_{r c / a}=b_{0}+X_{1 r}+e_{1} \\
& Y_{s c / d}=b_{0}+X_{1 s}+e_{2} \\
& Y_{t c / f}=b_{0}+X_{1 t}+e_{3}
\end{aligned}
$$

\section{Aim 3}

Aim 3 consists of 3 sub-hypotheses (3a-3c). Overall, it was expected that threat perceptions would predict threat-based emotional reactions which would predict support 
for anti-Muslim policies, representing a threat-emotion-behavior model of anti-Muslim bias (see Figure 7). Similar to aim 1, SEM was used to simultaneously test hypotheses 3a-3c. This technique is useful for estimating predictive relationships between multiple variables within a single model as it accounts for covariances between exogenous (i.e., predictive) variables (Kline, 2015). This is particularly useful given the expected correlations between each type of perceived threat. Similar to the first structural equation model, the role of each emotion cluster (i.e., realistic cluster, symbolic cluster, terroristic cluster) or discrete emotion (i.e., anger, distrust, fear) in mediating the relationships between threat perceptions and anti-Muslim policy support was examined by comparing the strengths of each mediational path. This model was tested separately from the first structural equation model which investigates more general attitudes toward Muslims (i.e., Islamophobia) in order to develop a better understanding of the mediating roles of specific emotions in the relationship between threat perceptions and anti-Muslim policy. This was tested separately from the first structural equation model for both theoretical and practical reasons. First, although there is evidence to suggest that threat perceptions predict emotional reactions, to my knowledge, there is no empirical evidence indicating whether emotions would predict or be predicted by Islamophobia, making the structure of a combined model unclear. Additionally, since the definition of Islamophobia is largely based on fear toward Muslims and the religion of Islam, including both Islamophobia and emotions toward Muslims, such as fear, would likely have introduced redundancy into the model. More practically, increasing the number of variables and paths to be estimated in the model would have increased model complexity which can have adverse effects on 
power. For these reasons, two structural equation models were tested separately to determine 1) the role of individual differences in predicting anti-Muslim attitudes and policy support through perceived threat, and 2) the role of perceived threat on antiMuslim policy support through distinct emotional reactions.

\section{Figure 7}

Aim 3 Full Model

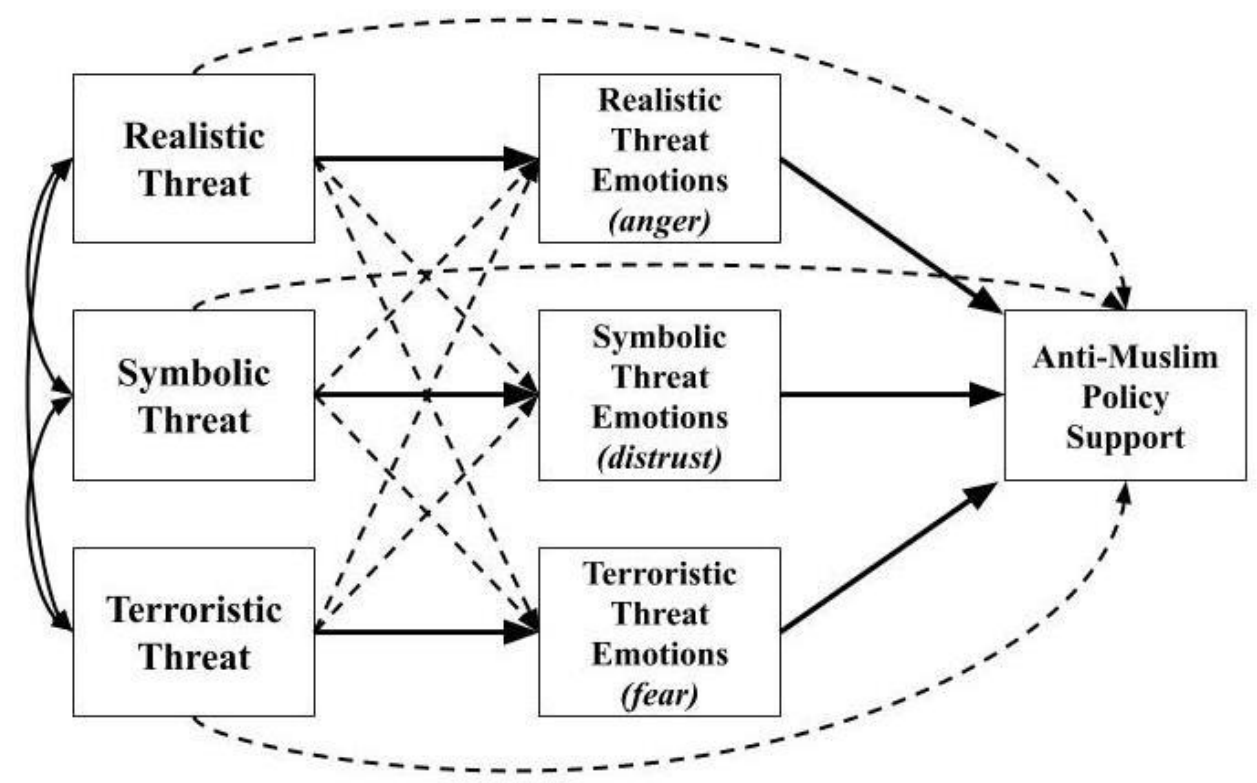

Note. Full hypothesized structural equation model for aim 3 with all paths included.

Hypothesis 3a. Research suggests that threat perceptions predict different emotional reactions, which may lead to different evaluative and behavioral outcomes, such as support for discriminatory policies toward a number of groups (e.g., Cottrell \& Neuberg, 2005; Lerner \& Keltner, 2000; Lerner \& Keltner, 2001). Therefore, it was hypothesized that realistic threat perceptions would predict support for anti-Muslim policies through its associated emotional components, which was determined in the 
exploratory hypothesis and hypotheses 2a-2c outlined above. Specifically, higher levels of realistic threat perceptions were expected to predict increased support for an antiMuslim policy regarding Muslim surveillance with this relationship partially mediated by increased levels of the realistic emotion cluster or anger (see Figure 8).

\section{Figure 8}

Theoretical Model for Hypothesis $3 a$

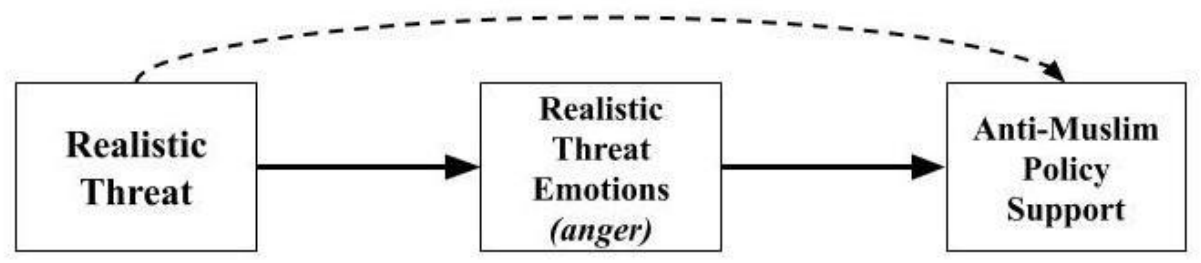

Note. See figure 7 for full hypothesized model.

Hypothesis 3b. Similar to hypothesis 3a, it was expected that higher levels of symbolic threat perceptions would predict increased support for an anti-Muslim policy regarding Muslim surveillance and that this relationship would be partially mediated by increased levels of the symbolic emotion cluster or distrust (see Figure 9).

\section{Figure 9}

Theoretical Model for Hypothesis $3 b$

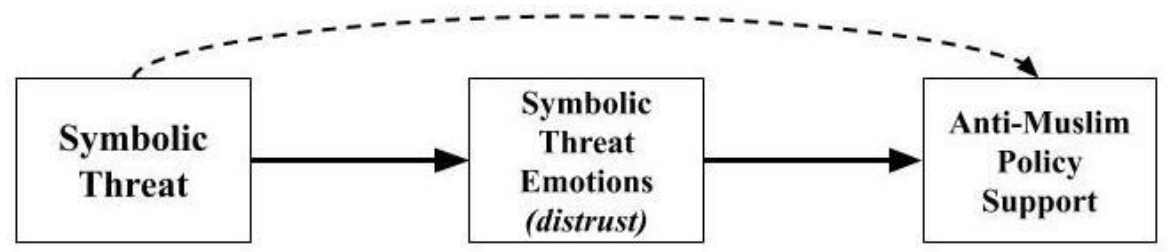

Note. See figure 7 for full hypothesized model. 
Hypothesis 3c. It was hypothesized that higher levels of terroristic threat

perceptions would predict increased support for an anti-Muslim policy regarding Muslim surveillance and that this relationship would be partially mediated by increased levels of the terroristic emotion cluster or fear (see Figure 10).

\section{Figure 10}

Theoretical Model for Hypothesis 3c

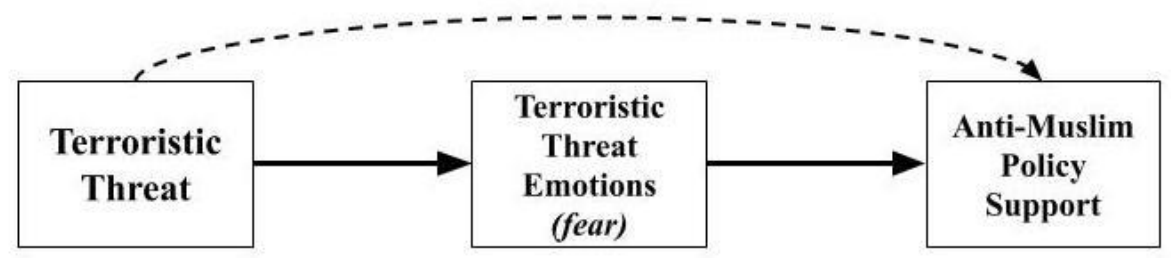

Note. See figure 7 for full hypothesized model. 


\section{Method}

\section{Power Analyses}

The current study primarily used structural equation modeling (SEM) to test the various hypotheses. Given the flexible nature of structural equation modeling and the model-dependent nature of a priori power analyses, there are not currently clear guidelines on how to conduct a priori power analyses using well-established tools, such as G*Power (Faul et al., 2007). Guidelines about the minimum number of participants necessary for adequate power (Wolf et al., 2013), as well as previous research testing similar types of mediational structural equation models (Uenal, 2016) suggest that a sample size of at least 200 is sufficient to detect small to medium effects $(.10-.50)$ with a power level of .80. In addition to these guidelines, an online SEM power calculator (Zhang \& Yuan, 2018) based on the suggestions of Satorra and Saris (1985) was used to determine the sample size necessary to detect a small effect (.10) with a power level of .80. This calculator is based on the Chi-square test. The results of these power analyses indicated that a minimum sample size of 138 for the first structural equation model (i.e., hypotheses 1a-1d) and a minimum sample size of 110 for the second structural equation model would be adequate to detect small to medium effects at a power level of .80 . Additionally, data simulation based on pilot data was used to better determine the ability to detect effects within the proposed models with various sample sizes. Based on these analyses, 500 participants were recruited to ensure a conservative sample size for all measures of interest after data reduction due to non-responding on certain items or early exit from the survey. 


\section{Participants}

Three-hundred and sixty-one participants were collected through Amazon's Mechanical Turk (MTurk) and 336 participants were collected through Portland State University (PSU) for a total of 697 participants. All recruitment was completely online due to the COVID-19 pandemic. Participants were recruited from these two populations in order to ensure a politically diverse enough sample. Although student samples tend to be more liberal than the general population, samples collected from MTurk tend to be more politically diverse and show similar reliability to more traditional sampling methods (Buhrmester et al., 2011; Feitosa et al., 2015; Johnson \& Borden, 2012). Given that several hypotheses were related to individual differences that are often associated with political orientation, the distributions of political ideology across samples were examined for normality to assess whether more targeted participant recruitment was required prior to hypothesis testing. As expected, when comparing the PSU and MTurk samples, there was a significant difference in political orientation with PSU participants being more liberal on average $(M=5.58, S D=1.30)$ compared to MTurk participants $(M=4.54, S D$ $=1.92), t(608)=-7.73, p<.001,95 \%$ CI $[-1.31,-0.78]$. Overall, the distribution of the combined sample was relatively normally distributed, however, with an average of 5.02 $(S D=1.74)$ and a skewness value of -0.75 which is well below the recommended absolute value of 2 (Gravetter et al., 2020). Although a greater proportion of the full sample reported being slightly to very liberal (64.2\% compared to $16.9 \%$ moderate and $18.8 \%$ slightly to very conservative), more conservative participants were not recruited based on the overall normal distribution. 
PSU students were recruited through online course announcements by their instructors in classes across several academic departments between September and December of 2020. MTurk participants were recruited through the Cloud Research Toolkit platform on September $19^{\text {th }}$, October $4^{\text {th }}$, and October $19^{\text {th }}$ of 2020. Participant recruitment was conducted over the course of several weeks and months in part to address the tumultuous and variable social and political climate in the United States surrounding the ongoing COVID-19 pandemic, the spike in Black Lives Matter protests across the country, and the 2020 presidential election. Given that no major events specific to Muslims in the United States or updates with the Muslim ban occurred during data collection, it was hoped that spreading out data collection aided in drowning out the potential for political events to impact responses to the current study. As with any study, however, findings should be considered within the historical and social context in which they are based.

Precautions were taken to ensure that robotic accounts were not able to access the survey through MTurk, including the use of a Completely Automated Public Turing test to tell Computers and Humans Apart (CAPTCHA). Geographic locations were restricted to the United States given that the hypotheses concerned attitudes of those living in the United States, specifically. Several data cleaning measures were taken prior to analyses. Thirty-seven participants were removed for failing to take the survey or complete the measures of interest beyond the demographics. Out of the remaining participants, 9 were removed for identifying as Muslims, and 1 participant was removed for being under the age of 18. No participants reported residing outside of the United States. An additional 16 
participants were removed due to duplicate IP addresses. Finally, 31 participants were removed for failing an attention check item. The final sample consisted of 603 participants (346 women, 234 men, 13 nonbinary, 4 other) with an average age of about 35 years $(M=34.7, S D=14.1)$. Overall, the sample was predominantly White $(394$ White, 41 Black, 48 Latin-o/a/x, 60 Asian, 45 multiracial, and 14 other), and slightly liberal, although political orientation was still relatively normally distributed $(M=5.01$, $S D=1.77)$.

\section{Procedure}

After completing the informed consent, participants completed a series of questionnaires measuring social attitudes including SDO (Ho et al., 2015), RWA (Manganelli Rattazzi et al., 2007), and Nationalism (Kosterman \& Feshbach, 1989). Participants also completed measures indicating their level of each type of perceived threat of Muslims (Uenal, 2016), emotional reactions toward Muslims (Cottrell \& Neuberg, 2005), level of Islamophobia (Lee et al., 2013), and support for several policies that restrict the rights of Muslims in the United States. Finally, participants read about the proposal of a senate bill that would allow police officers in the United States to stop and question anyone leaving a mosque who appears suspicious (see Appendix for full survey measures). 


\section{Measures}

\section{Social Attitudes}

Participants began by completing several scales intended to assess a number of social attitudes, including SDO (Ho et al., 2015), RWA (Manganelli Rattazzi et al., 2007), and Nationalism (Kosterman \& Feshbach, 1989).

Social Dominance Orientation. SDO was measured using a shortened Social Dominance Orientation Scale (SDO ${ }_{7}$; Ho et al., 2015) which consists of eight items measuring two subdimensions: dominance (SDO-D) and egalitarianism (SDO-E). Generally, SDO indicates one's support of existing social hierarchies that place certain groups of people above or below others (Pratto et al., 2006; Pratto et al., 1994), with the dominance subscale representing beliefs in active oppression of subordinate groups by dominant groups, and the egalitarianism subscale representing beliefs in the maintenance of social inequality (Ho et al., 2015). All items were measured on a 7-point Likert-style scale with higher values indicating more endorsement of each item (1-Strongly Disagree, 7-Strongly Agree). Example items include, “An ideal society requires some groups to be on top and others to be on the bottom" (dominance), and "We should work to give all groups an equal chance to succeed" (egalitarianism, reverse-coded). Based on the goals of the current study to understand the role of both SDO-D and SDO-E in predicting perceptions of Muslims and subsequent policy support, an average of the full $\mathrm{SDO}_{7}$ scale was used for analyses, $\alpha=.88$.

Right-wing Authoritarianism. RWA was measured using a shortened version of the RWA scale which consists of two subdimensions: aggression and submission, and 
conservatism (Manganelli Rattazzi et al., 2007). Fourteen items were measured on a 7point Likert-style scale with higher values indicating more endorsement of each item (1Strongly Disagree, 7-Strongly Agree). Example items include "Obedience and respect for authority are the most important values children should learn," (aggression and submission), and "Everyone should have their own lifestyle, religious beliefs, and sexual preferences, even if it makes them different from everyone else" (conservatism, reversecoded). This scale can be used by aggregating the full scale or each subdimensions depending on the specific hypotheses being tested (e.g., if they are related to one aspect of RWA, specifically, or levels of RWA, generally). Based on the goals of the current study to understand the role of both RWA aggression and submission and RWA conservatism, an average of the full RWA scale was used for analyses, $\alpha=.94$.

Nationalism. Nationalism was measured using the Nationalism subscale of the Patriotism/Nationalism Questionnaire (Kosterman \& Feshbach, 1989). This subscale represents the view that the United States is superior and should be dominant over other countries. All eight items were measured on a 7-point Likert-style scale with one item reverse-coded so that higher values indicated more endorsement of each item (1-Strongly Disagree, 7-Strongly Agree). Example items include, "Generally, the more influence America has on other nations, the better off they are," and "Other countries should try to make their governments as much like ours as possible." Based on the hypotheses related to Nationalism and its ethnocentric components, specifically, only the Nationalism subscale of the broader Patriotism/Nationalism Questionnaire was used, $\alpha=.91$. 


\section{Intergroup Bias}

Participants completed another series of questions intended to measure intergroup bias, including perceived threats posed by Muslims (Uenal, 2016), emotional responses toward Muslims (Cottrell \& Neuberg, 2005), level of Islamophobia (Lee et al., 2013), and support of discriminatory policies against Muslims.

Threat Perceptions. Realistic, symbolic, and terroristic threat perceptions toward Muslims were assessed using a measure adapted from Uenal (2016). Realistic threat perceptions represent threats to one's resources or social status, with an example item being, "Because of the presence of Muslims in the United States, Americans have more difficulties finding a job," $\alpha=.95$. Symbolic threat perceptions represent threats to one's moral or worldview, with an example item being, "I am worried that the American norms and values are threatened by the presence of Muslims," $\alpha=.97$. Finally, terroristic threat perceptions represent threats to one's physical safety or security, with an example item being, "It is only a matter of time before the United States will become a target for Islamist terrorists," $\alpha=.90$. All eleven items were measured on a 7-point Likert-style scale with higher values indicating more perceived threat (1-Strongly Disagree, 7-

Strongly Agree). Threat perceptions were aggregated separately to create three scores that represent levels of each type of perceived threat.

Emotional Reactions. Emotional reactions toward Muslims were measured using items from Cottrell and Neuberg (2005) which assess levels of several different emotions in response to different groups of people. These emotional reactions have been shown to predict intergroup bias in previous research (e.g., Cottrell \& Neuberg, 2005; Gervais et 
al., 2011). An example item for this scale would be "When I think about Muslims, I feel [fear, anger, distrust, disgust, anxiety, envy, pity, guilt].” All items were measured on a 5point Likert-style scale with higher values indicating higher levels of that emotion (1-Not at all, 5-Extremely). Based on a sociofunctional approach to prejudice that suggests certain emotions are representative of different kinds of perceived threats (Cottrell \& Neuberg, 2005; Gervais, 2014; Gervais et al., 2011), separate scores for each emotional reaction were used in analyses. Positive emotions were not measured as they were not expected to be representative of the negative types of perceived threats being investigated in the current study and have typically not been used in previous analyses investigating the emotional components of threat perceptions (e.g., Cottrell \& Neuberg, 2005).

Islamophobia. Levels of Islamophobia were measured with the Islamophobia scale which measures feelings of fear toward Muslims and Islam (Lee et al., 2013). This scale consists of items relating to anti-Muslim attitudes (e.g., "If I could, I would avoid contact with Muslims.") and anti-Islam attitudes (e.g., "Islam is a dangerous religion"). All items were measured on a 7-point Likert-type scale with higher values indicating higher levels of Islamophobia (1-Strongly Disagree, 7-Strongly Agree). Items were aggregated to create an average measure of Islamophobia including both anti-Muslim and anti-Islam attitudes, $\alpha=.98$.

Policy Support. Endorsement of discriminatory policies was assessed by having participants report their level of agreement with three statements about different policy initiatives, as well as responding to a "recently proposed bill" that would increase surveillance of Muslim communities by the police. The anti-Muslim policy measure used 
for aim 1 (hypotheses 1a-1d) consisted of three policy initiative items that were measured on a 7-point Likert-style scale with higher values indicating more agreement with each statement (1-Strongly Disagree, 7-Strongly Agree). The three items included, "I would support a policy to require government surveillance of all U.S. mosques", "I would support a policy banning the entry of all Muslims into the United States", and "I would support state universities limiting enrollment by members of racial and religious groups in proportion to their percentage of the state's population." These items were averaged to provide a composite score of general support for anti-Muslim policies, $\alpha=.94$. Although the item regarding university enrollment comes from previous work (Nobles \& Nobles, 1954, as cited in Andersen et al., 2012), the lack of empirical research on policies relating to Muslims specifically led to the self-development of the remaining two items based on proposed and actual policies in the United States (Al Jazeera, 2020; CRC, 2018; 2020). For the anti-Muslim policy outcome used for aim 3 (hypotheses 3a-3c), participants read a short paragraph describing a fictitious bill that was recently proposed to increase police surveillance of mosques and Muslim community centers (see Appendix). This bill was based on activities of the covert NYPD Demographics Unit which were revealed in 2011 (Apuzzo \& Goldman, 2011a; 2011b; Apuzzo et al., 2011). This paragraph outlined a recent bill (S.B. 5483) that was scheduled for a vote by the Senate and would enable local police to follow and question anyone seen leaving a mosque or Muslim community center with "reasonable suspicion". This was followed by a series of questions regarding the participant's thoughts and feelings about the passing of that bill which were aggregated into an average score indicating support for the proposed bill (e.g., "The 
passing of this bill will make the United States safer"; 1-Strongly Disagree, 7-Strongly

Agree; $\alpha=.91$ ).

\section{Demographics}

Participants completed demographic information including their racial and ethnic identity, gender identity, religious identity, age, and political ideology (see Appendix). 


\section{Results}

\section{Preliminary Analyses}

Univariate normality was assessed using boxplots which showed positively skewed distributions with some potential outliers on almost all of the variables of interest. Although positively skewed, most of the skewness and kurtosis values were below 2 (Gravetter \& Wallnau, 2014) with the exception of the general anti-Muslim policy measure (kurtosis $=2.14$ ). Given the nature of the distribution and the fact that these variables were measured on a restricted range of 1-7, the identified potential outliers were retained. Potential multivariate outliers were detected using Mahalanobis Distance using the variables of interest in each model. Most participants were identified as potential multivariate outliers for both aim 1 (hypotheses 1a-1d) and aim 3 (hypotheses 3a-3c). Given the large number of variables included in each model and the skew observed in the univariate distributions, all participants from the reduced sample described in the methods section were retained for all analyses.

The fact that almost all participants were identified as multivariate outliers suggests that the assumption of multivariate normality was violated. To follow up on this, Mardia's test of multivariate normality was conducted (Korkmaz et al., 2014). The results of this test confirmed the suspicion that multivariate normality could not be assumed in the analyses, warranting consideration when interpreting results ${ }^{1}$. The assumptions of

\footnotetext{
${ }^{1}$ Both structural equation models were also run with maximum likelihood estimation with robust standard errors and a scaled test statistic due to the violation of multivariate normality. These more conservative estimates did not change any of the interpretations of findings in either direction of relationships or changes to significance levels. Thus, the reported analyses are based on the originally planned estimation method (i.e., full information maximum likelihood with bootstrapped standard errors).
} 
homoscedasticity and multicollinearity were also assessed using QQ plots and variance inflation factors (VIF). All QQ plots showed acceptable levels of homoscedasticity except for the emotional reactions which appeared somewhat abnormal, suggesting some heteroscedasticity. VIF values were computed for both structural equation models. All VIF values for the first SEM were well below 10, suggesting that there were no multicollinearity issues with the variables included in SEM 1 (i.e., SDO, RWA, Nationalism, realistic threats, symbolic threats, terroristic threats, Islamophobia, and support for anti-Muslim policies). Most VIF values for the second SEM were below 10, with about 63 values indicating potential multicollinearity issues between the variables in SEM 2 (i.e., realistic threats, symbolic threats, terroristic threats, anger, distrust, and fear, and support for surveillance-specific anti-Muslim policy). Given the addition of the emotional reaction variables in SEM 2, it may be that the emotional reactions measured overlap conceptually to an extent, and thus, the values were retained for analyses with this consideration in mind.

\section{Descriptive Statistics}

Means, standard deviations, and correlations for the variables of interest in the first SEM, the cluster analysis, and the second SEM can be found in Tables 1, 2, and 3, respectively. As expected, SDO, RWA, Nationalism, and all perceptions of threat (i.e., realistic, symbolic, and terroristic) were moderately, positively correlated with one another with correlation coefficients ranging between .46 and .85 (see Table 1). Differences in the magnitude of correlations between SDO, RWA, and Nationalism and each type of threat perception were relatively small, suggesting that all of these variables 
are moderately correlated with one another. Each of these variables was also moderately, positively related to Islamophobia and both policy measures (see Tables 1 and 3). Finally, emotional reactions toward Muslims were all positively correlated. Fear, anger, distrust, disgust, and anxiety were all strongly correlated with correlation coefficients ranging between .70 and .85 . Pity, envy, and guilt showed moderate correlations with one another (correlation coefficients between .42 and .58) and small to moderate correlations with fear, anger, distrust, disgust, and anxiety (correlation coefficients between .10 and .35; see Table 2).

\section{Table 1}

Means, Standard Deviations, and Correlations for Aim 1 Structural Equation Model

\begin{tabular}{|c|c|c|c|c|c|c|c|c|c|c|}
\hline & 1 & 2 & 3 & 4 & 5 & 6 & 7 & 8 & $M$ & $S D$ \\
\hline 1. SDO & - & & & & & & & & 2.16 & 1.13 \\
\hline 2. RWA & $.61 * * *$ & - & & & & & & & 2.78 & 1.32 \\
\hline 3. Nationalism & $.55 * * *$ & $.77 * * *$ & - & & & & & & 2.84 & 1.37 \\
\hline 4. Realistic & $.63 * * *$ & $.67 * * *$ & $.65 * * *$ & - & & & & & 1.96 & 1.39 \\
\hline 5. Symbolic & $.57 * * *$ & $.67 * * *$ & $.62 * * *$ & $.85 * * *$ & - & & & & 2.15 & 1.67 \\
\hline 6. Terroristic & $.45 * * *$ & $.51 * * *$ & $.54 * * *$ & $.69 * * *$ & $.77 * * *$ & - & & & 2.91 & 1.77 \\
\hline 7. Islamophobia & $.58 * * *$ & $.63 * * *$ & $.61 * * *$ & $.85 * * *$ & $.89 * * *$ & $.74 * * *$ & - & & 2.14 & 1.56 \\
\hline 8. Policy Support & $.58 * * *$ & $.67 * * *$ & $.65 * * *$ & $.81 * * *$ & $.80 * * *$ & $.64 * * *$ & $.88 * * *$ & - & 1.97 & 1.55 \\
\hline
\end{tabular}

\section{Table 2}

Means, Standard Deviations, and Correlations Aim 2 Cluster Analyses

\begin{tabular}{|c|c|c|c|c|c|c|c|c|c|c|}
\hline & 1 & 2 & 3 & 4 & 5 & 6 & 7 & 8 & $M$ & $S D$ \\
\hline 1. Fear & - & & & & & & & & 1.8 & 1.14 \\
\hline 2. Anger & $.82 * * *$ & - & & & & & & & 1.64 & 1.08 \\
\hline 3. Distrust & $.83 * * *$ & $.79 * * *$ & - & & & & & & 1.91 & 1.22 \\
\hline 4. Disgust & $.74 * * *$ & $.85 * * *$ & $.76 * * *$ & - & & & & & 1.58 & 1.05 \\
\hline 5. Anxiety & $.85 * * *$ & $.75 * * *$ & $.79 * * *$ & $.70 * * *$ & - & & & & 1.71 & 1.07 \\
\hline 6. Pity & $.27 * * *$ & $.29 * * *$ & $.26^{* * * *}$ & $.28 * * *$ & $.32 * * *$ & - & & & 1.64 & 1.05 \\
\hline 7. Guilt & $.19 * * *$ & $.19 * * *$ & $.10^{*}$ & $.15^{* *}$ & $.23 * * *$ & $.47 * * *$ & - & & 1.45 & 0.91 \\
\hline 8. Envy & $.31 * * *$ & $.32 * * *$ & $.25 * * *$ & $.33 * * *$ & $.35 * * *$ & $.42 * * *$ & $.58 * * *$ & & 1.18 & 0.58 \\
\hline
\end{tabular}

$* p<.05, * * p<.01, * * * p<.001$ 
Table 3

Means, Standard Deviations, and Correlations Aim 3 Structural Equation Model

\begin{tabular}{lccccccccc} 
& $\mathbf{1}$ & $\mathbf{2}$ & $\mathbf{3}$ & $\mathbf{4}$ & $\mathbf{5}$ & $\mathbf{6}$ & $\mathbf{7}$ & $\boldsymbol{M}$ & $\boldsymbol{S D}$ \\
\hline 1. Realistic & - & & & & & & 1.96 & 1.39 \\
2. Symbolic & $.85^{* * *}$ & - & & & & & 2.15 & 1.67 \\
3. Terroristic & $.69^{* * *}$ & $.77^{* * *}$ & - & & & & 2.91 & 1.77 \\
4. Anger & $.60^{* * *}$ & $.63^{* * *}$ & $.52^{* * *}$ & - & & & 1.64 & 1.08 \\
5. Distrust & $.58^{* * *}$ & $.65^{* * *}$ & $.58^{* * *}$ & $.79^{* * *}$ & - & & 1.91 & 1.22 \\
6. Fear & $.58^{* * *}$ & $.62^{* * *}$ & $.57^{* * *}$ & $.82^{* * *}$ & $.83^{* * *}$ & - & 1.8 & 1.14 \\
7. Surveillance & & & & & & & & \\
Policy Support & $.71^{* * *}$ & $.68^{* * *}$ & $.53^{* * *}$ & $.42^{* * *}$ & $.42^{* * *}$ & $.42^{* * *}$ & - & 2.02 & 1.28 \\
\hline$* p<.05, * * p<.01, * * *$ & $<<.001$ & & & & & &
\end{tabular}

\section{Hypothesis Testing}

\section{Aim 1: Hypotheses 1a-1d}

Aim 1 of the current study investigated the roles of SDO, RWA, and Nationalism in predicting realistic, symbolic, and terroristic threat perceptions, Islamophobia, and anti-Muslim policy support. Structural equation modeling was used to simultaneously test hypotheses 1a-d in a single model using maximum likelihood estimation in the lavaan package in R (Rosseel, 2012). All indirect effects were tested using 500 bootstrapped standard errors based on simulations used to determine how many bootstrapped standard errors were needed to stabilize the standard errors for each path. Specifically, this model tested the hypotheses that a) SDO predicts Islamophobia through perceived realistic threats about Muslims, b) RWA predicts Islamophobia through perceived symbolic threats about Muslims, c) Nationalism predicts Islamophobia through perceived terroristic threats about Muslims, and d) Islamophobia mediates the relationships between threat perceptions (i.e., realistic, symbolic, terroristic) and support for policies that discriminate against Muslims (e.g., support for a Muslim ban) while controlling for 
participant political orientation and gender ${ }^{2}$. Given the validated nature of the scales used in this study, this model utilized observed variables rather than taking a latent approach to modeling which incorporates the measurement model. Although the chi-square value was significant, $\chi^{2}(9)=61.59, p<.01$, suggesting poor fit to the data, alternative fit indices were also examined to determine whether the fit was adequate. Overall, the structural equation model showed good fit to the data $(\mathrm{CFI}=.98, \mathrm{SRMR}=.02)$ based on standards suggested by Hu and Bentler (1999) for a good fitting model of at least .95 for the CFI fit index and at most .08 for the SMSR fit index. A post hoc power analysis using the semPower package in R (Moshagen \& Erdfelder, 2016) ${ }^{3}$ indicated that a power level of .99 was achieved for this model.

In terms of hypothesis testing, several specific hypotheses for aim 1 were confirmed while others were not (see Figure 11). In partial support of hypothesis 1a, results indicated that SDO directly predicted realistic threat perceptions, $b=.40, S E=$ $.06, \beta=.33, p<.001$ but not Islamophobia, $b=.10, S E=.05, \beta=.07, n s$, when accounting for the multiple mediators included in the model (i.e., realistic, symbolic, and

\footnotetext{
${ }^{2}$ Both the SEM for aim 1 (hypotheses 1a-1d) and aim 3 (hypotheses 3a-3c) were also tested with participant sub-sample (i.e., PSU or MTurk) included as a covariate to ensure the sampling method did not impact the results. The inclusion of this covariate did not change the direction of effects or interpretation of findings. The only change in path significance was for the indirect path between RWA and Islamophobia through perceived terroristic threat in the aim 1 SEM which still trended in the same direction but became marginally significant in the model including this additional covariate.

${ }^{3}$ Due to complications in utilizing the same SEM power calculator used for a priori power analyses for post hoc power analyses, a newer and more recently updated tool was identified. This package has undergone more vetting by the Comprehensive R Archive Network and may be more reliable than the tool used for a priori analyses. To compare the tools, mock "a priori" power analyses for both SEMs were conducted based on the parameters used in the original a priori power analyses. Results suggested that while an adequate sample was collected to detect an effect for SEM 1, the sample size may be too small for SEM 2, resulting in an underpowered model. It should be noted that this power is specific to model fit coefficients, however, and not path coefficients.
} 
terroristic threat perceptions). Further, the indirect effect of SDO on Islamophobia through realistic threat perceptions was significant, $b=.11, S E=.03, \beta=.08, p<.01$, $95 \%$ CI $[0.05,0.17]$, suggesting that as levels of SDO increased, perceived realistic threat of Muslims increased, which in turn, predicted higher levels of Islamophobia. The indirect effect between SDO and Islamophobia through realistic threat perceptions was slightly smaller than the indirect effects between SDO and Islamophobia through symbolic, $b=.16, S E=.04, \beta=.12, p<.001,95 \% \mathrm{CI}[0.07,0.24]$, and larger than the indirect effects between SDO and Islamophobia through terroristic threat perceptions, $b=$ $.02, S E=.01, \beta=.02, p<.05,95 \%$ CI $[0.00,0.04]$. 


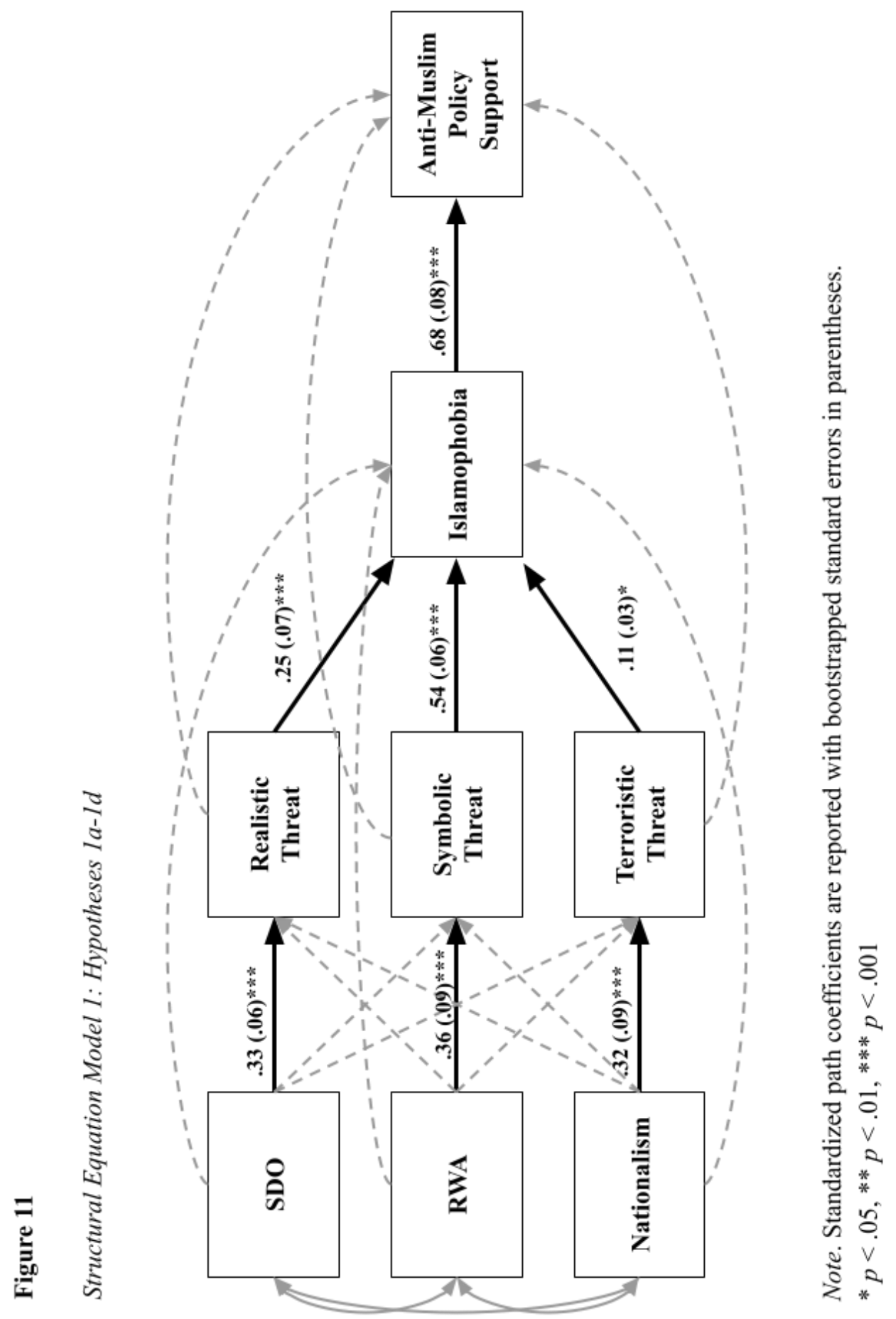


In support of hypothesis $1 \mathrm{~b}$, RWA predicted symbolic threat perceptions, $b=.46$, $S E=.09, \beta=.36, p<.001$, but not Islamophobia, $b=-.05, S E=.05, \beta=-.04, n s$. The indirect effect of RWA on Islamophobia through symbolic threat perceptions, however, was significant, $b=.23, S E=.05, \beta=.20, p<.001,95 \% \mathrm{CI}[0.13,0.33]$, suggesting that as levels of RWA increased, perceived symbolic threat of Muslims increased, which in turn, predicted higher levels of Islamophobia. The indirect effect between RWA and Islamophobia through symbolic threat perceptions was stronger than the indirect effects between RWA and Islamophobia through realistic, $b=.07, S E=.02, \beta=.06, p<.01$, $95 \% \mathrm{CI}[0.02,0.12]$, or terroristic threat perceptions, $b=.02, S E=.01, \beta=.02, p<.05$, $95 \%$ CI $[0.00,0.05]$.

In partial support of hypothesis 1c, Nationalism predicted terroristic threat perceptions, $b=.41, S E=.09, \beta=.32, p<.001$, but not Islamophobia, $b=.04, S E=.04$, $\beta=.03, n s$. The indirect effect of Nationalism on Islamophobia through terroristic threat perceptions, however, was significant, $b=.04, S E=.02, \beta=.04, p<.05,95 \%$ CI [0.01, 0.07], suggesting that as levels of Nationalism increased, perceived terroristic threat of Muslims increased, which in turn, predicted higher levels of Islamophobia. The indirect effect between Nationalism and Islamophobia through terroristic threat perceptions was smaller than the indirect effects between Nationalism and Islamophobia through realistic, $b=.08, S E=.03, \beta=.07, p<.01,95 \%$ CI $[0.02,0.15]$, and symbolic threat perceptions, $b=.15, S E=.04, \beta=.13, p<.001,95 \%$ CI $[0.07,0.21]$.

In support of hypothesis $1 \mathrm{~d}$, Islamophobia was predicted by realistic, $b=.28, S E$ $=.07, \beta=.25, p<.001$, symbolic, $b=.50, S E=.06, \beta=.54, p<.001$, and terroristic 
threat perceptions, $b=.10, S E=.03, \beta=.11, p<.01$, and anti-Muslim policy support was predicted by Islamophobia, $b=.68, S E=.08, \beta=.68, p<.001$. Further, Islamophobia significantly mediated the relationships between realistic, $b=.19, S E=.05$, $\beta=.17, p<.001,95 \%$ CI $[0.10,0.28]$, symbolic, $b=.34, S E=.05, \beta=.37, p<.001$, $95 \% \mathrm{CI}[0.24,0.45]$, and terroristic threat perceptions, $b=.07, S E=.03, \beta=.08, p<.01$, $95 \%$ CI $[0.02,0.12]$, and anti-Muslim policy support, suggesting that as each type of perceived threat increased, feelings of Islamophobia increased, which then lead to increased support for anti-Muslim policies.

Together, these findings largely supported hypothesis 1 that SDO, RWA, and Nationalism each predict Islamophobia through several types of perceived threat (i.e., realistic, symbolic, and terroristic) which subsequently predicts support for anti-Muslim policies (e.g., Muslim ban). One deviation from the expected findings was that the indirect effects of each type of perceived threat did not vary substantially in size from each predictor (e.g., SDO, RWA) to Islamophobia. For example, the indirect effect of realistic threat perceptions on the relationship between SDO and Islamophobia was slightly weaker than that of symbolic threat perceptions but slightly stronger than that of terroristic threat perceptions. This indirect effect may be driven by the stronger effect of symbolic threats on Islamophobia given that each ideological difference variable directly predicted the expected type of threat perception better than the other ideological difference variables (i.e., SDO best predicted realistic threats, RWA best predicted symbolic threats, Nationalism best predicted terroristic threats). These differences were small, however, and would likely not hold much practical significance even if the 
differences were statistically significantly different. Rather, the pattern of findings that each of these types of threat perceptions acted as mediators between each of the individual difference characteristic (i.e., SDO, RWA, and Nationalism) while accounting for the effects of one another suggests that these ideological constructs are likely to independently facilitate perceived threats to one's resources, values, and safety (see Table 4 for all direct and indirect effects). Further, the finding that Islamophobia simultaneously mediated the relationships between realistic, symbolic, and terroristic threat perceptions and anti-Muslim policy support suggested that perceived threats influenced both general intergroup attitudes (i.e., Islamophobia) and more specific behavioral intentions that would negatively impact specific groups (i.e., anti-Muslim policy support). Overall, the full model accounted for about $80 \%$ of the variance in anti-Muslim policy support $\left(r^{2}=\right.$ .80 ; see Figure 12 for all significant direct effects). 


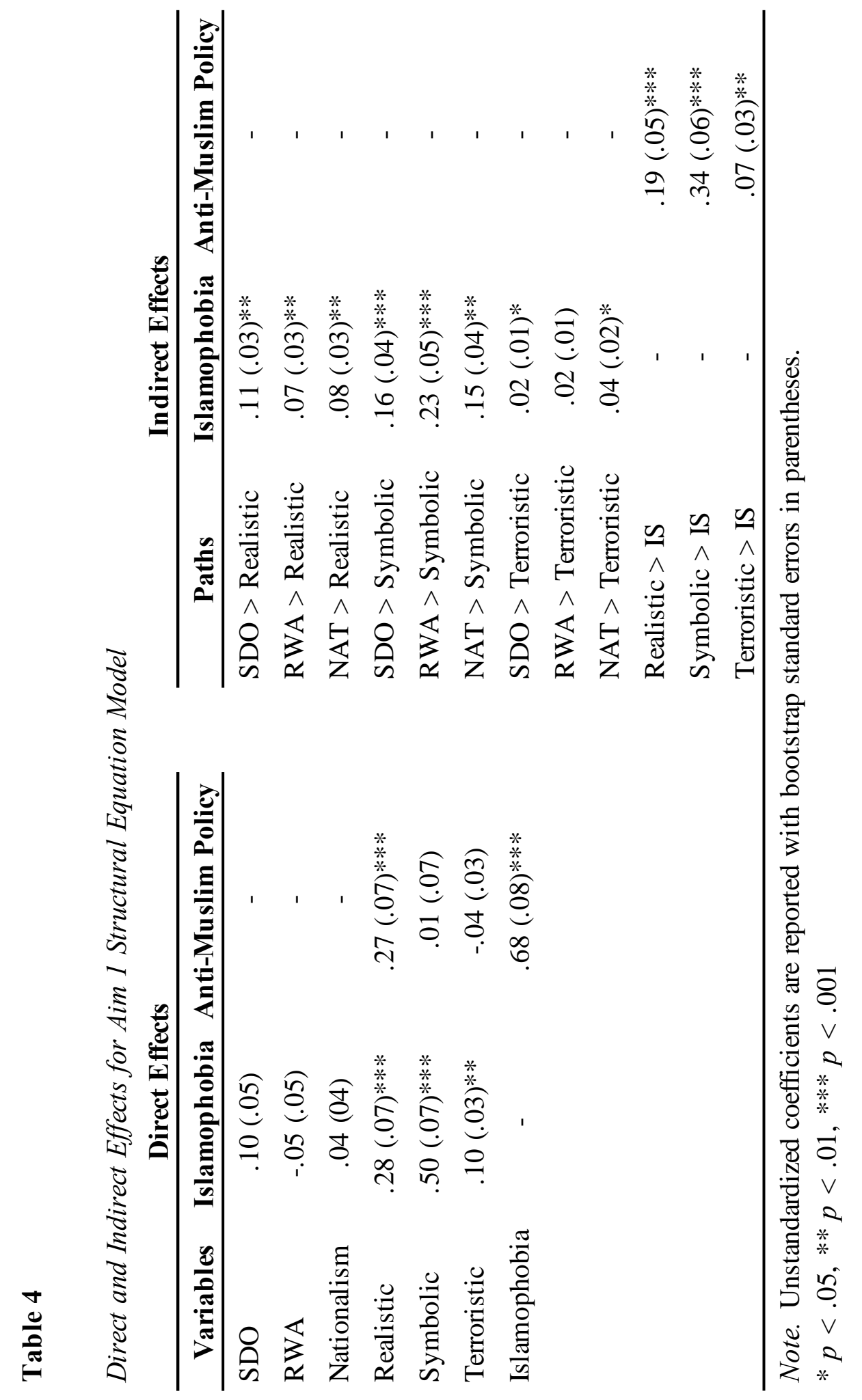




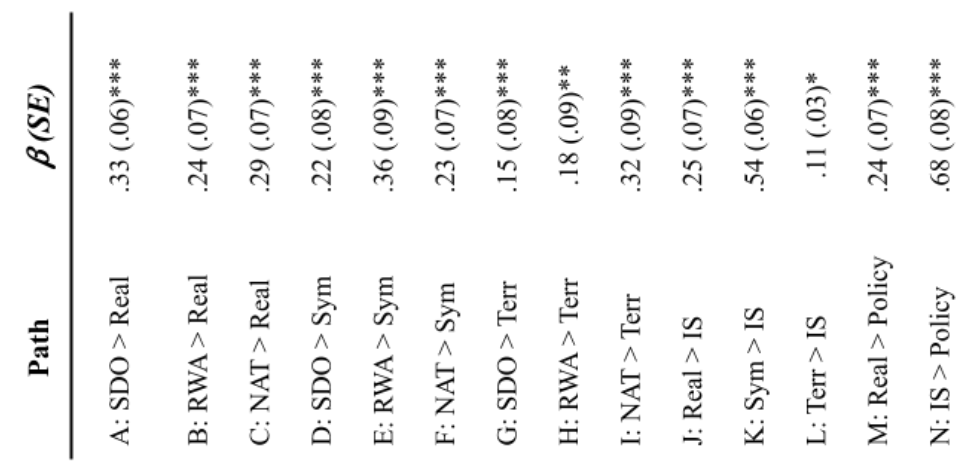

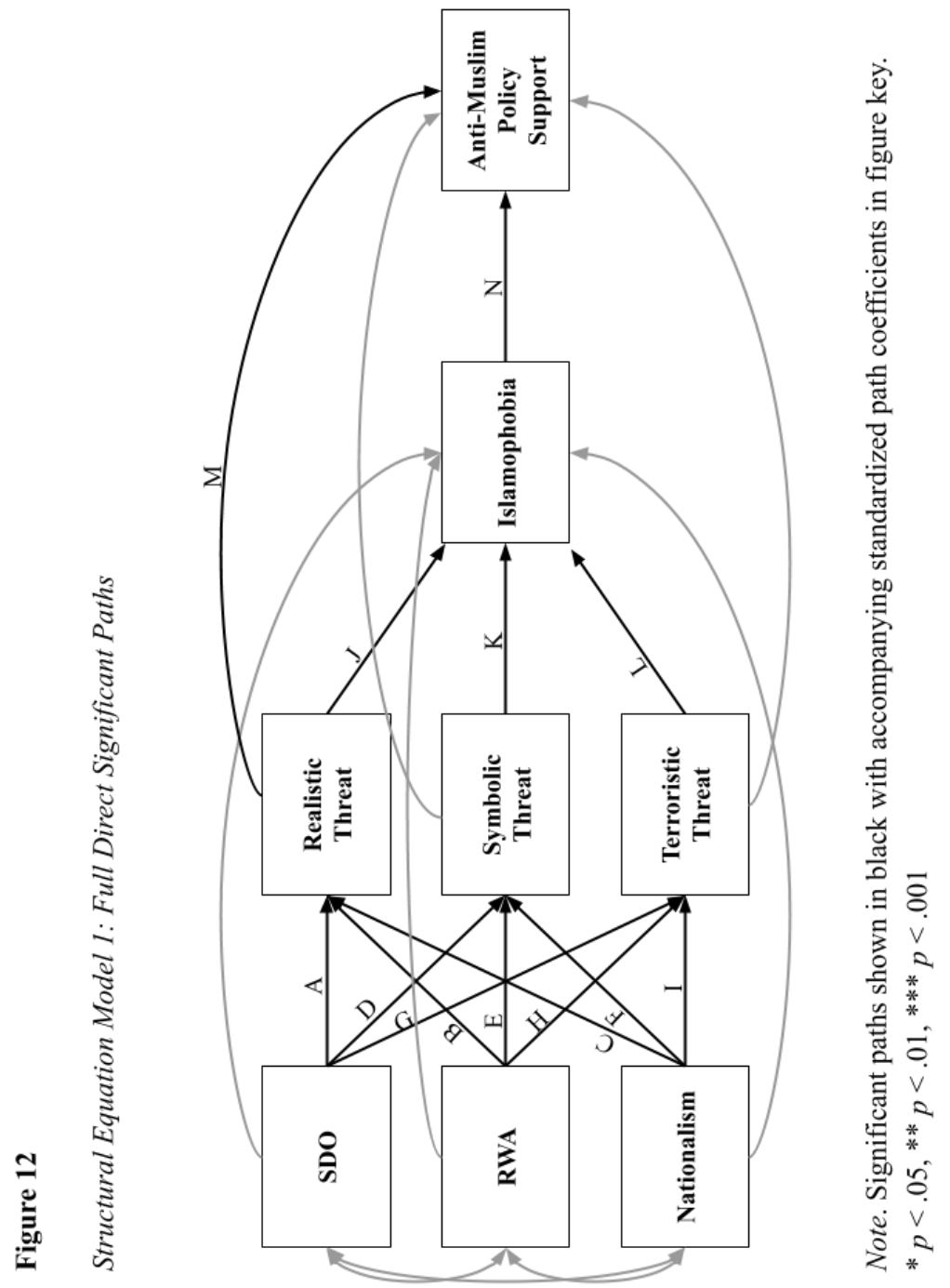




\section{Aim 2: Exploratory Hypothesis and Hypotheses 2a-2c}

The second aim of this study attempted to determine the emotional components of distinct types of threat perceptions. Aim 2 consisted of both a data-driven exploratory hypothesis and a theory-based hypothesis in the event that the results of the exploratory hypothesis were unclear. Several clustering approaches were used in order to determine which emotions clustered with which threat perceptions. First, $k$-means cluster analysis was used to determine how emotions cluster with the number of clusters set to 3 to map onto the 3 threat perception measures used. Given that this is an iterative process that is initially randomly configured, the $k$-means clustering approach was run approximately 25 times (James et al., 2013). Hierarchical cluster analysis was then used to get a more robust picture of the emotion clusters using an average link dissimilarity based on Euclidean distance (James et al., 2013). Visualization of the dendrogram presenting all of the possible clusters suggested that a 2 -cluster solution was more ideal than the 3 -cluster solution that was expected to emerge. Overall, the findings of the cluster analyses were inconclusive with a large majority of participants clustering into the first cluster. Rather than revealing clusters containing different discrete emotions, as was expected, the resulting clusters appeared to represent the magnitude of endorsement of all emotional reactions (i.e., low, medium, and high emotion endorsers), leaving it unclear how to aggregate different emotions into broader categories as was intended. This helps explain why most participants fell within the first cluster as the emotion variables were skewed with most people reporting low endorsement of all emotional reactions toward Muslims. Given that the interest in emotions involves the impact of categorically discrete types of 
emotion (e.g., anger as opposed to distrust), rather than the overall magnitude of emotion endorsement, several theoretically relevant emotional reaction items were used as observed variables in the regression models and SEM 2 (i.e., anger, distrust, and fear).

Based on the inconclusive results of the cluster analyses, the contingency plan described previously was employed and hypotheses $2 a-2 c$ were tested to determine if different types of threat perceptions better predicted emotions that should theoretically be more or less related to different threats (Cottrell \& Neuberg, 2005; Gervais et al., 2011; Lerner et al., 2003). A series of regression analyses were run and compared for fit with the expectation that 1) realistic threat perceptions would best predict feelings of anger compared to symbolic and terroristic threat perceptions, 2) symbolic threat perceptions would best predict feelings of distrust compared to realistic and terroristic threat perceptions, and 3) terroristic threat perceptions would best predict fear compared to realistic and symbolic threat perceptions. Three non-nested models for each emotion (i.e., anger, distrust, and fear) were compared for fit using the Bayesian Information Criterion (BIC) to determine which type of perceived threat best predicted each emotion. Models with lower BIC values are considered better fitting models. In general, differences that are less than 2 are not considered practically meaningful, differences between 2 and 6 provide some evidence of a superior model, differences between 6 and 10 provide strong evidence of a superior model, and differences larger than 10 provide very strong evidence of a better fitting model (Fabozzi et al., 2014).

In partial support of hypothesis $2 \mathrm{a}$, anger was predicted by realistic, $b=.42, S E=$ $.03, \beta=.59, p<.001,95 \%$ CI [0.37, 0.48], BIC $=1079.94$, symbolic, $b=.37, S E=.02, \beta$ 
$=.63, p<.001,95 \% \mathrm{CI}[0.33,0.42], B I C=1046.81$, and terroristic threat perceptions, $b=$ $.31, S E=.03, \beta=.52, p<.001,95 \%$ CI $[0.26,0.36], B I C=1120.15$ (see Table 5). In contradiction to predictions, standardized coefficients suggested that anger was more strongly predicted by realistic than terroristic threat perceptions but was more strongly predicted by symbolic than realistic threat perceptions. Comparison of BIC values suggested that symbolic threats predicting anger resulted in the best fitting model, followed by realistic and terroristic threat perceptions, respectively. All BIC difference values between the three models were greater than 10 , providing strong evidence that symbolic threat perceptions were a better predictor of anger toward Muslims than realistic or terroristic threat perceptions.

\section{Table 5}

Regression Analyses for Hypothesis 2a: Threat Perceptions Predicting Angt

\begin{tabular}{rlcccccc}
\hline Model & \multicolumn{1}{c}{ Variable } & $\boldsymbol{b}$ & $\boldsymbol{S E}$ & $\mathbf{9 5 \%} \mathbf{C I}$ & $\boldsymbol{\beta}$ & $\boldsymbol{t}$ & BIC \\
\hline Realistic & (Intercept) & $0.71^{* * *}$ & 0.08 & & & 9.47 & \\
& Realistic Threats & $0.42^{* * *}$ & 0.03 & {$[0.37,0.48]$} & 0.59 & 15.03 & 1079.94 \\
& & & & & & \\
Symbolic & (Intercept) & $0.73^{* * *}$ & 0.07 & & & 10.43 & \\
& Symbolic Threats & $0.37^{* * *}$ & 0.02 & {$[0.33,0.42]$} & 0.63 & 16.41 & 1046.81 \\
& & & & & & \\
Terroristic & (Intercept) & $0.62^{* * *}$ & 0.09 & & & 6.66 & \\
& Terroristic Threats & $0.31^{* * *}$ & 0.03 & {$[0.26,0.36]$} & 0.52 & 12.34 & 1120.15 \\
\hline
\end{tabular}

Note. Each model run independently and compared for fit using standardized coefficients and BIC.

$* \mathrm{p}<.05, * * \mathrm{p}<.01, * * * \mathrm{p}<.001$

In support of hypothesis $2 \mathrm{~b}$, distrust was also predicted by realistic, $b=.47, S E=$ $.03, \beta=.57, p<.001,95 \%$ CI $[0.40,0.53], B I C=1247.88$, symbolic, $b=.44, S E=.02, \beta$ $=.65, p<.001,95 \% \mathrm{CI}[0.39,0.49], B I C=1175.44$, and terroristic threat perceptions, $b=$ 
$.39, S E=.03, \beta=.58, p<.001,95 \%$ CI $[0.34,0.44], B I C=1237.69$ (see Table 6). As

predicted, standardized coefficients suggested that distrust was more strongly predicted by symbolic than realistic or terroristic threat perceptions. Further, the BIC value indicated that this was the best fitting regression model. Comparison of BIC values suggested that symbolic threats predicting distrust resulted in the best fitting model, followed by terroristic and realistic threat perceptions, respectively. All BIC difference values between the three models were greater than 10, providing strong evidence that symbolic threat perceptions were a better predictor of distrust toward Muslims than realistic or terroristic threat perceptions.

\section{Table 6}

Regression Analyses for Hypothesis 2b: Threat Perceptions Predicting Dist

\begin{tabular}{rlcccccc}
\hline Model & \multicolumn{1}{c}{ Variable } & $\boldsymbol{b}$ & $\boldsymbol{S E}$ & $\mathbf{9 5 \%}$ CI & $\beta$ & $\boldsymbol{t}$ & BIC \\
\hline Realistic & (Intercept) & $0.91^{* * *}$ & 0.08 & & & 10.8 & \\
& Realistic Threats & $0.47^{* * *}$ & 0.03 & {$[0.40,0.53]$} & 0.57 & 14.59 & 1247.88 \\
& & & & & & \\
Symbolic & (Intercept) & $0.86^{* * *}$ & 0.07 & & & 11.5 & \\
& Symbolic Threats & $0.44^{* * *}$ & 0.02 & {$[0.39,0.49]$} & 0.65 & 17.79 & 1175.44 \\
& & & & & & & \\
Terroristic & (Intercept) & $0.65^{* * *}$ & 0.1 & & & 6.61 & \\
& Terroristic Threats & $0.39^{* * *}$ & 0.03 & {$[0.34,0.44]$} & 0.58 & 14.69 & 1237.69 \\
\hline
\end{tabular}

Note. Each model run independently and compared for fit using standardized coefficients and BIC.

$* \mathrm{p}<.05, * * \mathrm{p}<.01, * * * \mathrm{p}<.001$

In partial support of hypothesis $2 \mathrm{c}$, fear was predicted by realistic, $b=.44, S E=$ $.03, \beta=.58, p<.001,95 \%$ CI $[0.38,0.50], B I C=1173.79$, symbolic, $b=.39, S E=.02, \beta$ $=.61, p<.001,95 \% \mathrm{CI}[0.34,0.44], B I C=1138.29$, and terroristic threat perceptions, $b=$ $.36, S E=.03, \beta=.57, p<.001,95 \%$ CI $[0.31,0.41], B I C=1168.65$ (see Table 7). Contrary to predictions, standardized coefficients suggested that fear was more strongly 
predicted by symbolic threat perceptions than realistic or terroristic threat perceptions. Comparison of BIC values suggested that symbolic threats predicting fear resulted in the best fitting model, followed by terroristic and realistic threat perceptions, respectively. The BIC difference values between symbolic threat and both realistic and terroristic threat perceptions were larger than 10 , providing strong evidence that symbolic threat perceptions were a better predictor of fear toward Muslims than realistic or terroristic threat perceptions. The BIC difference value between realistic and terroristic threat perceptions, however, was only 5.14, providing some evidence that terroristic threat perceptions were a better predictor of fear than realistic threat perceptions.

Based on the small differences in standardized effect sizes between each type of threat perception in predicting each emotion, these findings suggest that there is likely overlap in the relationships between each type of perceived threat and emotional responses to groups perceived as threatening. Additionally, given that symbolic threat perceptions came out as a better predictor of each emotion than realistic or terroristic threat perceptions, there is some evidence that symbolic threat perceptions may be more likely to elicit several kinds of emotional responses compared to realistic or terroristic threat perceptions. 


\section{Table 7}

Regression Analyses for Hypothesis 2c: Threat Perceptions Predicting Fear

\begin{tabular}{rlcccccc}
\hline Model & \multicolumn{1}{c}{ Variable } & $\boldsymbol{b}$ & $\boldsymbol{S E}$ & $\mathbf{9 5 \%} \mathbf{C I}$ & $\beta$ & $\boldsymbol{t}$ & BIC \\
\hline Realistic & (Intercept) & $0.85^{* * *}$ & 0.08 & & & 10.76 & \\
& Realistic Threats & $0.44^{* * *}$ & 0.03 & {$[0.38,0.50]$} & 0.58 & 14.58 & 1173.79 \\
& & & & & & \\
Symbolic & (Intercept) & $0.87^{* * *}$ & 0.07 & & & 11.71 & \\
& Symbolic Threats & $0.39^{* * *}$ & 0.02 & {$[0.34,0.44]$} & 0.61 & 16.02 & 1138.29 \\
& & & & & & & \\
Terroristic & (Intercept) & $0.63^{* * *}$ & 0.09 & & & 6.72 & \\
& Terroristic Threats & $0.36^{* * *}$ & 0.03 & {$[0.31,0.41]$} & 0.57 & 14.34 & 1168.65 \\
\hline
\end{tabular}

Note. Each model run independently and compared for fit using standardized coefficients and BIC.

$* \mathrm{p}<.05, * * \mathrm{p}<.01, * * * \mathrm{p}<.001$

\section{Aim 3: Hypotheses 3a-3c}

As with aim 1, structural equation modeling was used to simultaneously test hypotheses 3a-c in a single model using maximum likelihood estimation in the lavaan package in R (Rosseel, 2012). All indirect effects were tested using 500 bootstrapped standard errors. Specifically, this model tested the hypotheses that a) realistic threat perceptions would predict support for anti-Muslim policies through anger, b) symbolic threat perception would predict support for anti-Muslim policies through distrust, and c) terroristic threat perceptions would predict support for anti-Muslim policies through fear while controlling for participant political orientation and gender. This model utilized observed variables rather than taking a latent approach to modeling which incorporates the measurement model. Although the chi-square value was significant, $\chi^{2}(6)=15.92, p$ $<.05$, suggesting poor fit to the data, alternative fit indices were also examined to determine whether the fit was adequate. Overall, the structural equation model showed good fit to the data $(\mathrm{CFI}=.99, \mathrm{SRMR}=.02)$ based on standards suggested by $\mathrm{Hu}$ and 
Bentler (1999) for a good fitting model of at least .95 for the CFI fit index and at most .08 for the SMSR fit index. A post hoc power analysis using the semPower package in $\mathrm{R}$ (Moshagen \& Erdfelder, 2016) indicated that a power level of .64 was achieved for this model.

In terms of hypothesis testing, several specific hypotheses for aim 3 were confirmed while others were not (See Figure 13). In partial support of hypothesis 3a, results indicated that realistic threat perceptions predicted both anger, $b=.14, S E=.06, \beta$ $=.18, p<.05$, and Muslim surveillance policy support, $b=.39, S E=.07, \beta=.41, p<$ .001. The indirect effect of realistic threat perceptions on Muslim surveillance policy support through anger, however, was not significant, $b=-.01, S E=.01, \beta=-.01, n s, 95 \%$ CI [-0.03, 0.02], suggesting that while increased perceptions of realistic threats by Muslims predicted both anger and support for a Muslim surveillance policy, the relationship between realistic threat perceptions and policy support was not explained by feelings of anger toward Muslims. The indirect effects between realistic threat perceptions and Muslim surveillance policy support through distrust, $b=-.002, S E=.01$, $\beta=-.003, n s, 95 \%$ CI $[-0.02,0.01]$, and fear, $b=.01, S E=.01, \beta=.01, n s, 95 \%$ CI [0.02, 0.04], were also not significant. 


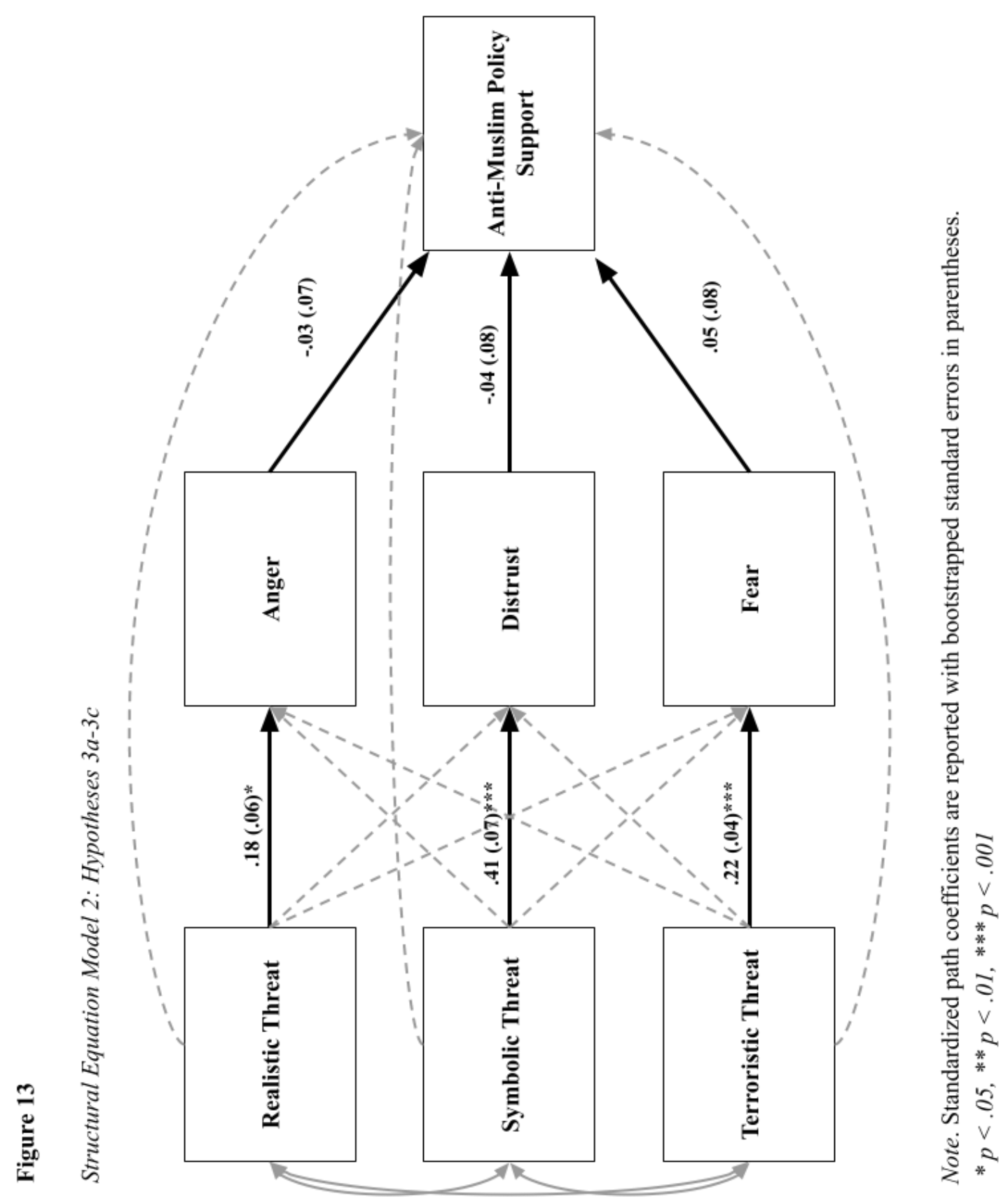


In partial support of hypothesis $3 \mathrm{~b}$, results indicated that symbolic threat perceptions predicted both distrust, $b=.29, S E=.07, \beta=.41, p<.001$, and Muslim surveillance policy support, $b=.18, S E=.07, \beta=.23, p<.05$. The indirect effect of symbolic threat perceptions on Muslim surveillance policy support through distrust, however, was not significant, $b=-.01, S E=.02, \beta=-.01, n s, 95 \%$ CI [-0.06, 0.04], suggesting that while increased perceptions of symbolic threats by Muslims predicted both distrust and support for a Muslim surveillance policy, the relationship between symbolic threat perceptions and policy support was not explained by feelings of distrust toward Muslims. The indirect effects between symbolic threat perceptions and Muslim surveillance policy support through anger, $b=-.01, S E=.02, \beta=-.01, n s, 95 \%$ CI [-0.04, 0.03], and fear, $b=.01, S E=.02, \beta=.01, n s, 95 \%$ CI [-0.02, 0.04], were also not significant.

In partial support of hypothesis $3 \mathrm{c}$, results indicated that terroristic threat perceptions predicted fear, $b=.14, S E=.04, \beta=.22, p<.001$, but not Muslim surveillance policy support, $b=-.01, S E=.03, \beta=-.01, n s$. Further, the indirect effect of terroristic threat perceptions on Muslim surveillance policy support through fear was not significant, $b=.01, S E=.01, \beta=.01, n s, 95 \%$ CI [-0.02, 0.03], suggesting that while increased perceptions of terroristic threats by Muslims predicted fear, they did not predict support for a Muslim surveillance policy either directly or through feelings of fear. The indirect effects between terroristic threat perceptions and Muslim surveillance policy support through anger, $b=-.001, S E=.004, \beta=-.002, n s, 95 \%$ CI [-0.01, 0.01], and distrust, $b=-.01, S E=.01, \beta=-.01, n s, 95 \% \mathrm{CI}[-0.03,0.02]$, were also not significant. 
Together, these findings leave hypothesis 3 largely unsupported. Consistent with the hypothesized relationships, realistic, symbolic, and terroristic threat perceptions all directly predicted anger, distrust, and fear. Realistic and symbolic threat perceptions also directly predicted Muslim surveillance policy support, but terroristic threat perceptions did not. Further, emotional reactions toward Muslims did not mediate the relationships between any type of perceived threat and Muslim surveillance policy support, which was inconsistent with the hypotheses (see Table 8 for all direct and indirect effects). Overall, the full model accounted for about $56 \%$ of the variance in Muslim surveillance policy support $\left(r^{2}=.56\right.$; see Figure 14 for all significant direct effects; see Table 9 for a summary of hypothesis support for all models). 


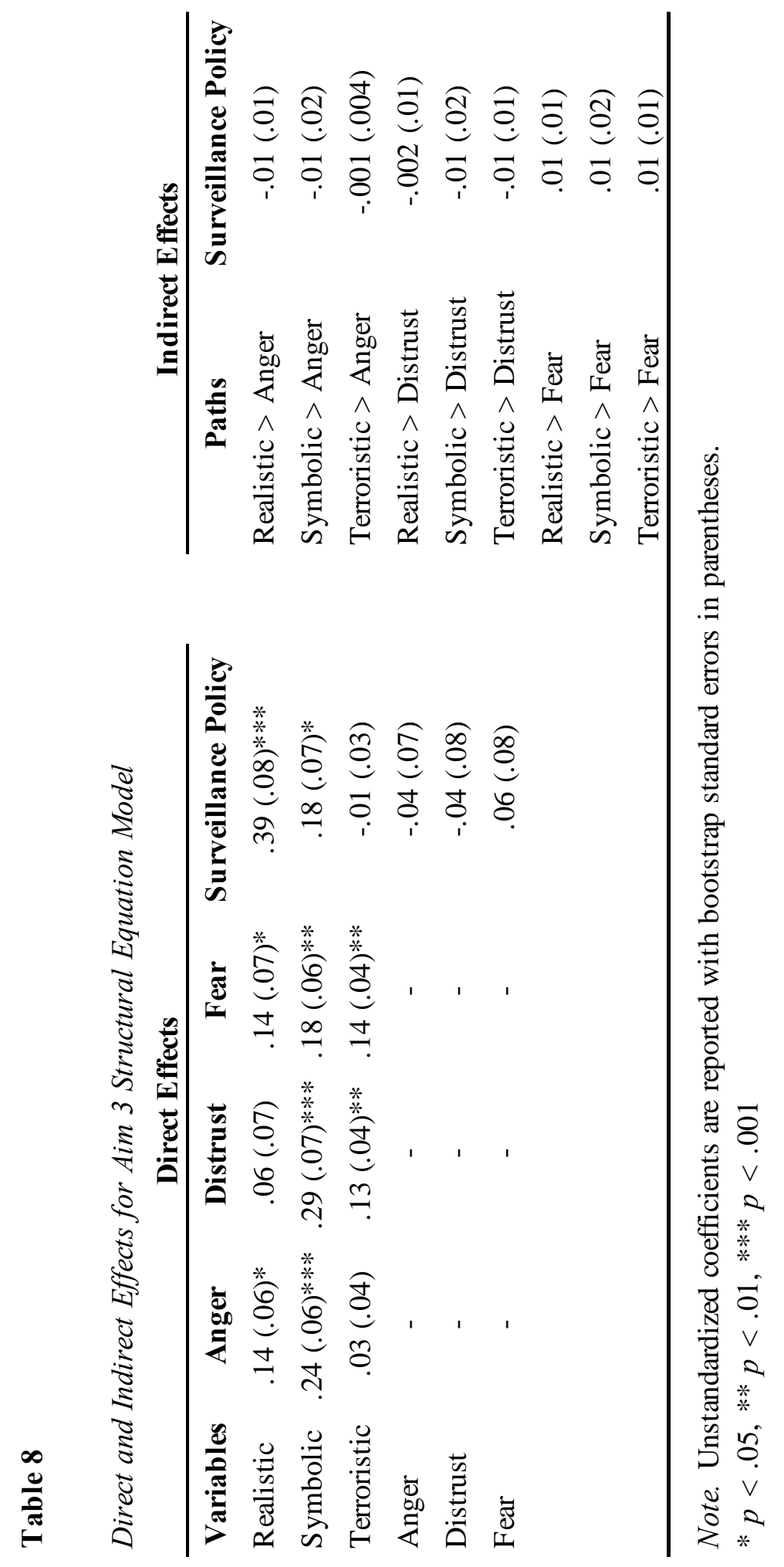




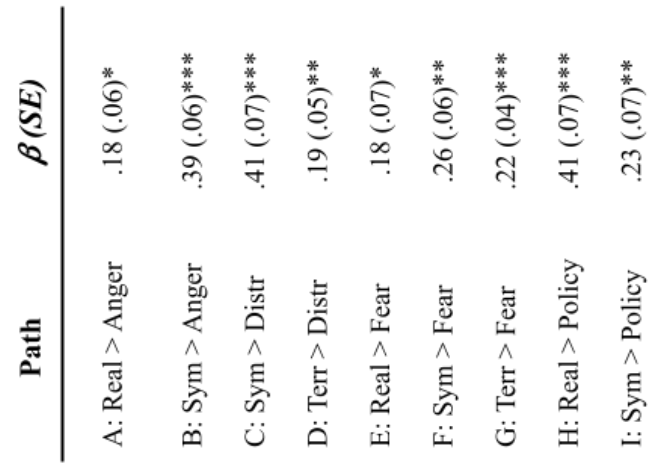

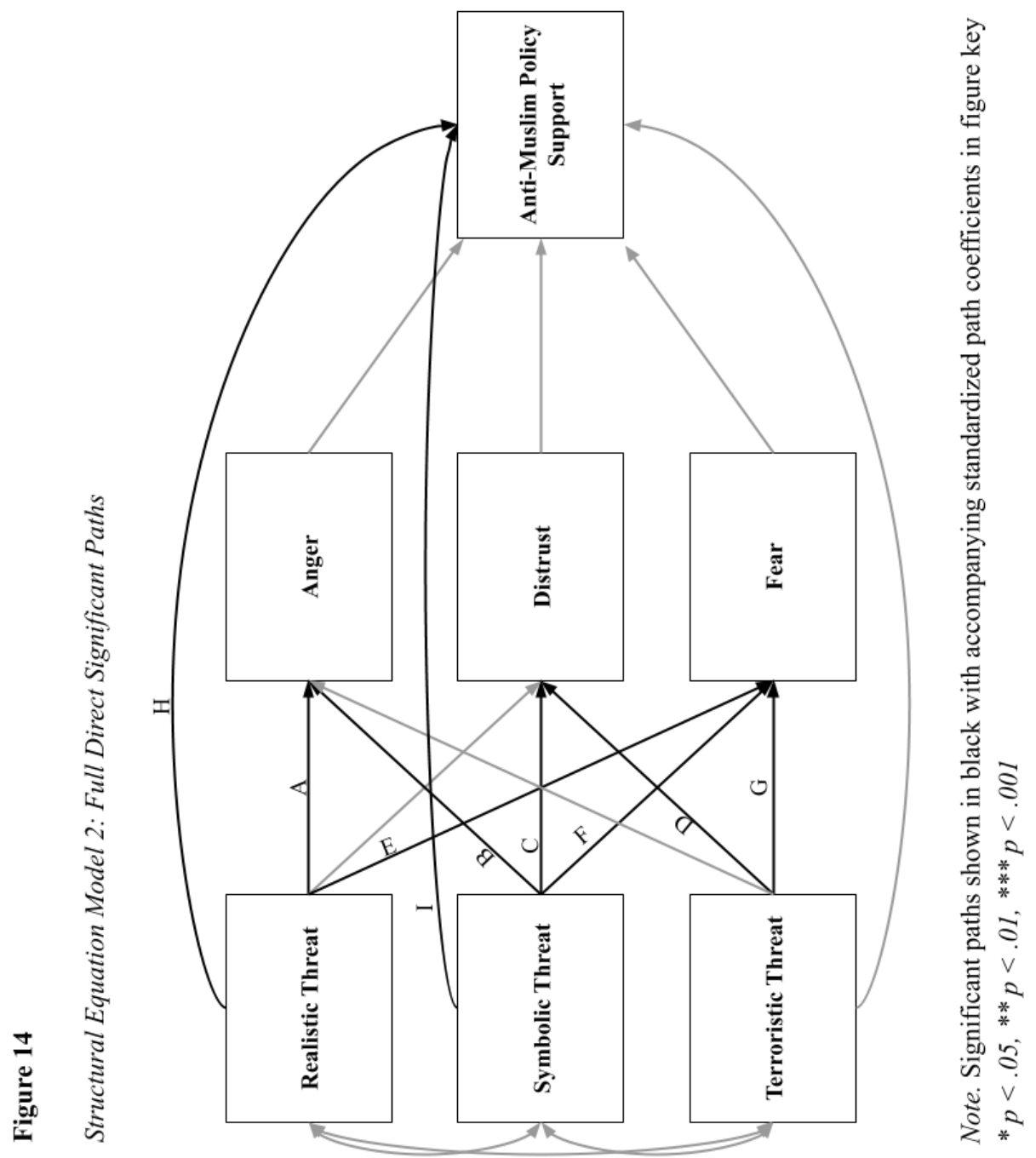


Table 9

Summary of Hypothesis Support

Hypothesis

Conclusion

Partially Supported

1b $($ RWA $>$ Sym > IS $)$

1c $($ NAT $>$ Terr $>$ IS $)$

1d $($ Real/Sym/Terr $>$ IS > Policy $)$

Exploratory Hypothesis (Emotion Clusters)

2a (Real > Anger)

$2 \mathrm{~b}($ Sym $>$ Distrust $)$

2c $($ Terr $>$ Fear $)$

3a (Real > Anger $>$ Policy)

3b $($ Sym $>$ Distrust $>$ Policy $)$

$3 c$ (Terr $>$ Fear $>$ Policy)

Partially Supported

Fully Supported

Partially Supported

Fully Supported

Unsupported

Partially Supported

Fully Supported

Partially Supported

Partially Supported better than realistic or terroristic threat perceptions

Terroristic threat perceptions predicted fear, but symbolic threat perceptions were a better predictor of fear

Realistic threat perceptions predicted anger and anti-Muslim policy support, but symbolic threat perceptions were a better predictor of anger and anger did not mediate the relationships between perceived threats and anti-Muslim policy support

Symbolic threat perceptions predicted distrust more than realistic or terroristic threat perceptions and anti-Muslim policy support, but distrust did not mediate the relationships between perceived threats and anti-Muslim policy support

Terroristic threat perceptions predicted fear, but did not predict anti-Muslim policy support and fear was better predicted by symbolic threat perceptions but did not mediate the relationships between perceived threats and anti-Muslim policy support

Note . Real $=$ Realistic Threat Perceptions, Sym $=$ Symbolic Threat Perceptions, Terr $=$ Terroristic Threat Perceptions, IS = Islamophobia, NAT = Nationalism 


\section{Discussion}

The current study elucidates the roles of several individual differences in ideology and threat perceptions in predicting anti-Muslim attitudes and policy support. Overall, the current study provides partial support for several of the hypotheses and reveals important insights for future research aimed at understanding threat-based emotional reactions. Aim 1 (hypotheses 1a-1d) focused on the role of threat perceptions in driving the relationships between individual differences in ideology and anti-Muslim attitudes and policy, representing an ideology-threat-attitude-behavior model of anti-Muslim bias. The results of the SEM for aim 1 suggest that SDO, RWA, and Nationalism simultaneously predicted Islamophobia through perceived realistic, symbolic, and terroristic threats. These increases in Islamophobic attitudes also helped to explain the relationships between each type of threat perception and anti-Muslim policy support, such as the Muslim ban. Contrary to the expectation that each ideological difference would be most related to conceptually similar types of threat (i.e., SDO/realistic, RWA/symbolic, Nationalism/terroristic), it appeared that symbolic threat perceptions were the strongest predictor and mediator of anti-Muslim attitudes and subsequent policy support. This indirect effect appears to be driven by the particularly strong relationship between symbolic threats and Islamophobia as the pattern of relationships between each ideology and each threat perception was consistent with expectations (i.e., that SDO would best predict realistic threats, RWA would best predict symbolic threats, and Nationalism would best predict terroristic threats). The indirect effects of each type of perceived threat did not vary substantially in size from each predictor to Islamophobia, however, making 
it unclear how practically meaningful these differences are. Despite these unexpected findings, the overall pattern of results revealed that several related, but distinct individual differences in ideology (i.e., SDO, RWA, Nationalism) help to explain increases in participants' anti-Muslim attitudes and policy support and that they do so through several types of perceived threats related to resources, values, and safety.

Aim 2 (exploratory hypothesis and hypotheses $2 \mathrm{a}-2 \mathrm{c}$ ) focused on evaluating the emotional components of each type of threat perception, including the more recent addition of terroristic threat perceptions within the intergroup threat theory framework. Findings from aim 2 provided insights about the emotional components of perceived threats that will be important for future research in this area. Results of the $k$-means and hierarchical cluster analyses were inconclusive which led to the testing of hypotheses 2a$2 \mathrm{c}$ as part of an a priori analysis contingency plan. Instead of utilizing emotion clusters in regression analyses, this contingency plan relied on existing theory which suggests that anger tends to be representative of realistic threats (Cottrell \& Neuberg, 2005), distrust tends to be representative of symbolic threats (Gervais et al., 2011), and fear tends to be representative of terroristic threats (Lerner et al., 2003). Nine separate regression analyses were run with each type of perceived threat predicting each emotion in order to compare model fit and determine which type of threat perception best predicted anger, distrust, and fear. Results indicated that each type of perceived threat predicted anger, distrust, and fear when entered separately into a regression analysis. Symbolic threat perceptions accounted for the most variance in each emotion but the difference in effect sizes between symbolic threat perceptions and the other two types of perceived threats were 
small. BIC comparisons also suggested that symbolic threat perceptions were the best predictor of anger, distrust, and fear compared to realistic and terroristic threat perceptions. Together, these findings suggest that there is likely overlap in which types of perceived threats elicit which emotional responses and possibly that symbolic threat perceptions are more likely to elicit various emotional responses, in general.

Aim 3 (hypotheses 3a-3c) focused on evaluating the mediating roles of distinct emotions in the relationships between each type of perceived threat and support for increased surveillance of Muslims by law enforcement. Findings from aim 3 were largely unsupported. The SEM simultaneously examined whether threat-based emotions mediated the relationships between distinct types of perceived threats and anti-Muslim policy support. Realistic and symbolic threat perceptions directly predicted support for an anti-Muslim policy, but terroristic threat perceptions did not. This is somewhat consistent with findings from aim 1 (hypotheses 1a-1d) that the direct effects between symbolic and terroristic threats and anti-Muslim policy support were not significant when accounting for the indirect effect of Islamophobia in these relationships. Although realistic, symbolic, and terroristic threat perceptions predicted anger, distrust, and fear, these emotional reactions did not mediate the relationships between perceived threats and antiMuslim policy support. Still, this analysis provided additional insights for future research beyond those of aim 2 . Specifically, results showed that symbolic threat perceptions most strongly predicted fear, distrust, and anger while simultaneously accounting for the relationships between symbolic, realistic, and terroristic threat perceptions and each emotion. This provides further support to the notion that symbolic threat perceptions may 
be particularly important in driving emotional reactions compared to realistic and terroristic threat perceptions. The nonsignificant mediating effects of emotional reactions in the relationships between perceived threats and policy support are somewhat inconsistent with previous work (e.g., Wirtz et al., 2015), however, and require further investigation in future studies. Possible reasons for the nonsignificant results obtained are discussed below.

\section{Implications}

The findings of the current study contribute to our understanding of the roles of individual differences in ideology, threat perceptions, and emotions in prejudice and discrimination toward Muslims in the United States in several ways. Findings from the first aim suggest that differences in ideology (i.e., SDO, RWA, and Nationalism) predict different types of perceived threats (i.e., realistic, symbolic, terroristic) which then influence support for anti-Muslim policies through Islamophobia. This work builds on past research suggesting that SDO is a predictor of Islamophobia and that realistic, symbolic, and terroristic threat perceptions each mediate this relationship (Uenal, 2016) by incorporating two other individual difference variables (i.e., RWA and Nationalism) that are more conceptually related to symbolic and terroristic threats, respectively. Despite a few deviations from expectations, these findings help to disentangle the independent roles of SDO, RWA, and Nationalism as predictors of Islamophobia through realistic, symbolic, and terroristic threat perceptions by simultaneously testing all of these relationships. Similarly, these findings point to the independent role of each type of threat perception as predictors of anti-Muslim policy support through Islamophobia, suggesting 
that threat perceptions not only impact intergroup attitudes but that these intergroup attitudes also influence behavioral intentions. This may have important implications for understanding which individuals, such as those high in SDO, RWA, and Nationalism, will be prone to perceive Muslims as threatening and how these perceptions of threat will impact intergroup relations. Although longer-term, experimental designs would be needed to further understand the cause and effect of the established relationships, these findings suggest that those who are higher in SDO, RWA, and Nationalism will be more likely to perceive Muslims as realistic, symbolic, and terroristic threats, broadly, which impact Islamophobia attitudes and anti-Muslim policy support.

Understanding which types of people are more likely to perceive certain types of threats holds implications for future research aimed at political messaging regarding active policy issues. Specifically, it may be useful to consider how the framing of policy initiatives differentially influences support by those who are higher in each of these individual differences. If proponents of policies, such as increased surveillance of Muslims, use stereotypes about Muslims as terrorists to justify their arguments, then those higher in certain ideologies, such as SDO or RWA, may be more likely to support these policies and politicians whose goals align with perceived threat reduction. Other evidence for these relationships exists with several studies pointing to RWA and SDO as predictors of support for Donald Trump in the 2016 Presidential election (e.g., Craig \& Richeson, 2014b, Womick et al., 2018) as well as the mediating role perceived realistic threat on support for Trump and anti-immigrant policies, such as the Muslim ban (Major et al., 2018; Osborn et al., 2019). Despite a lack of evidence that wide-sweeping policies 
that reduce immigration of Muslims promote national safety (Ali, 2016; Elsheikh et al., 2017), politicians like Donald Trump have been successful at garnering support for these kinds of harsh policies that disproportionately impact immigrants from Muslim-majority countries (Trump, 2017b) by building a base of supporters who, based on the findings of this and other studies, are more likely to perceive certain groups as threatening to their resources, values, and safety. In the case of Muslims, this heightened sensitivity to perceived threats leads to higher levels of Islamophobia and support for anti-Muslim policies such as the Muslim ban.

The second aim of the current study attempted to build on previous research that has explored the emotional components of realistic and symbolic threats by incorporating the recent addition of terroristic threats to intergroup threat theory (Obaidi et al., 2018; Uenal, 2016). In earlier conceptions of this theory, realistic threats encompassed both resource and safety threats. The current study followed research that suggests that resource and safety threats are conceptually different, and thus, should be investigated as distinct types of threat perceptions (Crawford, 2014; Uenal, 2016) and reassessed the emotional components of these threats under this new framework. Although the exploratory hypothesis and hypotheses $2 \mathrm{a}-2 \mathrm{c}$ were largely unsupported, these findings provide insight into how threat perceptions and emotions are related which will be important for future research. Specifically, symbolic threat perceptions were a better predictor of several distinct emotions (i.e., anger, distrust, fear) compared to realistic and terroristic threat perceptions. Although the differences in the effect of each type of threat perception on each emotion were relatively small, these findings suggest that threats to 
one's values may be more likely to elicit emotional responses, in general. This may be due to the importance of personal values in one's social identity which value-violating groups may be perceived to threaten (Rios et al., 2018). Thus, perceived threats to one's social identity may be tied to more emotional responses compared to threats to one's resources or safety. Future research would need to directly test these possibilities, however.

Finally, the third aim of this study builds on previous research investigating predictors of attitudes toward Muslims and support for policy initiatives that have realworld impacts on Muslims living in the United States, such as a Muslim ban or increasing the surveillance of Muslims in the United States. Specifically, extending on work suggesting that threat perceptions influence support for discriminatory, group-based policies (e.g., Mukherjee et al., 2013; Rios et al., 2018; Stephan et al., 2015), the third aim of this study was to elucidate the role of emotions in support for anti-Muslim policies by investigating the mediational role of threat-based emotional reactions. Similar to hypotheses $2 \mathrm{a}-2 \mathrm{c}$, hypotheses $3 \mathrm{a}-3 \mathrm{c}$ were largely unsupported and suggested the same pattern of findings that symbolic threat perceptions best predicted each emotional reaction compared to realistic and terroristic threat perceptions even when simultaneously estimated, lending more evidence that symbolic threat perceptions may be particularly important in guiding emotional reactions. Although each type of perceived threat predicted anger, distrust, and fear, these emotional reactions did not predict nor mediate the relationships between each type of perceived threat and support for increased police surveillance of Muslims in the United States. The findings from aims 2 and 3 are 
inconsistent with previous work suggesting that discrete emotions predict policy support (Lerner et al., 2003) and mediate the relationships between perceived threat and policy support (Wirtz et al., 2015).

One possibility for this inconsistency may be the general and explicit nature of the emotion measures used. Average ratings on each emotional reaction item were well below the midpoint on the scale, suggesting that most participants did not highly endorse experiencing these emotional reactions when thinking about Muslims, in general.

Previous research implicating the roles of discrete emotions in support for anti-Muslim policies, however, have often used more contextualized measures of emotions or experimentally induced certain emotions (Lerner et al., 2003). Thus, it may be that asking participants their broad emotional reactions to a specific group that they may or may not regularly interact with led to the low endorsement of any specific emotion. Still, the findings that almost every type of perceived threat predicted anger, distrust, and fear ${ }^{4}$ may hold implications for future research exploring the use of threat- or emotion-based language in policy proposals. For example, much of the language used in President Trump's Muslim Ban focused on the impending threat that outside terrorists pose to Americans while targeting Muslim-majority countries (Trump, 2017a; Trump, 2017b). The use of such fear-based language and reliance on stereotypes of Muslims as terrorists likely influenced both other politician's and the public's support for this policy. Future research may build on these findings in order to better understand how emotionally

\footnotetext{
${ }^{4}$ Exceptions to this pattern include the nonsignificant effect of realistic threat perceptions on distrust and the nonsignificant effect of terroristic threat perceptions on anger.
} 
charged language shifts how people think about, perceive, and subsequently support different policy initiatives which can have far-reaching and negative impacts.

\section{Applied Implications and Interventions}

Although this work did not directly test any applied practices or interventions, the findings may help inform real-world applications. Given that the outcomes of interest in this study revolved around policies that hold implications for the policing of Muslims, this study may have important implications for understanding the experiences of Muslims with law enforcement in the United States. Research suggests that police officers have higher levels of certain ideologies, such as SDO (Sidanius et al., 1994), which, based on the findings of the current study, could influence their threat perceptions and attitudes toward Muslims. It is important to understand police officers' perceptions of Muslims given increases in Muslim surveillance by police officers, and thus, increased contact between these two groups. To better understand police officers' perceptions of Muslims and how this impacts policing of these communities, future research could investigate whether police officers higher in SDO, RWA, and Nationalism are more likely to perceive Muslims as threatening or endorse stereotypes of Muslims as terrorists. Such research could also utilize actual policing outcomes, rather than policy support, perhaps focusing on outcomes relevant to surveilling, such as increased contact without arrest or time spent monitoring areas with known mosques and Muslim community centers. This would allow for more insight into the impacts of attitudes and threat perceptions on actual Muslim surveillance by police that has resulted from policy implementation (e.g., Patriot Act). 
This research may also have implications for how policy proposals and bills are drafted and evaluated prior to bringing them to a vote. Given ideological differences such as SDO and RWA may influence susceptibility to perceive Muslims as threatening, it may be that politicians who are higher in these ideologies will be more likely to perceive Muslims as threatening which could impact how they write policy proposals and frame their arguments. Further, because Muslims tend to be overrepresented in media reporting of terrorism (Kearns et al., 2019b) and stereotyped as terrorists (Ekman, 2015), perceived threats of this group may be particularly problematic for policy decisions. Based on these considerations, one potential policy implication from the current study might be to employ objective, non-partisan policy proposal evaluators to assess whether the claims and justifications for new policies (and particularly those that could have consequential impacts on specific groups) are based in evidence of actual potential threats rather than perceptions of threats largely based in stereotypes. Such a process would allow for a more objective, third-party view of new issues before formally bringing them into political discourse and would help ensure that political issues being debated and voted on are based on evidence and facts as much as possible.

\section{Limitations and Considerations}

As with all psychological research, important considerations when interpreting the findings are the social and historical contexts in which the data were collected. During participant recruitment, the United States and the world had been dealing with the effects of the COVID-19 pandemic for the better part of a year. Not only did this result in all participant interactions occurring online, making it hard to control for external 
distractions while participants completed the survey, but participants may have been handling a number of additional life stressors brought on by the pandemic (e.g., job loss, illness) that may have impacted attention. An attention check item was used to remove participants who did not pay attention to the survey instructions to attend to this possibility. During this time, there was also an emphasis on the Black Lives Matter movement as protests erupted across the United States in response to several fatal police shootings involving unarmed Black people. This may have impacted the salience of the importance of social justice and group-based equity, especially for liberal participants who tend to be lower in ideological beliefs like SDO and RWA (Wilson \& Sibley, 2013) and support more egalitarian policies (Pratto et al., 1994). Finally, data collection occurred during the months leading up to the 2020 presidential election involving thenPresident Trump who initiated and signed the Muslim ban into effect in 2017 (Trump, 2017b). Although controversial as a President and candidate, no known major actions or events specific to the Muslim ban or related issues occurred within the Trump administration during the time of data collection. Although it is unlikely that any of these social or historical factors meaningful impacted the relationships examined in the current study, it is important to consider the findings within this context. For example, COVID19 has been shown to increase perceptions of threat and intergroup intolerance in general (Van Bavel et al., 2020), an effect which could have generalized to participants' susceptibility to perceive Muslims as threats. Similarly, it could be that the societal emphasis on group-based equity in policing impacted intergroup attitudes toward 
multiple minority groups who may experience disproportionate attention and force from law enforcement.

As with any study, there are also several limitations of the current investigation.

One limitation of the current study is the correlational nature of non-experimental survey data. Although SEM allows for causal inference, these techniques do not replace experimental manipulation or longitudinal approaches in terms of determining causality. Thus, in order to establish the robustness of the current study's findings, implementing an experimental or longitudinal approach would be an important next step. For example, future work could manipulate the salience of specific types of threats by Muslims to determine whether priming threat perceptions systematically leads to more or less support of discriminatory policies for those who are high in SDO, RWA, and Nationalism compared to those who are low in these ideologies to better understand how different types of threat perceptions are related and interact.

The nature of the measures used in this study also presents a limitation in that they are self-reported and explicit. As such, these measures may be susceptible to social desirability which appeared to be the case based on the low means for each measure. Although averages on each measure were similar to those from other studies using these measures, the fact that social desirability may have been suppressing the true level of each attitude presents a limitation to our ability to identify the relationships of interest. Explicit measures may also be inappropriate for the nature of some of the measures used, such as emotions, which occur in response to specific contexts or situations and often occur outside of our conscious awareness. This limitation hints at a larger limitation of 
the current study design. Specifically, this study only uses explicit measures of attitudes and perceptions, which may paint a modest picture of the phenomena of interest. Specifically, because attitudes and perceptions occur at both explicit and implicit levels (e.g., Devine, 1989; Smith \& DeCoster, 2000), measuring each emotion in an explicit way limits our understanding to what participants are able and willing to report. Participants may not be consciously aware of which emotions they feel in response to Muslims, making it difficult for them to report these feelings, and difficult for the current study to illuminate the role of these emotions in support for anti-Muslim policies. Future work should aim to address this limitation through the use of implicit measures of bias toward Muslims that are more contextually bound to a specific event or situation. Implicit measures could come in many forms, including video face-reading technology (e.g., Noldus FaceReader Software) in order to measure emotional responses to stimuli intended to manipulate perceived threat (e.g., Muslims vs non-Muslims in an airport setting). Although positive emotions were excluded from the current study due to the study's focus on inherently negative types of perceived threat, this type of work would allow for easy inclusion of positive emotions as this technology provides continuous measures of positive, negative, and neutral emotions, allowing for a relative comparison of simultaneous positive and negative expressions.

The last limitation of this study that is important to consider is that the measures of social attitudes, threat perceptions, and emotional reactions toward Muslims were not contextually bound, meaning that they are assessing each construct at a general level without a specific context. This limits our understanding of how these factors may 
interact and influence each other in different ways depending on the situational context at hand. Given research that suggests that several of the variables of interest may be more or less important for predicting outcomes based on the context (e.g., individual differences in ideology, threat perceptions), exploring the influence of these factors in different contexts is important (e.g., Rios et al., 2018). As mentioned briefly above, emotional reactions are typically elicited by specific situations or stimuli, limiting the ability of the emotion measures used in this study to explain the broad relationships of interest. In thinking of the stronger impact of symbolic threats, it may be that symbolic threats are particularly salient for Muslims in the absence of other contextual cues. For example, it may be that Muslims encountered in airports will be perceived more as terroristic threats whereas Muslims encountered walking down the street will be perceived more as symbolic threats. Future work could address this limitation by orienting the situational context around the specific outcome variable in question. For example, if the relationship of interest is whether fear mediates the relationship between terroristic threat perceptions and increased support for police surveillance of Muslims, it may be relevant to manipulate terroristic threats by having some participants read about the attacks of $9 / 11$ before answering questions about their attitudes toward Muslims and support for antiMuslim policies. Focusing future research on specific contexts, rather than taking a more general approach as the current study did, will be helpful in better understanding the impact of terrorism stereotypes about Muslims that are largely driven by media on subsequent support for discriminatory policies that directly impact Muslims in the United States. 


\section{Future Directions}

Future exploration of this work will include the consideration of theoretically plausible alternative structural equation models, particularly for aim 1 (hypotheses 1a-1d) which provided support for an ideology-threat-attitude-behavior model of anti-Muslim bias. Although this model fits well into the intergroup threat theory framework (e.g., Stephen et al., 2015), this theory reflects some flexibility in the direction of relationships between attitudes, threat perceptions, and behaviors. First, an alternative model in which the direction of relationships between each type of perceived threat and Islamophobia is reversed (i.e., an ideology-attitude-threat-behavior model of anti-Muslim bias) will be tested and compared to the hypothesized model for aim 1 with the plan of identifying a superior model which will be transparently prepared for publication. Another potential avenue could be to investigate the roles of specific facets of Islamophobia on support for different types of anti-Muslim policies. As previously described, Islamophobia consists of both an anti-Muslim and anti-Islam component (Uenal, 2016). This type of distinction may be important in determining how Islamophobia may differentially contribute to support for policies that specifically target members of a religious group compared to those that target broader religious beliefs or a religious doctrine. For example, it may be that support for policies that impact individual Muslims, such as surveillance by law enforcement, will be most predicted by the anti-Muslim facet of Islamophobia, whereas support for policies aimed at reducing the influence of Islam on American society, such as a Muslim ban, will be most predicted by the anti-Islam facet of Islamophobia. Similarly, alternative models could assess whether different types of perceived threats 
predict different types of policies (e.g., Muslim ban vs Muslim enrollment limits at American universities). For instance, if terroristic threats predict support for a Muslim ban better than symbolic threats, this may allow for more targeted intervention to break down stereotypes and misinformation that are relevant for terroristic threat perceptions, specifically. Both of these approaches would require the separation of the aggregated anti-Muslim policy support items used to address aim 1, however, and may not be as easily compared to the originally hypothesized model due to these changes in measurement.

Future research should also aim to examine the potential interactive effects of individual differences on the relationships between ideology, threat perceptions, and policy support. Although political orientation was used as a covariate in the current models, it may be that political ideology actually moderates the relationships between perceived threats and Islamophobia. The role of political orientation could be further explored using multigroup modeling to determine whether political orientation changes the pattern or strength of the mediational effects. Additionally, some research has suggested that ideologies such as SDO and RWA can have additive and interactive effects on intergroup attitudes (e.g., Wilson \& Sibley, 2013), something which was not explored in the hypothesized models. Although the current study points to an independent and additive effect of SDO, RWA, and Nationalism on perceived threats and anti-Muslim attitudes, it could be that these ideologies also interact in various ways to change the nature or strength of the indirect effects of perceived threats on anti-Muslim policy support. Although adding several interaction terms to the already complex hypothesized 
model may make the interpretation of the effects difficult, smaller alternative models could be run to investigate the interactive effects of SDO, RWA, and Nationalism on each type of perceived threat and anti-Muslim attitudes individually to get a fuller idea of the impact of multiple ideologies on anti-Muslim policy support.

To better understand the inconclusive results of aims 2 (exploratory hypothesis and hypotheses $2 \mathrm{a}-2 \mathrm{c}$ ) and 3 (hypotheses 3a-3c), alternative models that test whether the direction of relationships between threat perceptions and emotions should be reversed will also be tested. Although less theoretically conventional, it could be that emotional reactions are used as indicators of the type of threat perceived in a given situation (i.e., an emotion-threat-behavior model of anti-Muslim bias). Results will be compared to the hypothesized models, however, based on the low power for SEM 2, a larger sample size may be needed to better understand these relationships. Comparisons of alternative models such as those proposed above are typical in SEM due to the fact that for any good fitting model, there is an infinite number of equally good fitting models. It should be noted, however, that any alternative models showing a better fit to the data would need to be retested in an independent sample to avoid the possibility of capitalizing on chance with post hoc analyses.

Another area for future research lies in the measurement of actual behavioral outcomes (e.g., signing a petition to promote the signing of a policy into law) rather than the behavioral intentions used in the current study (i.e., self-reported policy support). Although reported support for policies should indicate the likelihood that one would behave in accordance with this support when presented the opportunity, it does not 
necessarily translate to behavior, which may be influenced by several factors not examined here (e.g., context, norms; Ajzen \& Fishbein, 2005). Future work should aim to implement behavioral measures when possible. For example, one could present participants with a number of fictitious petitions for new laws related to Muslim surveillance as a measure of participant's willingness to promote anti-Muslim policies through their actions. Although participants would not be signing real petitions, this could provide insight into the influence of individual differences in ideology, threat perceptions, and emotional reactions in predicting discrimination against Muslims. Another possibility that was previously mentioned would be to use actual policing data specific to the policing of Muslims. Although data between law enforcement agencies is not always standardized or complete, investigations could be conducted at a local or organizational level when data is available to allow for a deeper understanding of the actual impacts of identity-based policing on Muslims in the United States.

To further disentangle the relationships between perceived threats and emotions, future work could utilize experimental methods to examine the impacts of priming different types of threats toward Muslims on subsequent emotional reactions and support for anti-Muslim policies. For example, by providing participants with a vignette or supposed headline that primes threat of a realistic (e.g., "Muslims among highest wage earners in the United States"), symbolic (e.g., "Americans are increasingly converting from Christianity to Islam"), or terroristic (e.g., "Muslim terrorist attacks on the rise in the United States") nature, and then measuring their emotional responses and subsequent support for policies that would hinder Muslims growth and development in American 
society, we may be able to better understand whether and how emotions impact relations between perceived threats and policy. Another adaptation that could be implemented in future work would be to measure emotions on a more implicit level (e.g., through face reading technology) to better assess discrete emotional responses to differences in perceived threat. Utilizing technology aimed at assessing smaller and less controllable expressions of emotional change may be particularly beneficial to addressing the potential for social desirability in intergroup bias research.

A final area for future research could be to explore how these effects translate to prejudice toward other groups and subsequent policy support. Given that the scope of this research was to investigate how different ideologies and perceptions influence policies that specifically impact Muslims, it is unclear whether these mechanisms are unique to Muslims or whether these effects would be stronger toward Muslims than other groups. Moving forward, it would be beneficial to explore how the mechanisms of individual differences in ideology, threat perceptions, and emotions function for other religious or ethnic groups. Future research should investigate how individual differences in SDO, RWA, and Nationalism impact perceptions of threat toward multiple religious and ethnic groups, such as Jewish people or non-Muslim Middle Easterners. This would provide insight on how generalizable the mechanisms examined in the current study are for other groups of people and other types of policy support.

\section{Conclusion}

The current study contributes to our understanding of the simultaneous roles of individual differences in ideology, threat perceptions, anti-Muslim attitudes, and 
emotions in support for anti-Muslim policies in the United States. Aim 1 (hypotheses 1a1d) evaluated an ideology-threat-attitude-behavior model of anti-Muslim bias that simultaneously investigated the roles of ideology (i.e., SDO, RWA, Nationalism), threat perceptions (i.e., realistic, symbolic, terroristic), and Islamophobia in predicting antiMuslim policy support. Findings suggested that each of these ideologies simultaneously predict each type of perceived threat which then mediates the relationships between ideology and Islamophobia and subsequent anti-Muslim policy support, with symbolic threat perceptions having the largest effects on these relationships. This research sheds light on the individual differences in threat perceptions, and thus, the types of people who may be more attuned to different types of threats. This study also provided some considerations for future research regarding the emotional components of each threat perception. Aim 2 (exploratory hypothesis and hypotheses 2a-2c) evaluated the emotional components of perceived threats and provided important insights for future research regarding the overlap in emotional representations of each type of perceived threat as well as the importance of symbolic threat perceptions in eliciting various discrete emotions. Aim 3 (hypotheses 3a-3c) evaluated the mediating roles of distinct emotions in the relationships between different types of perceived threats and support for increased surveillance of Muslims by law enforcement. Although expectations regarding the mediations were unsupported, findings provided additional information for future research that extends on those from aim 2. That is, just as symbolic threat perceptions appeared to be the best predictor of each type of emotion when tested separately, this pattern held when simultaneously accounting for the relationships between each type of 
perceived threat and each discrete emotional reaction. Altogether, this study suggests that those higher in SDO, RWA, and Nationalism are more likely to perceive Muslims as realistic, symbolic, and terroristic threats which increase their feelings of Islamophobia and support for anti-Muslim policies. This has implications for who may be more or less likely to vote against the interests of Muslims in the United States and guides future work exploring how to minimize reliance on perceived threat and emotional reactions in policy decisions. Further, this study points to the importance of symbolic threat perceptions in mediating the relationships between each ideological difference and anti-Muslim attitudes and policy support which may suggest that -at least in the absence of other contextual cues - symbolic threat perceptions of Muslims are particularly important for predicting Islamophobia, negative emotions, and anti-Muslim policy support. Although the roles of emotions in the relationships between perceived threats and anti-Muslim policy support were less clear in the current study, this work helps to inform future research interested in the emotional components of threat perceptions of Muslims by also pointing to the importance of symbolic threats for negative emotional reactions toward Muslims. Ultimately, this study supports much of the existing literature on individual differences in ideology, threat perceptions, and anti-Muslim attitudes while providing several compelling areas of future research. 


\section{References}

Abrams, D., de Vyver, J. Van, Houston, D. M., \& Vasiljevic, M. (2017). Does terror defeat contact? Intergroup contact and prejudice toward Muslims before and after the London bombings. Peace and Conflict, 23(3), 260-268. https://doi.org/10.1037/pac0000167

Abu-Ras, W., Suárez, Z. E., \& Abu-Bader, S. (2018). Muslim Americans' safety and well-being in the wake of Trump: A public health and social justice crisis. American Journal of Orthopsychiatry, 88(5), 503-515. https://doi.org/10.1037/ort0000321

ACLU. (2020). Timeline of the Trump Muslim Ban. Retrieved March 25, 2020, from https://www.aclu-wa.org/pages/timeline-muslim-ban

Adelman, L., \& Verkuyten, M. (2019). Prejudice and the Acceptance of Muslim Minority Practices. Social Psychology, 51(1), 1-16. https://doi.org/10.1027/a000001

Ajzen, I., \& Fishbein, M. (2005). The Influence of Attitudes on Behavior. In D. Albarracín, B. T. Johnson, \& M. P. Zanna (Eds.), The handbook of attitudes (pp. 173-221). Routledge. https://doi.org/10.4324/9781410612823.ch5

Ali, A. I. (2016). Citizens under Suspicion: Responsive Research with Community under Surveillance. Anthropology and Education Quarterly, 47(1), 78-95. https://doi.org/10.1111/aeq.12136

Al Jazeera. (2020). Trump to expand travel ban to six additional countries. Retrieved April 5, 2020, from https://www.aljazeera.com/news/2020/01/trump-expand-travelban-additional-countries-official-200131201717956.html

Altemeyer, B. (1981). Right-wing Authoritarianism. University of Manitoba press.

American public supports President Biden's first moves. (2021, January 24). Ipsos. https://www.ipsos.com/en-us/news-polls/abc-news-biden-unity-012421

Andersen, N. C., Brinson, M., \& Stohl, M. (2012). On-screen Muslims: Media priming and consequences for public policy. Journal of Arab \& Muslim Media Research, 4(2), 203-221. https://doi.org/10.1386/jammr.4.2-3.203_1

Apuzzo, M., \& Goldman, A. (2011a). With CIA help, NYPD moves covertly in Muslim areas. Retrieved May 17, 2020, from https:/www.pulitzer.org/winners/matt-apuzzoadam-goldman-eileen-sullivan-and-chris-hawley 
Apuzzo, M., \& Goldman, A. (2011b). Inside the spy unit that NYPD says doesn't exist. Retrieved May 17, 2020, from https://www.pulitzer.org/winners/matt-apuzzo-adamgoldman-eileen-sullivan-and-chris-hawley

Apuzzo, M., Goldman, A., \& Sullivan, E. (2011). NYPD's spying programs yielded only mixed results. Retrieved May 17, 2020, from https://www.pulitzer.org/winners/mattapuzzo-adam-goldman-eileen-sullivan-and-chris-hawley

Ayub, N., \& Jehn, K. A. (2010). The Moderating Influence of Nationalism on the Relationship Between National Diversity and Conflict. Negotiation and Conflict Management Research, 3(3), 249-275. https://doi.org/10.1111/j.17504716.2010.00060.x

Barrett, L. F., Mesquita, B., Ochsner, K. N., \& Gross, J. J. (2007). The Experience of Emotion. Annual Review of Psychology, 58, 373-403. Retrieved from http://doi.wiley.com/10.1113/jphysiol.1983.sp014635

Biden, J. R. (2021). Proclamation on Ending Discriminatory Bans on Entry to The United States. https://www.whitehouse.gov/briefing-room/presidentialactions/2021/01/20/proclamation-ending-discriminatory-bans-on-entry-to-theunited-states/

Blackwood, L., Hopkins, N., \& Reicher, S. (2016). From Theorizing Radicalization to Surveillance Practices: Muslims in the Cross Hairs of Scrutiny. Political Psychology, 37(5), 597-612. https://doi.org/10.1111/pops.12284

Bleich, E. (2011). What is islamophobia and how much is there? Theorizing and measuring an emerging comparative concept. American Behavioral Scientist, 55(12), 1581-1600. https://doi.org/10.1177/0002764211409387

Brambilla, M., \& Butz, D. A. (2013). Intergroup threat and outgroup attitudes: Macrolevel symbolic threat increases prejudice against gay men. Social Psychology, 44(5), 311-319. https://doi.org/10.1027/1864-9335/a000127

Bravo López, F. (2011). Towards a definition of Islamophobia: Approximations of the early twentieth century. Ethnic and Racial Studies, 34(4), 556-573. https://doi.org/10.1080/01419870.2010.528440

Brown, R., \& Hewstone, M. (2005). An integrative theory of intergroup contact. Advances in Experimental Social Psychology, 37, 255-343. https://doi.org/10.1016/S0065-2601(05)37005-5 
Buhrmester, M., Kwang, T., \& Gosling, S. D. (2011). Amazon's Mechanical Turk: A new source of inexpensive, yet high-quality, data? Perspectives on Psychological Science, 6(1), 3-5. https://doi.org/10.1177/1745691610393980

Center for Constitutional Rights. (2018). Hassan v. City of New York. Retrieved April 5, 2020, from https://ccrjustice.org/home/what-we-do/our-cases/hassan-v-city-newyork $\% 0 \mathrm{~A}$

Center for Constitutional Rights. (2020). Tanvir v. Tanzin (formerly Tanvir v. Holder and Tanvir v. Lynch). Retrieved April 5, 2020, from https://ccrjustice.org/home/whatwe-do/our-cases/tanvir-v-holder

Choma, B. L., Hodson, G., \& Costello, K. (2012). Intergroup disgust sensitivity as a predictor of islamophobia: The modulating effect of fear. Journal of Experimental Social Psychology, 48(2), 499-506. https://doi.org/10.1016/j.jesp.2011.10.014

Ciftci, S. (2012). Islamophobia and Threat Perceptions: Explaining Anti-Muslim Sentiment in the West. Journal of Muslim Minority Affairs, 32(3), 293-309. https://doi.org/10.1080/13602004.2012.727291

Clore, G. L., Gasper, K., \& Garvin, E. (2000). Affect as Information. In J. P. Forgas (Ed.), Handbook of Affect and Social Cognition (pp. 122-145). https://doi.org/10.4324/9781410606181

Collingwood, L., Lajevardi, N., \& Oskooii, K. A. R. (2018). A Change of Heart? Why Individual-Level Public Opinion Shifted Against Trump's "Muslim Ban." Political Behavior, 40(4), 1035-1072. https://doi.org/10.1007/s11109-017-9439-z

Cook, C. L., Cottrell, C. A., \& Webster, G. D. (2015). No good without God: Antiatheist prejudice as a function of threats to morals and values. Psychology of Religion and Spirituality, 7(3), 217-226. https://doi.org/10.1037/rel0000013

Cook, C. L., Li, Y. J., Newell, S. M., Cottrell, C. A., \& Neel, R. (2018). The world is a scary place: Individual differences in belief in a dangerous world predict specific intergroup prejudices. Group Processes \& Intergroup Relations, 21(4), 584-596. https://doi.org/10.1177/1368430216670024

Cottrell, C. A., \& Neuberg, S. L. (2005). Different Emotional Reactions to Different Groups: A Sociofunctional Threat-Based Approach to "Prejudice". Journal of Personality and Social Psychology, 88(5), 770-789. https://doi.org/10.1037/00223514.88.5.770

Craig, M. A., \& Richeson, J. A. (2014a). More Diverse Yet Less Tolerant? How the Increasingly Diverse Racial Landscape Affects White Americans' Racial Attitudes. 
Personality and Social Psychology Bulletin, 40(6), 750-761.

https://doi.org/10.1177/0146167214524993

Craig, M. A., \& Richeson, J. A. (2014b). Not in my backyard! authoritarianism, social dominance orientation, and support for strict immigration policies at home and abroad. Political Psychology, 35(3). https://doi.org/10.1111/pops.12078

Crowson, H. M. (2009). Predicting perceptions of symbolic and realistic threat from terrorists: The role of right-wing authoritarianism and social dominance orientation. Individual Differences Research, 7(2), 113-118.

Dekker, H., Malova, D., \& Hoogendoorn, S. (2003). Nationalism and Its Explanations. Political Psychology, 24(2), 345-376. https://doi.org/10.1111/0162-895X.00331

Devine, P. G. (1989). Attitudes and Social Cognition Stereotypes and Prejudice: Their Automatic and Controlled Components. Journal of Personality and Social Psychology, 56(1), 5-18. https://doi.org/10.1002/smll.201700748

Doosje, B., Zimmermann, A., Küpper, B., Zick, A., \& Meertens, R. (2009). Terrorist Threat and Perceived Islamic Support for Terrorist Attacks as Predictors of Personal and Institutional Out-Group Discrimination and Support for Anti-Immigration Policies - Evidence from 9 European countries. Revue Internationale de Psychologie Sociale, 22(3), 203-233.

Dovidio, J. F., Kawakami, K., \& Gaertner, S. L. (2002). Implicit and explicit prejudice and interracial interaction. Journal of Personality and Social Psychology, 82(1), 6268. https://doi.org/10.1037/0022-3514.82.1.62

Dubosh, E., Poulakis, M., \& Abdelghani, N. (2015). Islamophobia and Law Enforcement in a Post 9/11 World. Islamophobia Studies Journal, 3(1), 139-157. https://doi.org/10.13140/RG.2.1.1834.1523

Duckitt, J., \& Sibley, C. G. (2010). Right-Wing Authoritarianism and Social Dominance Orientation Differentially Moderate Intergroup Effects on Prejudice. European Journal of Personality, 24, 583-601. https://doi.org/10.1002/per

Dunwoody, P. T., \& McFarland, S. G. (2018). Support for Anti-Muslim Policies: The Role of Political Traits and Threat Perception. Political Psychology, 39(1), 89-106. https://doi.org/10.1111/pops.12405

Echebarria-Echabe, A., \& Guede, E. F. (2007). A New Measure of Anti-Arab Prejudice: Reliability and Validity Evidence. Journal of Applied Social Psychology, 37(5), 1077-1091. https://doi.org/10.1111/j.1559-1816.2007.00200.x 
Ekman, M. (2015). Online Islamophobia and the politics of fear: manufacturing the green scare. Ethnic and Racial Studies, 38(11), 1986-2002. https://doi.org/10.1080/01419870.2015.1021264

Elsheikh, E., Sisemore, B., \& Lee, N. R. (2017). Legalizing Othering: The United States of Islamophobia. Retrieved from http://haasinstitute.berkeley.edu/sites/default/files/haas_institute_legalizing_othering _the_united_states_of_islamophobia.pdf\%0Ahttp://web.archive.org/web/201709100 02152/http://haasinstitute.berkeley.edu/sites/default/files/haas_institute_legalizing_o the

Essien, I., Stelter, M., Kalbe, F., Koehler, A., Mangels, J., \& Meliß, S. (2017). The shooter bias: Replicating the classic effect and introducing a novel paradigm. Journal of Experimental Social Psychology, 70, 41-47. https://doi.org/10.1016/j.jesp.2016.12.009

Fabozzi, F.J., Focardi, S.M., Rachev, S.T., \& Arshanapalli, B.G. (2014). Appendix E: Model selection criterion: AIC and BIC. The basics of financial econometrics: Tools, concepts, and asset management applications. Hoboken, NJ, USA: John Wiley \& Sons, Inc, 399-430.

Faul, F., Erdfelder, E., Lang, A.-G., \& Buchner, A. (1007). G*Power 3: A flexible statistical power analysis program for the social, behavioral, and biomedical sciences. Behavior Research Methods, 39(2), 175-191.

Fazio, R. H., \& Olson, M. A. (2003). Implicit Measures in Social Cognition Research: Their Meaning and Use. Annual Review of Psychology, 54(1), 297-327. https://doi.org/10.1146/annurev.psych.54.101601.145225

Feitosa, J., Joseph, D. L., \& Newman, D. A. (2015). Crowdsourcing and personality measurement equivalence: A warning about countries whose primary language is not English. Personality and Individual Differences, 75, 47-52. https://doi.org/10.1016/j.paid.2014.11.017

Fischer, P., Greitemeyer, T., \& Kastenmüller, A. (2007). What do we think about Muslims? The validity of Westerners' implicit theories about the associations between Muslims' religiosity, religious identity, aggression potential, and attitudes toward terrorism. Group Processes and Intergroup Relations, 10(3), 373-382. https://doi.org/10.1177/1368430207078697

Garner, S., \& Selod, S. (2015). The Racialization of Muslims: Empirical Studies of Islamophobia. Critical Sociology, 41(1), 9-19. https://doi.org/10.1177/0896920514531606 
Gelman, A., Fagan, J., \& Kiss, A. (2007). An analysis of the New York City police department's "stop-and- frisk" policy in the context of claims of racial bias. Journal of the American Statistical Association, 102(479), 813-823. https://doi.org/10.1198/016214506000001040

Gerber, M. M., \& Jackson, J. (2017). Justifying violence: legitimacy, ideology and public support for police use of force. Psychology, Crime and Law, 23(1), 79-95. https://doi.org/10.1080/1068316X.2016.1220556

Gervais, W. M. (2014). Everything is permitted? People intuitively judge immorality as representative of atheists. PLOS ONE, 9(4). https://doi.org/10.1371/journal.pone.0092302

Gervais, W. M., Shariff, A. F., \& Norenzayan, A. (2011). Do you believe in atheists? Distrust is central to anti-atheist prejudice. Journal of Personality and Social Psychology, 101(6), 1189-1206. https://doi.org/10.1037/a0025882

Golec de Zavala, A., Guerra, R., \& Simão, C. (2017). The relationship between the brexit vote and individual predictors of prejudice: Collective narcissism, right wing authoritarianism, social dominance orientation. Frontiers in Psychology, 8(November), 1-14. https://doi.org/10.3389/fpsyg.2017.02023

Gonsalkorale, K., von Hippel, W., Sherman, J. W., \& Klauer, K. C. (2009). Bias and regulation of bias in intergroup interactions: Implicit attitudes toward Muslims and interaction quality. Journal of Experimental Social Psychology, 45(1), 161-166. https://doi.org/10.1016/j.jesp.2008.07.022

Gravetter, F. J., Wallnau, L. B., Forzano, L. A. B., \& Witnauer, J. E. (2020). Essentials of statistics for the behavioral sciences. Cengage Learning.

Greenwald, A. G., \& Banaji, M. R. (1995). Implicit social cognition: Attitudes, selfesteem, and stereotypes. Psychological Review, 102(1), 4-27. https://doi.org/10.1037/0033-295X.102.1.4

Henderson, N. J., Ortiz, C. W., Sugie, N. F., \& Law, J. M. (2006). Law Enforcement \& Arab American Community Relations After September 11, 2001: Technical Report. New York, NY: Vera Institute of Justice.

Hitlan, R. T., Carillo, K., Zárate, M. A., \& Aikman, S. N. (2007). Attitudes toward immigrant groups and the September 11 terrorist attacks. Peace and Conflict, 13(2), 135-152. https://doi.org/10.1080/10781910701270970

Ho, A. K., Sidanius, J., Kteily, N., Sheehy-Skeffington, J., Pratto, F., Henkel, K. E., ... Stewart, A. L. (2015). The Nature of Social Dominance Orientation: Theorizing and 
Measuring Preferences for Intergroup Inequality Using the New SDO 7 Scale. Journal of Personality and Social Psychology, 109(6), 1003-1028.

https://doi.org/10.1037/pspi0000033

Hodson, G., Choma, B. L., Boisvert, J., Hafer, C. L., MacInnis, C. C., \& Costello, K. (2013). The role of intergroup disgust in predicting negative outgroup evaluations. Journal of Experimental Social Psychology, 49(2), 195-205.

https://doi.org/10.1016/j.jesp.2012.11.002

Hodson, G., \& Costello, K. (2007). Interpersonal disgust, ideological orientations, and dehumanization as predictors of intergroup attitudes. Psychological Science, 18(8), 691-698. https://doi.org/10.1111/j.1467-9280.2007.01962.x

Hu, L. T., \& Bentler, P. M. (1999). Cutoff criteria for fit indexes in covariance structure analysis: Conventional criteria versus new alternatives. Structural Equation Modeling, 6(1), 1-55. https://doi.org/10.1080/10705519909540118

Huddy, L., \& Khatib, N. (2007). American Patriotism, National Identity, and Political Involvement. American Journal of Political Science, 51(1), 63-77. https://doi.org/10.1111/j.1540-5907.2007.00237.x

James, G., Witten, D., Hastie, T., \& Tibshirani, R. (2013). Unsupervised Learning. In An introduction to statistical learning (pp. 373-418). Springer. https://doi.org/10.1007/978-1-4614-7138-7

Johnson, D. R., \& Borden, L. A. (2012). Participants at Your Fingertips: Using Amazon's Mechanical Turk to Increase Student-Faculty Collaborative Research. Teaching of Psychology, 39(4), 245-251. https://doi.org/10.1177/0098628312456615

Johnson, M. K., Labouff, J. P., Rowatt, W. C., Patock-Peckham, J. a., \& Carlisle, R. D. (2012). Facets of right-wing authoritarianism mediate the relationship between religious fundamentalism and attitudes toward Arabs and African Americans. Journal for the Scientific Study of Religion, 51(1), 128-142. https://doi.org/10.1111/j.1468-5906.2011.01622.x

Kauff, M., Asbrock, F., Wagner, U., Pettigrew, T. F., Hewstone, M., Schäfer, S. J., \& Christ, O. (2017). (Bad) Feelings about Meeting Them? Episodic and Chronic Intergroup Emotions Associated with Positive and Negative Intergroup Contact As Predictors of Intergroup Behavior. Frontiers in Psychology, 8(August), 1-11. https://doi.org/10.3389/fpsyg.2017.01449

Kearns, E. M., Betus, A. E., \& Lemieux, A. F. (2019a). When Data Do Not Matter: Exploring Public Perceptions of Terrorism. Studies in Conflict \& Terrorism, 1-22. https://doi.org/10.1080/1057610X.2018.1543145 
Kearns, E. M., Betus, A. E., \& Lemieux, A. F. (2019b). Why Do Some Terrorist Attacks Receive More Media Attention Than Others? Justice Quarterly, 36(6), 985-1022. https://doi.org/10.1080/07418825.2018.1524507

Keeling, D. G., \& Hughes, T. T. (2011). Police Officer Attitudes Toward Muslims and Islam: "Worlds Apart"? American Journal of Criminal Justice. https://doi.org/10.1007/s12103-010-9091-1

Kemmelmeier, M., \& Winter, D. G. (2008). Showing Patriotism, But Reaping Nationalism? Political Psychology, 29(6). https://doi.org/0162-895X

Kende, A., \& Krekó, P. (2020). Xenophobia, prejudice, and right-wing populism in EastCentral Europe. Current Opinion in Behavioral Sciences, 34, 29-33. https://doi.org/10.1016/j.cobeha.2019.11.011

Kishi, K. (2017). Assaults against Muslims in U.S. surpass 2001 level. Retrieved May 17, 2020, from https://www.pewresearch.org/fact-tank/2017/11/15/assaults-againstmuslims-in-u-s-surpass-2001-level/

Kline, R. B. (2015). Coming of Age. In Principles and Practice of Structural Equation Modeling (4th ed., pp. 7-24). Guilford Publications.

Korkmaz, S., Goksuluk, D., \& Zararsiz, G. (2014). MVN: An R package for assessing multivariate normality. The R Journal, 6(2), 151-162.

Kosterman, R., \& Feshbach, S. (1989). Toward a Measure of Patriotic and Nationalistic Attitudes. International Society of Political Psychology, 10(2), 257-274.

Kyriakides, C., Virdee, S., \& Modood, T. (2009). Racism, Muslims and the National Imagination. Journal of Ethnic and Migration Studies, 35(2), 289-308. https://doi.org/10.1080/13691830802586443

Lee, S. A., Gibbons, J. A., Thompson, J. M., \& Timani, H. S. (2009). The Islamophobia Scale: Instrument development and initial validation. International Journal for the Psychology of Religion, 19(2), 92-105. https://doi.org/10.1080/10508610802711137

Lee, S. a., Reid, C. a., Short, S. D., Gibbons, J. a., Yeh, R., \& Campbell, M. L. (2013). Fear of Muslims: Psychometric evaluation of the Islamophobia Scale. Psychology of Religion and Spirituality, 5(3), 157-171. https://doi.org/10.1037/a0032117

Legal Information Institute. (n.d.a). Fifth Amendment. Retrieved May 22, 2020, from https://www.law.cornell.edu/constitution/fifth_amendment 
Legal Information Institute. (n.d.b). 14th Amendment. Retrieved May 22, 2020, from https://www.law.cornell.edu/constitution/amendmentxiv

Lehmiller, J. J., \& Schmitt, M. T. (2006). Group domination and inequality in context: Evidence for the unstable meanings of social dominance and authoritarianism. European Journal of Social Psychology, 37, 704-724. https://doi.org/10.1002/ejsp

Lerner, J. S., Gonzalez, R. M., Small, D. A., \& Fischhoff, B. (2003). Effects of fear and anger on perceived risks of terrorism: A national field experiment. Psychological Science, 14(2), 144-150. https://doi.org/10.1111/1467-9280.01433

Lerner, J. S., \& Keltner, D. (2001). Fear, Anger, and Risk. Journal of Personality and Social Psychology, 81(1), 146-159.

Lerner, J. S., \& Keltner, D. (2000). Beyond valence: Toward a model of emotion-specific influences on judgement and choice. Cognition \& Emotion, 14(4), 473-493. https://doi.org/10.1080/026999300402763

Lipka, M., \& Hackett, C. (2017). Why Muslims are the world's fastest-growing religious group. Retrieved May 13, 2020, from https://www.pewresearch.org/facttank/2017/04/06/why-muslims-are-the-worlds-fastest-growing-religious-group/

Mackie, D. M., Devos, T., \& Smith, E. R. (2000). Intergroup emotions: explaining offensive action tendencies in an intergroup context. Journal of Personality and Social Psychology, 79(4), 602-616. https://doi.org/10.1037/0022-3514.79.4.602

Major, B., Blodorn, A., \& Blascovich, G. (2018). The threat of increasing diversity: Why many White Americans support Trump in the 2016 presidential election. Group Processes and Intergroup Relations, 21(6), 931-940. https://doi.org/10.1177/1368430216677304

Mallinas, S. R., Crawford, J. T., \& Frimer, J. A. (2019). Subcomponents of Right-Wing Authoritarianism Differentially Predict Attitudes Toward Obeying Authorities. Social Psychological and Personality Science, 194855061984392. https://doi.org/10.1177/1948550619843926

Manganelli Rattazzi, A. M., Bobbio, A., \& Canova, L. (2007). A short version of the Right-Wing Authoritarianism (RWA) Scale. Personality and Individual Differences, 43(5), 1223-1234. https://doi.org/10.1016/j.paid.2007.03.013

Meeropol, R. (2015). Muslim until proven innocent: The post-9/11 Ashcroft raids. Security Journal, 28(2), 184-197. https://doi.org/10.1057/sj.2015.5 
Meuleman, R., Bekhuis, H., Lubbers, M., \& Scheepers, P. (2013). Own culture first? nationalism and the preference for national cultural goods. International Journal of Public Opinion Research, 25(4), 436-458. https://doi.org/10.1093/ijpor/eds024

Miller, M. K., Clark, J. D., \& Alvarez, M. J. (2020). Exploring the boundaries of societally acceptable bias expression toward Muslim and atheist defendants in four mock-juror experiments. The Social Science Journal, 1-36. https://doi.org/10.1016/j.soscij.2019.09.004

Mohamed, B. (2018). New estimates show U.S. Muslim population continues to grow. Retrieved May 13, 2020, from https://www.pewresearch.org/facttank/2018/01/03/new-estimates-show-u-s-muslim-population-continues-to-grow/

Molina, L. E., Phillips, N. L., \& Sidanius, J. (2014). National and ethnic identity in the face of discrimination: Ethnic Minority and Majority Perspectives. Cultural Diversity and Ethnic Minority Psychology. https://doi.org/10.1037/a0037880

Morales, L. (2010). A Scientific Measure of Religious Prejudice in America. Retrieved March 19, 2020, from https://news.gallup.com/opinion/queue/172625/scientificmeasure-religious-prejudice-america.aspx

Morrison, K. R., Plaut, V. C., \& Ybarra, O. (2010). Predicting whether multiculturalism positively or negatively influences white Americans' intergroup attitudes: The role of ethnic identification. Personality and Social Psychology Bulletin, 36(12), 16481661. https://doi.org/10.1177/0146167210386118

Moshagen, M., \& Erdfelder, E. (2016). A new strategy for testing structural equation models. Structural Equation Modeling: A Multidisciplinary Journal, 23(1), 54-60. https://doi.org/10.1080/10705511.2014.950896

Moss, A. J., Blodorn, A., Van Camp, A. R., \& O’Brien, L. T. (2019). Gender equality, value violations, and prejudice toward Muslims. Group Processes and Intergroup Relations, 22(2), 288-301. https://doi.org/10.1177/1368430217716751

Mukherjee, S., Molina, L. E., \& Adams, G. (2013). "Reasonable Suspicion" About Tough Immigration Legislation: Enforcing Laws or Ethnocentric Exclusion? Cultural Diversity and Ethnic Minority Psychology. https://doi.org/10.1037/a0032944

Nabi, R. L. (2002). The theoretical versus the lay meaning of disgust: Implications for emotion research. Cognition and Emotion, 16(5), 695-703. https://doi.org/10.1080/02699930143000437 
Noor, M., Kteily, N., Siem, B., \& Mazziotta, A. (2019). "Terrorist” or "Mentally Ill”: Motivated Biases Rooted in Partisanship Shape Attributions About Violent Actors. Social Psychological and Personality Science. https://doi.org/10.1177/1948550618764808

North, C. S., Gordon, M., Kim, Y.-S., Wallace, N. E., Smith, R. P., Pfefferbaum, B., ... Pollio, D. E. (2014). Expression of Ethnic Prejudice in Focus Groups from Agencies Affected by the 9/11 Attacks on the World Trade Center. Journal of Ethnic And Cultural Diversity in Social Work, 23(2), 93-109. https://doi.org/10.1080/15313204.2014.903134

Nosek, B. A., Smyth, F. L., Hansen, J. J., Devos, T., Lindner, N. M., Ranganath, K. A., ... Banaji, M. R. (2007). Pervasiveness and correlates of implicit attitudes and stereotypes. European Review of Social Psychology, 18(1), 36-88. https://doi.org/10.1080/10463280701489053

Obaidi, M., Kunst, J. R., Kteily, N., Thomsen, L., \& Sidanius, J. (2018). Living under threat: Mutual threat perception drives anti-Muslim and anti-Western hostility in the age of terrorism. European Journal of Social Psychology, 48(5), 567-584. https://doi.org/10.1002/ejsp.2362

Office of the Inspector General. (2018). DHS Implementation of Executive Order \#13769 "Protecting the Nation From Foreign Terrorist Entry Into the United States." Department of Homeland Security.

Office of the Inspector General. (2003). The September 11 Detainees: A Review of the Treatment of Aliens Held on Immigration Charges in Connection with the Investigation of the September 11 Attacks. https://doi.org/10.1007/s13398-014-01737.2

Osborn, H. J., Sosa, N., \& Rios, K. (2019). Perceiving demographic diversity as a threat: Divergent effects of multiculturalism and polyculturalism. Group Processes \& Intergroup Relations, 1-18. https://doi.org/10.1177/1368430219880606

Osborne, D., Milojev, P., \& Sibley, C. G. (2017). Authoritarianism and National Identity: Examining the Longitudinal Effects of SDO and RWA on Nationalism and Patriotism. Personality and Social Psychology Bulletin, 43(8), 1086-1099. https://doi.org/10.1177/0146167217704196

Osborne, D., Satherley, N., Yogeeswaran, K., Hawi, D., \& Sibley, C. G. (2019). White nationalism and multiculturalism support: Investigating the interactive effects of white identity and national attachment on support for multiculturalism. New Zealand Journal of Psychology, 48(1), 62-70. 
Park, J., Felix, K., \& Lee, G. (2007). Implicit attitudes toward Arab-Muslims and the moderating effects of social information. Basic and Applied Social Psychology, 29(1), 35-45. https://doi.org/10.1080/01973530701330942

Perry, R., Sibley, C. G., \& Duckitt, J. (2013). Dangerous and competitive worldviews: A meta-analysis of their associations with Social Dominance Orientation and RightWing Authoritarianism. Journal of Research in Personality, 47(1), 116-127. https://doi.org/10.1016/j.jrp.2012.10.004

Pettigrew, T. F. (2017). Social psychological perspectives on Trump supporters. Journal of Social and Political Psychology, 5(1), 107-116. https://doi.org/10.5964/jspp.v5i1.750

Pew Research Center. (2011). Muslim Americans: No signs of growth in alienation or support for extremism. [Online report posted in Pew Research Religion and Public Life Project]. Retrieved May 23, 2020, from https://www.peoplepress.org/2011/08/30/muslim-americans-no-signs-of-growth-in-alienation-orsupport-for-extremism/

Pew Research Center. (2017). U.S. Muslims Concerned About Their Place in Society, but Continue to Believe in the American Dream. Retrieved March 31, 2020, from https://www.pewforum.org/2017/07/26/findings-from-pew-research-centers-2017survey-of-us-muslims/

Poynting, S., \& Mason, V. (2007). The resistible rise of Islamophobia: Anti-Muslim racism in the UK and Australia before 11 September 2001. Journal of Sociology, 43(1), 61-86. https://doi.org/10.1177/1440783307073935

Pratt, D. (2011). Islamophobia: Ignorance, imagination, identity and interaction. Islam and Christian-Muslim Relations, 22(4), 379-389. https://doi.org/10.1080/09596410.2011.606185

Pratto, F., Sidanius, J., \& Levin, S. (2006). Social dominance theory and the dynamics of intergroup relations: Taking stock and looking forward. European Review of Social Psychology, 17(1), 271-320. https://doi.org/10.1080/10463280601055772

Pratto, F., Sidanius, J., Stallworth, L. M., \& Malle, B. F. (1994). Social Dominance Orientation : A Personality Variable Predicting Social and Political Attitudes. American Psychological Association, 67(4), 741-763. https://doi.org/10.1037/00223514.67.4.741

Pratto, F., Stallworth, L. M., \& Conway-Lanz, S. (1998). Social dominance orientation and the ideological legitimization of social policy. Journal of Applied Social 
Psychology, 28(20), 1853-1875. https://doi.org/10.1111/j.1559-

1816.1998.tb01349.x

Raiya, H. A., Pargament, K. I., Mahoney, A., \& Trevino, K. (2008). When Muslims Are Perceived as a Religious Threat: Examining the Connection Between Desecration, Religious Coping, and Anti-Muslim Attitudes. Basic and Applied Social Psychology, 30(4), 311-325. https://doi.org/10.1080/01973530802502234

Ramirez, D. A. (2012). Developing Partnerships between Law Enforcement and American Muslim, Arab, and Sikh Communities: A Promising Practices Guide. SSRN Electronic Journal. https://doi.org/10.2139/ssrn.1998442

Reynolds, K. J., Turner, J. C., Haslam, S. a, \& Ryan, M. K. (2001). The role of personality and group factors in explaining prejudice. Journal of Experimental Social Psychology, 37, 427-434. https://doi.org/10.1006/jesp.2000.1473

Rios, K., Sosa, N., \& Osborn, H. (2018). An experimental approach to intergroup threat theory: Manipulations, moderators, and consequences of realistic vs. symbolic threat. European Review of Social Psychology, 29(1), 212-255. https://doi.org/10.1080/10463283.2018.1537049

Ritchie, H., Hasell, J., Appel, C., \& Roser, M. (2019). Terrorism. Retrieved March 26, 2020, from https://ourworldindata.org/terrorism

Rosseel, Y. (2012). Lavaan: An R package for structural equation modeling and more. Version 0.5-12 (BETA). Journal of Statistical Software, 48(2), 1-36.

Rowatt, W. C., Franklin, L. M., \& Cotton, M. (2005). Patterns and Personality Correlates of Implicit and Explicit Attitudes Toward Christians and Muslims. Journal for the Scientific Study of Religion, 44(1), 29-43. https://doi.org/10.1111/j.14685906.2005.00263.x

Saleem, M., Prot, S., Anderson, C. A., \& Lemieux, A. F. (2017). Exposure to Muslims in Media and Support for Public Policies Harming Muslims. Communication Research, 44(6), 841-869. https://doi.org/10.1177/0093650215619214

Satorra, A., \& Saris, W. E. (1985). Power of the likelihood ratio test in covariance structure analysis. Psychometrika, 50(1), 83-90. https://doi.org/10.1007/BF02294150

Schiffer, S., \& Wagner, C. (2011). Anti-Semitism and Islamophobia - new enemies, old patterns. Race \& Class, 52(3), 77-84. https://doi.org/10.1177/0306396810389927 
Schwarz, N. (2012). Feelings-as-information theory. In Handbook of Theories of Social Psychology: Volume 1 (pp. 289-308). https://doi.org/10.4135/9781446249215.n15

Shen, O., Al-Jamaly, H., Siemers, M., \& Stone, N. (2018). Charting Death: Reality vs Reported. Retrieved April 5, 2020, from https://owenshen24.github.io/chartingdeath/

Sheridan, L. P. (2006). Islamophobia Pre- and Post-September 11th, 2001. Journal of Interpersonal Violence, 21(3), 317-336.

Sidanius, J., Liu, J. H., Shaw, J. S., \& Pratto, F. (1994). Social Dominance Orientation, Hierarchy Attenuators and Hierarchy Enhancers: Social Dominance Theory and the Criminal Justice System. Confronting Racism: The Problem and the Response, 338366.

Sidanius, J., Pratto, F., van Laar, C., \& Levin, S. (2004). Social dominance theory: Its agenda and method. Political Psychology, 25(6), 845-880.

https://doi.org/10.1111/j.1467-9221.2004.00401.x

Skitka, L. J. (2005). Patriotism or Nationalism? Understanding Post-September 11,2001, Flag-Display Behavior'. Journal of Applied Social Psychology, 35(10), 1995-2011.

Smith, A. G., \& Winter, D. G. (2002). Right-wing authoritarianism, party identification, and attitudes toward feminism in student evaluations of the Clinton-Lewinsky story. Political Psychology, 23(2), 355-383. https://doi.org/10.1111/0162-895X.00285

Smith, E. R., \& DeCoster, J. (2000). Dual-process models in social and cognitive psychology: Conceptual integration and links to underlying memory systems. Personality and Social Psychology Review, 4(2), 108-131. https://doi.org/10.1207/S15327957PSPR0402_01

Stephan, W. G., Boniecki, K. A., Ybarra, O., Bettencourt, A., Ervin, K. S., Jackson, L. A., ,.. Renfro, C. L. (2002). The role of threats in the racial attitudes of Blacks and Whites. Personality and Social Psychology Bulletin, 28(9), 1242-1254. https://doi.org/10.1177/01461672022812009

Stephan, W. G., Renfro, C. L., \& Davis, M. D. (2009). The Role of Threat in Intergroup Relations. Improving Intergroup Relations: Building on the Legacy of Thomas $F$. Pettigrew, 55-72. https://doi.org/10.1002/9781444303117.ch5

Stephan, W. G., \& Stephan, C. W. (2000). An integrated threat theory of prejudice. Reducing prejudice and discrimination. 
Stephan, W. G., Ybarra, O., \& Rios, K. (2015). Intergroup Threat Theory. In T. D. Nelson (Ed.), Handbook of Prejudice, Stereotyping, and Discrimination (2nd ed., pp. 255-278). New York, NY: Psychology Press. https://doi.org/10.1002/9781118783665.ieicc0162

Stone, R. (2021). End of Trump's 'Muslim ban' a relief to researchers, but obstacles remain.

Swami, V., Barron, D., Weis, L., \& Furnham, A. (2018). To Brexit or not to Brexit: The roles of Islamophobia, conspiracist beliefs, and integrated threat in voting intentions for the United Kingdom European Union membership referendum. British Journal of Psychology, 109(1), 156-179. https://doi.org/10.1111/bjop.12252

Tapias, M. P., Glaser, J., Keltner, D., Vasquez, K., \& Wickens, T. (2007). Emotion and prejudice: Specific emotions toward outgroups. Group Processes and Intergroup Relations, 10(1), 27-39. https://doi.org/10.1177/1368430207071338

Thomsen, L., Green, E. G. T., \& Sidanius, J. (2008). We will hunt them down: How social dominance orientation and right-wing authoritarianism fuel ethnic persecution of immigrants in fundamentally different ways. Journal of Experimental Social Psychology, 44(6), 1455-1464. https://doi.org/10.1016/j.jesp.2008.06.011

Todosijevic, B. (1998). Relationships Between Authoritarianism and Nationalist. CEU (Central European University), 1-22.

Trump, D. J. (2017a). Executive Order Protecting the Nation from Foreign Terrorist Entry into the United States. Retrieved May 22, 2020, from https://www.whitehouse.gov/presidential-actions/executive-order-protecting-nationforeign-terrorist-entry-united-states/

Trump, D. J. (2017b). Presidential Proclamation Enhancing Vetting Capabilities and Processes for Detecting Attempted Entry Into the United States by Terrorists or Other Public-Safety Threats. Retrieved May 22, 2020, from https://www.whitehouse.gov/presidential-actions/presidential-proclamationenhancing-vetting-capabilities-processes-detecting-attempted-entry-united-statesterrorists-public-safety-threats/

Uenal, F. (2016). Disentangling islamophobia: The differential effects of symbolic, realistic, and terroristic threat perceptions as mediators between social dominance orientation and islamophobia. Journal of Social and Political Psychology, (July), 151. https://doi.org/10.5964/jspp.v4i1.463

Unkelbach, C., Forgas, J. P., \& Denson, T. F. (2008). The turban effect: The influence of Muslim headgear and induced affect on aggressive responses in the shooter bias 
paradigm. Journal of Experimental Social Psychology, 44(5), 1409-1413. https://doi.org/10.1016/j.jesp.2008.04.003

Van Bavel, J. J., Baicker, K., Boggio, P. S., Capraro, V., Cichocka, A., Cikara, M., ... \& Willer, R. (2020). Using social and behavioural science to support COVID-19 pandemic response. Nature human behaviour, 4(5), 460-471.

Velasco González, K., Verkuyten, M., Weesie, J., \& Poppe, E. (2008). Prejudice towards Muslims in The Netherlands: Testing integrated threat theory. British Journal of Social Psychology, 47(4), 667-685. https://doi.org/10.1348/014466608X284443

Wang, S. C., Raja, A. H., \& Azhar, S. (2019). "A Lot of Us Have a Very Difficult Time Reconciling What Being Muslim Is": A Phenomenological Study on the Meaning of Being Muslim American. Cultural Diversity and Ethnic Minority Psychology. https://doi.org/10.1037/cdp0000297

Wasserman, M. A. (2015). First amendment limitations on police surveillance: The case of the Muslim surveillance program. New York University Law Review, 90(5), 17861826.

Wilson, M. S., \& Sibley, C. G. (2013). Social dominance orientation and right-wing authoritarianism: Additive and interactive effects on political conservatism. Political Psychology, 34(2), 277-284. https://doi.org/10.1111/j.1467-9221.2012.00929.x

Wirtz, C., van der Pligt, J., \& Doosje, B. (2015). Negative attitudes toward Muslims in the Netherlands: The role of symbolic threat, stereotypes, and moral emotions. Peace and Conflict: Journal of Peace Psychology, 22(1), No Pagination Specified. https://doi.org/10.1037/pac0000126

Wolf, E. J., Harrington, K. M., Clark, S. L., \& Miller, M. W. (2013). Sample Size Requirements for Structural Equation Models: An Evaluation of Power, Bias, and Solution Propriety. Educational and Psychological Measurement, 73(6), 913-934. https://doi.org/10.1177/0013164413495237

Womick, J., Rothmund, T., Azevedo, F., King, L. A., \& Jost, J. T. (2018). Group-Based Dominance and Authoritarian Aggression Predict Support for Donald Trump in the 2016 U.S. Presidential Election. Social Psychological and Personality Science, 10(5), 643-652. https://doi.org/10.1177/1948550618778290

Yogeeswaran, K., Usman Afzali, M., Andrews, N. P., Chivers, E. A., Wang, M. J., Devos, T., \& Sibley, C. G. (2019). Exploring New Zealand national identity and its importance for attitudes toward Muslims and support for diversity. New Zealand Journal of Psychology, 48(1), 29-35. 
Zhang, Z., \& Yuan, K.-H. (2018). Practical Statistical Power Analysis Using WebPower and R. Granger, IN: ISDSA Press. Retrieved from https://webpower.psychstat.org/models/sem02/

Zmigrod, L., Rentfrow, P. J., \& Robbins, T. W. (2018). Cognitive underpinnings of nationalistic ideology in the context of Brexit. Proceedings of the National Academy of Sciences, 115(19), E4532-E4540. https://doi.org/10.1073/pnas.1708960115 


\section{Appendix: Survey Materials}

1. Age

a. What is your age?

2. Urbanicity

a. What best describes the area you live in?

i. Urban

ii. Suburban

iii. Rural

3. State of Residence

iv. Other (Please specify:

a. What state do you currently reside in?

4. Socioeconomic Status (SES)

a. Please estimate your socioeconomic status.

i. Very high

ii. High

iii. Somewhat high

iv. Average

v. Somewhat low

vi. Low

vii. Very low

5. Profession/Occupation

a. What is your current profession/occupation?

6. Education Level

a. What is your highest level of education?

i. Less than high school degree

ii. High school graduate

iii. Some college

iv. Bachelor's degree

v. Graduate or professional degree

7. Race/Ethnicity

a. With which racial/ethnic group do you identify?

i. White, European

ii. Black, African

iii. Native American, First Nations

iv. Latino/a/x

v. East, South, or Southeast Asian

vi. Middle Eastern, Arab

vii. Hawaiian Native, Pacific Islander

viii. Multiracial (Please specify :

ix. Not listed (Please specify : 


\section{Gender}

a. With what gender do you identify?

i. Woman

ii. Man

iii. Non-Binary

iv. Not listed (Please specify :

b. Do you identify as transgender?
i. Yes
ii. No
iii. Unsure

9. U.S. Native

\section{a. Were you born in the United States?}

i. Yes

ii. No (if no: how many years have you lived in the US:

\section{Political Ideology}

a. Which of the following best represents your political views?

i. Very conservative

ii. Conservative

iii. Slightly conservative

iv. Neither liberal or conservative (please specify:

v. Slightly liberal

vi. Liberal

vii. Very liberal

\section{Religious Identification}

a. What is your religious identity?
i. Agnostic
ii. Atheist
iii. Buddhist
iv. Catholic
v. Christian
vi. Hindu
vii. Jewish
viii. Muslim
ix. None/No religious affiliation
X. Not listed (Please specify :

\section{Social Dominance Orientation (SDO7; Ho et al., 2015).}

a. Please indicate how much you agree or disagree with each statement below by selecting a number from 1 to 7 on the scale below. You can work quickly; your first feeling is generally best: 1 (strongly disagree) - 7 (strongly agree). $\boldsymbol{R}=$ reverse scored.

i. An ideal society requires some groups to be on top and others to be on the bottom.

ii. Some groups of people are simply inferior to other groups. 
iii. Groups at the bottom are just as deserving as groups at the top. $\boldsymbol{R}$

iv. No one group should dominate in society. $\boldsymbol{R}$

v. It is unjust to try to make groups equal.

vi. Group equality should not be our primary goal.

vii. We should work to give all groups an equal chance to succeed. $\boldsymbol{R}$

viii. We should do what we can to equalize conditions for different groups. $\boldsymbol{R}$

13. Right-wing Authoritarianism (RWA; Manganelli Rattazzi et al., 2007)

a. Please indicate how much you agree or disagree with each statement below by selecting a number from 1 to 7 on the scale below: 1 (strongly disagree) - 7 (strongly agree). $\boldsymbol{R}=$ reverse scored.

i. Authoritarian aggression and submission subscale:

1. Our country desperately needs a mighty leader who will do what has to be done to destroy the radical new ways and sinfulness that are ruining us.

2. The majority of those who criticize proper authorities in government and religion only create useless doubts in people's minds.

3. The situation in our country is getting so serious, the strongest method would be justified if they eliminated troublemakers and got us back to our true path.

4. What our country really needs instead of more "civil rights" is a good stiff dose of law and order.

5. Obedience and respect for authority are the most important values children should learn.

6. The fact on crime, sexual immorality, and the recent public disorders all show we have to crack down harder on deviant groups and troublemakers if we are going to save our moral standards and preserve law and order.

7. What our country needs most is disciplined citizens, following national leaders in unity.

ii. Conservatism subscale:

1. Atheists and others who have rebelled against the established religions are no doubt every bit as good and virtuous as those who attend church regularly. $\boldsymbol{R}$

2. A lot of our rules regarding sexual behavior are just customs which are not necessarily any better or holier than those which other people follow. $\boldsymbol{R}$

3. There is absolutely nothing wrong with nudist camps. $\boldsymbol{R}$

4. Homosexuals and feminists should be praised for being brave enough to defy "traditional family values." $\boldsymbol{R}$

5. Everyone should have their own lifestyle, religious beliefs, and sexual preferences, even if it makes them different from everyone else. $\boldsymbol{R}$ 
6. People should pay less attention to the Church and the Pope, and instead develop their own personal standards of what is moral and immoral. $\boldsymbol{R}$

7. It is good that nowadays young people have greater freedom "to make their own rules" and to protest against things they don't like. $\boldsymbol{R}$

\section{Nationalism (Kosterman \& Feshbach, 1989)}

a. Please indicate how much you agree or disagree with each statement below by selecting a number from 1 to 7 on the scale below: 1 (strongly disagree) - 7 (strongly agree).

i. In view of America's moral and material superiority, it is only right that we should have the biggest say in deciding United Nations policy.

ii. The first duty of every young American is to honor the national American history and heritage.

iii. The important thing for the U.S. foreign aid program is to see to it that the U.S. gains a political advantage.

iv. Other countries should try to make their government as much like ours as possible.

v. Generally, the more influence America has on other nations, the better off they are.

vi. Foreign nations have done some very fine things, but it takes America to do things in a big way.

vii. It is important that the U.S. win in international sporting competitions like the Olympics.

viii. It is really not important that the U.S. be number one in whatever it does. $\boldsymbol{R}$

\section{Threat perceptions (adapted from Uenal, 2016)}

a. Please indicate how much you agree or disagree with each statement below by selecting a number from 1 to 7 on the scale below: 1 (strongly disagree) - 7 (strongly agree).

i. Realistic Threat:

1. The presence of Islam in the United States threatens our economic prosperity.

2. Because of the presence of Islam, the education system in the United States is threatened.

3. Because of the presence of Muslims in the United States, Americans have more difficulties finding a job.

4. Because of the presence of Muslims in the United States, Americans have more difficulties finding housing.

ii. Symbolic Threat:

1. I am worried that the Western culture is endangered by Islam. 
2. I am worried that the Christian norms and values are threatened by Islam.

3. I am worried that the American norms and values are threatened by the presence of Muslims.

4. I am worried that our rights and freedom are threatened by the presence of Muslims.

iii. Terroristic Threat:

1. I am worried that peace is threatened by radical Islamist groups in the United States.

2. It is only a matter of time before the United States will become a target for Islamist terrorists.

3. Sometimes I think I could become a victim of an Islamist terrorist attack myself.

16. Islamophobia (Lee et al., 2009; Lee et al., 2013)

a. Please indicate how much you agree or disagree with each statement below by selecting a number from 1 to 7 on the scale below: 1 (strongly disagree) - 7 (strongly agree).

i. I would support any policy that would stop the building of new mosques (Muslim place of worship) in the U.S.

ii. If possible, I would avoid going to places where Muslims would be.

iii. I would become extremely uncomfortable speaking with a Muslim.

iv. Just to be safe, it is important to stay away from places where Muslims could be.

v. I dread the thought of having a professor that is Muslim.

vi. If I could, I would avoid contact with Muslims.

vii. If I could, I would live in a place where there were no Muslims.

viii. Muslims should not be allowed to work in places where many Americans gather such as airports.

ix. Islam is a dangerous religion.

x. The religion of Islam supports acts of violence.

xi. Islam supports terrorist acts.

xii. Islam is anti-American.

xiii. Islam is an evil religion.

xiv. Islam is a religion of hate.

Xv. I believe that Muslims support the killings of all non-Muslims.

xvi. Muslims want to take over the world.

17. Emotional reactions (Cottrell \& Neuberg, 2005)

a. Please indicate how much you agree or disagree with each statement below by selecting a number from 1 to 5 on the scale below: 1 (not at all) 7 (extremely).

i. When I think about Muslims I feel...

1. Fear

2. Anger 

3. Distrust
4. Disgust
5. Anxiety
6. Pity
7. Guilt
8. Envy

18. Policy Support (Items 1 and 2 self-created; item 3 from Nobles \& Nobles, 1954 , as cited in Andersen, Brinson, \& Stohl, 2012)

a. Please indicate how much you agree or disagree with each statement below by selecting a number from 1 to 7 on the scale below: 1 (strongly disagree) - 7 (strongly agree).

i. I would support a policy to require government surveillance of all U.S. mosques.

ii. I would support the banning of all Muslims into the United States.

iii. I would support state universities limiting enrollment by members of racial and religious groups in proportion to their percentage of the state's population.

\section{Summary of "Proposed" Muslim Surveillance Program in United States}

a. A Senate bill which calls for increased police surveillance of Muslims was recently scheduled for a vote. The Surveillance for Public Safety Act (S.B. 5483) would enable increased police surveillance of Muslims and their communities in the United States with the goal of preventing domestic terrorism. If passed, this bill would then go to a conference committee for final approval before being sent to the President for signing. If signed by the President, this law would allow police officers and law enforcement agencies to stop and request information from individuals seen leaving a mosque or Islamic community center regarding their identity, reason for visiting the mosque or community center, and other pertinent information that law enforcement officials deem useful in preventing terrorism in the United States as long as they have reasonable suspicion. Supporters of this bill cite the importance of understanding who is visiting mosques and why in relation to the war on terror in the United States. Providing police officers this extra allowance to question those visiting mosques aids in this effort. Opponents, on the other hand, argue that "reasonable suspicion" is vague and allows for undue questioning of those who are practicing their religious freedoms in the United States.

\section{Support for "Proposed" Muslim Surveillance Program in United States}

a. Please indicate how much you agree or disagree with each statement below by selecting a number from 1 to 7 on the scale below: 1 (strongly disagree) - 7 (strongly agree).

i. I would support the decision to pass this bill to increase police surveillance of Muslim communities and mosques.

ii. Having increased police surveillance of Muslim communities and mosques through this bill would reduce crime in the United States. 
iii. The passing of this bill would make the United States safer.

iv. The passing of this bill would increase racial profiling in the United States. $\boldsymbol{R}$

v. The passing of this bill would increase religious profiling in the United States. $\boldsymbol{R}$

vi. Increasing Muslim surveillance through this bill would have a negative impact on Muslim-police interactions. $\boldsymbol{R}$

vii. Passing this bill would have a negative impact on the lives of Muslims in the United States. $\boldsymbol{R}$ 